University of Louisville

ThinkIR: The University of Louisville's Institutional Repository

Electronic Theses and Dissertations

$12-2017$

\title{
Winds of courage a mallet concerto for solo mallets and wind ensemble.
}

Ross Elliott

University of Louisville

Follow this and additional works at: https://ir.library.louisville.edu/etd

Part of the Composition Commons

\section{Recommended Citation}

Elliott, Ross, "Winds of courage a mallet concerto for solo mallets and wind ensemble." (2017). Electronic Theses and Dissertations. Paper 2823.

https://doi.org/10.18297/etd/2823

This Master's Thesis is brought to you for free and open access by ThinkIR: The University of Louisville's Institutional Repository. It has been accepted for inclusion in Electronic Theses and Dissertations by an authorized administrator of ThinkIR: The University of Louisville's Institutional Repository. This title appears here courtesy of the author, who has retained all other copyrights. For more information, please contact thinkir@louisville.edu. 


\title{
Winds of Courage \\ a Mallet Concerto
}

for Solo Mallets and Wind Ensemble

By

Ross Elliott

B.M., Bowling Green State University, 2015

\author{
A Thesis \\ Submitted to the Faculty of the \\ School of Music of the University of Louisville \\ in Partial Fulfillment of the Requirements \\ for the Degree of
}

Master of Music in Music Composition

School of Music

University of Louisville

December 2017 
Copyright (C2017 by Ross Elliott.

All Rights Reserved. 



\section{Winds of Courage \\ a Mallet Concerto}

for solo Mallets and Wind Ensemble

By

Ross Elliott

B.M., Bowling Green State University, 2015

A Thesis Approved on

December 12, 2017

by the following Thesis Committee:

Steve Rouse

Thesis Director

John Ritz

Frederick Speck 


\section{ACKNOWLEDGEMENT}

First and foremost, I would like to thank Steve Rouse for all of his support, wisdom, advice, and mentoring throughout this process; as well as being my composition professor during my time of the University of Louisville.

Secondly, I would like to thank my parents and family for all of their support in my musical endeavors. 


\section{TABLE OF CONTENTS}

Signature Page

Dedication

ii

Instrumentation

Program Notes

Winds of Courage

I. Nerves of Butterflies

1

II. Tears of Thoughts

22

III. Smiles of Hope

Curriculum Vitae 


\title{
INSTRUMENTATION
}

\author{
Piccolo \\ Flute 1, 2 \\ Oboe 1,2 \\ Clarinet in $\mathrm{Eb}$ \\ Clarinet in $\mathrm{Bb}$ 1, 2, 3 \\ Bass Clarinet in $\mathrm{B} b$ \\ Bassoon 1, 2 \\ Contrabassoon \\ Alto Saxophone 1, 2 \\ Tenor Saxophone \\ Baritone Saxophone \\ Trumpet in $\mathrm{Bb}$ 1, 2, 3 (straight mutes required) \\ Horn in F 1, 2, 3, 4 \\ Trombone 1, 2 (straight mutes required) \\ Bass Trombone \\ Euphonium \\ Tuba \\ Solo Mallets \\ I. Marimba (5-octave) \\ II. Vibraphone (bow required) \\ III. Xylophone
}

Timpani (4)

Percussion Instruments Needed (Shared as needed):

Marimba, Xylophone, Vibraphone (bow needed), Glockenspiel, Crotales (bow needed), Tubular Bells;

Mark Tree, Suspended Cymbals, Crash Cymbals, Triangle, Sleigh Bells;

Temple Blocks, Tambourine, Snare Drum, Bass Drum.

Percussion 1

I. Glockenspiel, Marimba

II. Vibraphone (bow required)

III. Mark Tree, Marimba

Percussion 2

I. Crotales, Xylophone, Suspended Cymbal

II. Crotales (bow required)

Percussion 3

III. Crotales, Glockenspiel, Crash Cymbals

I. Suspended Cymbal, Tubular Bells, Glockenspiel, Mark Tree

II. Glockenspiel

III. Triangle, Snare Drum, Mark Tree

Percussion 4

I. Triangle, Snare Drum,

II. Tubular Bells, Suspended Cymbal

III. Sleigh Bells, Temple Blocks, Tambourine, Bass Drum

Percussion 5

I. Bass Drum, Mark Tree, Triangle

II. Triangle, Sleigh Bells, Mark Tree

III. Suspended Cymbal, Tambourine

Harp

Piano

String Bass

Score is Transposed.

Total duration: ca. 18:30

I. Nerves of Butterflies: ca. 7:45

II. Tears of Thoughts: ca 6:45

III. Smiles of Hope: ca. 3:45 


\section{PROGRAM NOTES}

Winds of Courage is a motivically-driven composition based on a repeating chordal pattern. Although being written out, the solo mallets parts sound somewhat improvisatory, which is a key element to the part. In a way, the concerto illustrates what it is like to have a crush on someone; where the first movement is getting up the courage to talk to them; the second movement, crying from failing to say what you need to say or not getting up the courage to talk to them, or getting rejected; and the final movement, when things work out in a positive manner, or being rejected, but finally able to move on.

"Nerves of Butterflies" focuses on two different ideas that oscillate back and forth. Episodic in nature, the movement alternates between sections of pure ensemble and sections with the focus on the Marimba. The movement migrates towards a motive that is spread throughout the entire ensemble, including the soloist.

"Tears of Thoughts" begins with an atmospheric quality amongst the solo Vibraphone and ensemble. The movement focuses on the repetition of a three, and sometimes four, chord progression.

"Smiles of Hope" is based on the chord progression from the first movement. This movement is very similar to the first movement as this movement in motivic-based and driven. Most of the movement deals with the main motive being "bounced" around throughout the ensemble. 

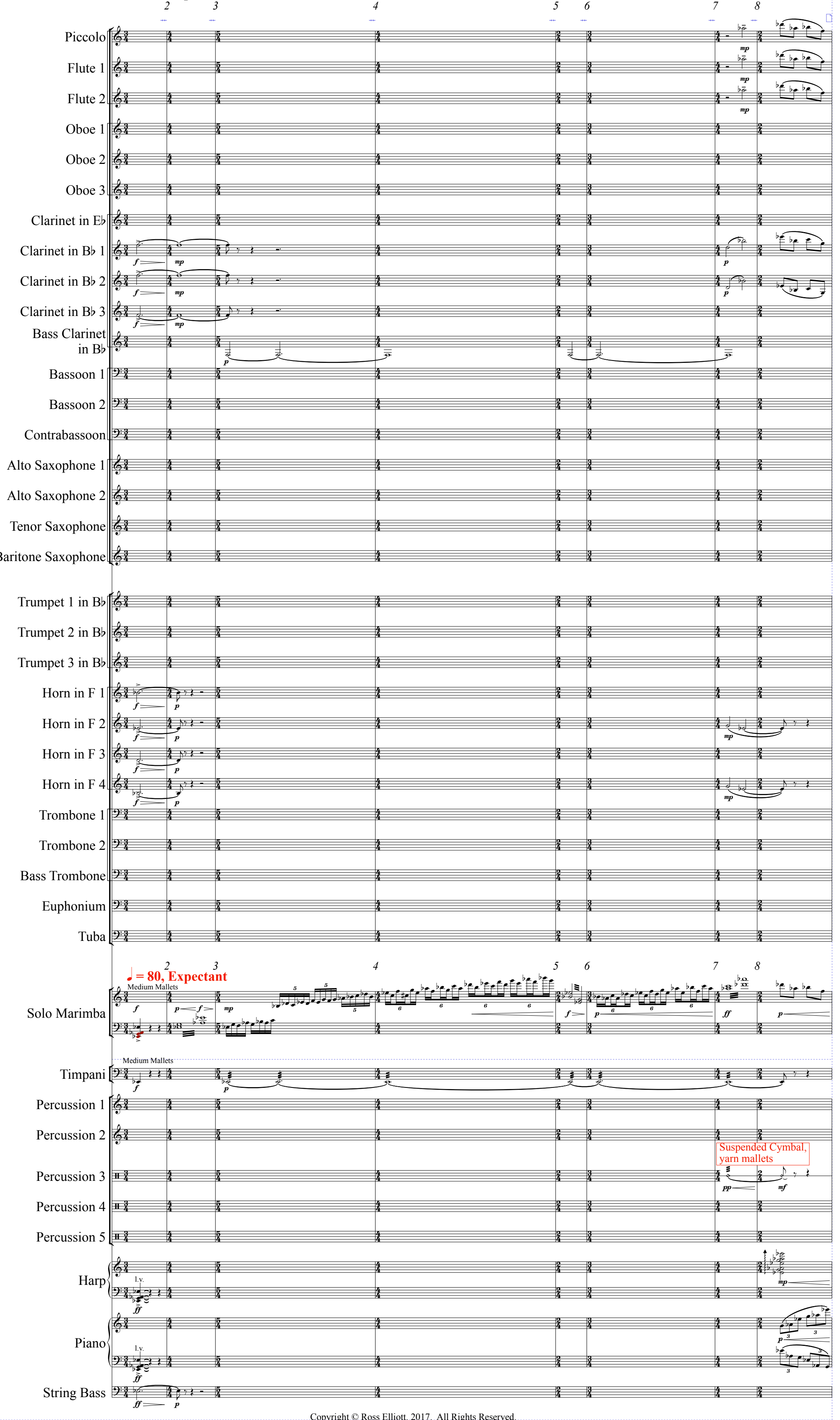

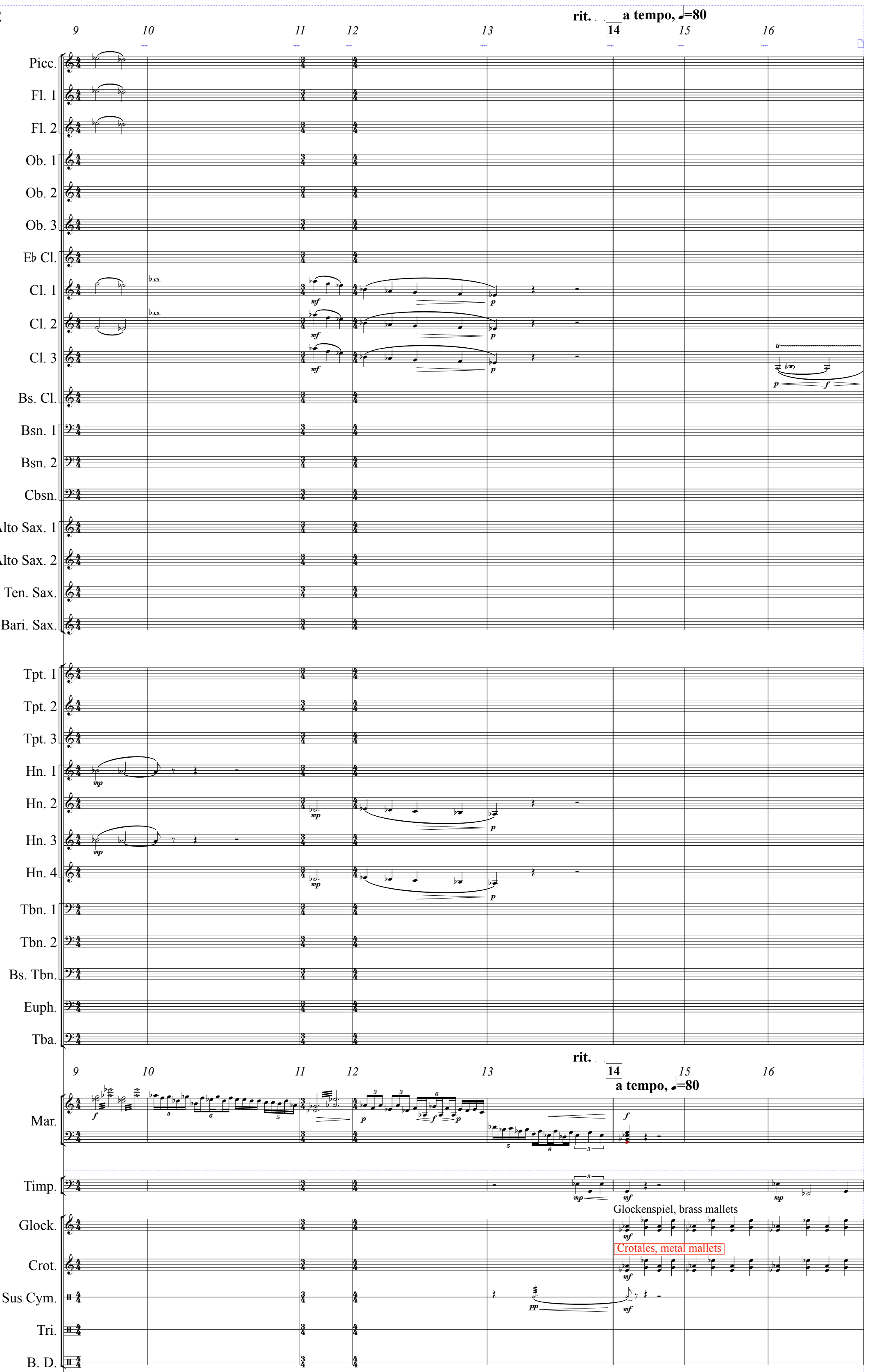

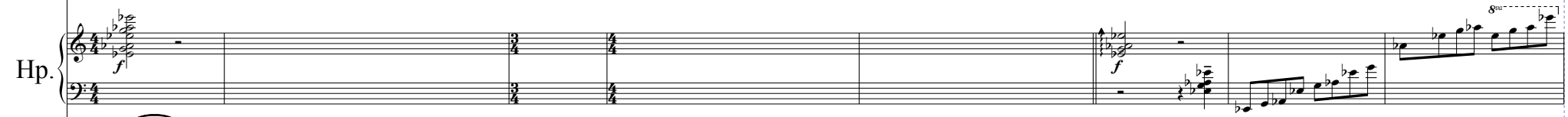

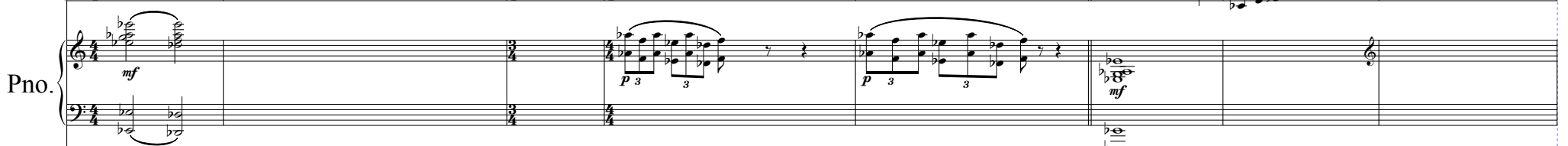

S. Bass 

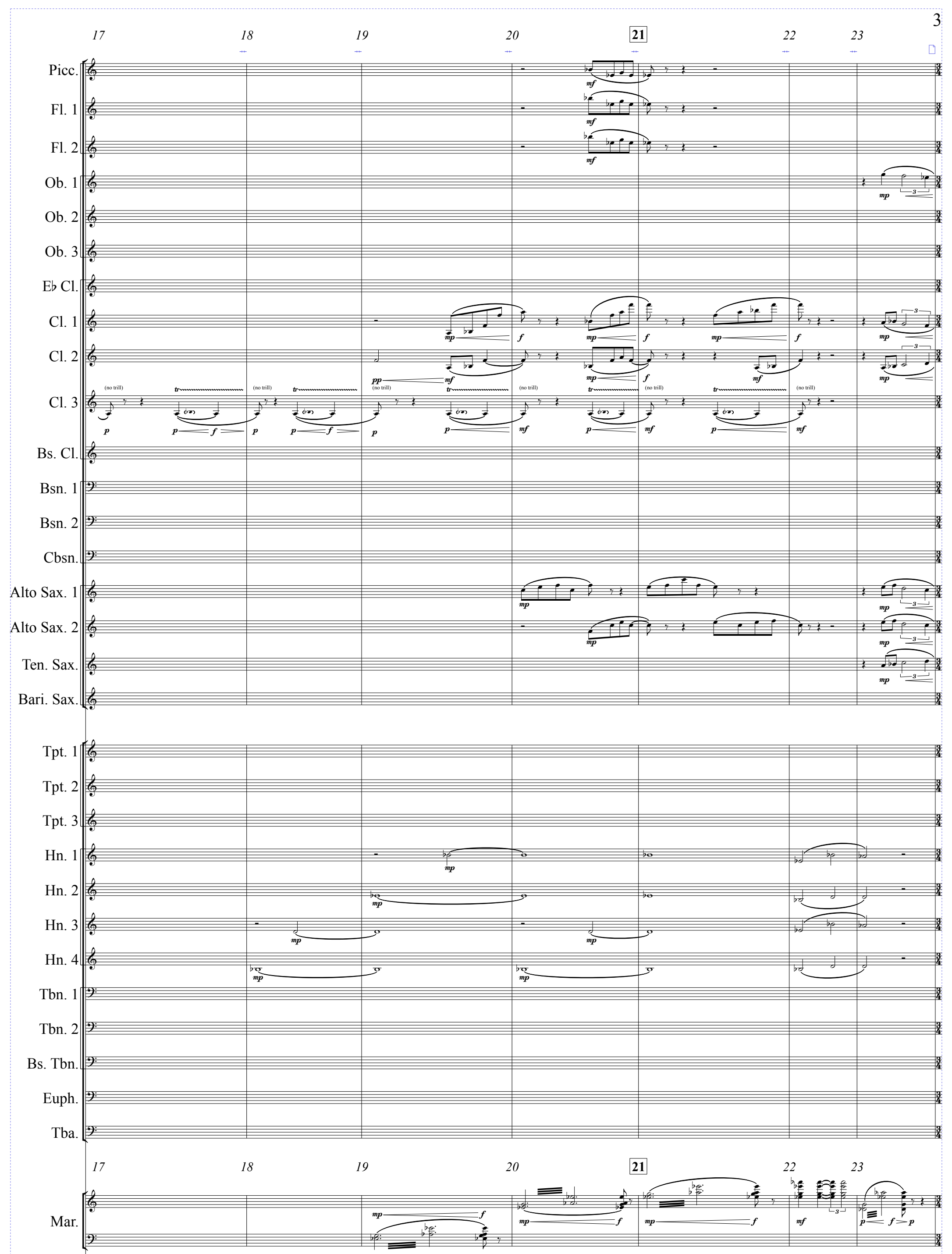

Timp.

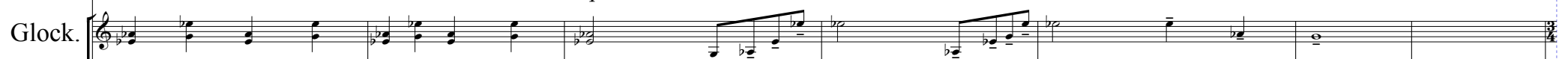
Crot. Sus Cym.

Tri.

B. D. "

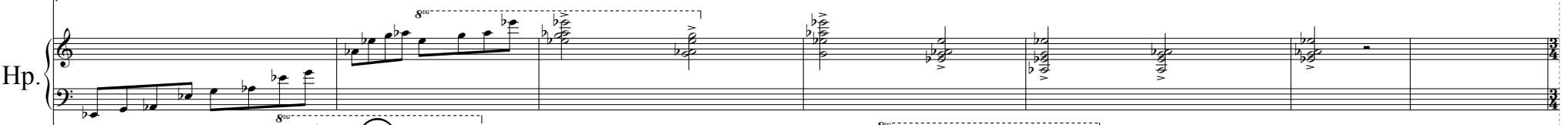

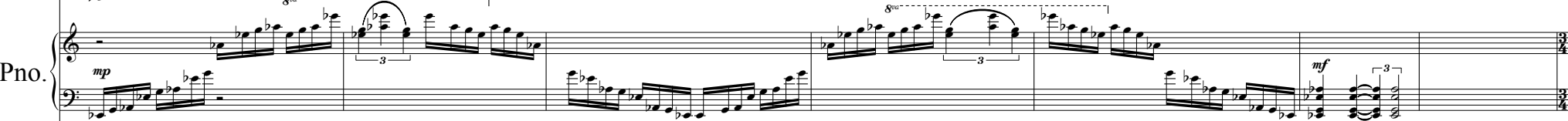
S. Bass 

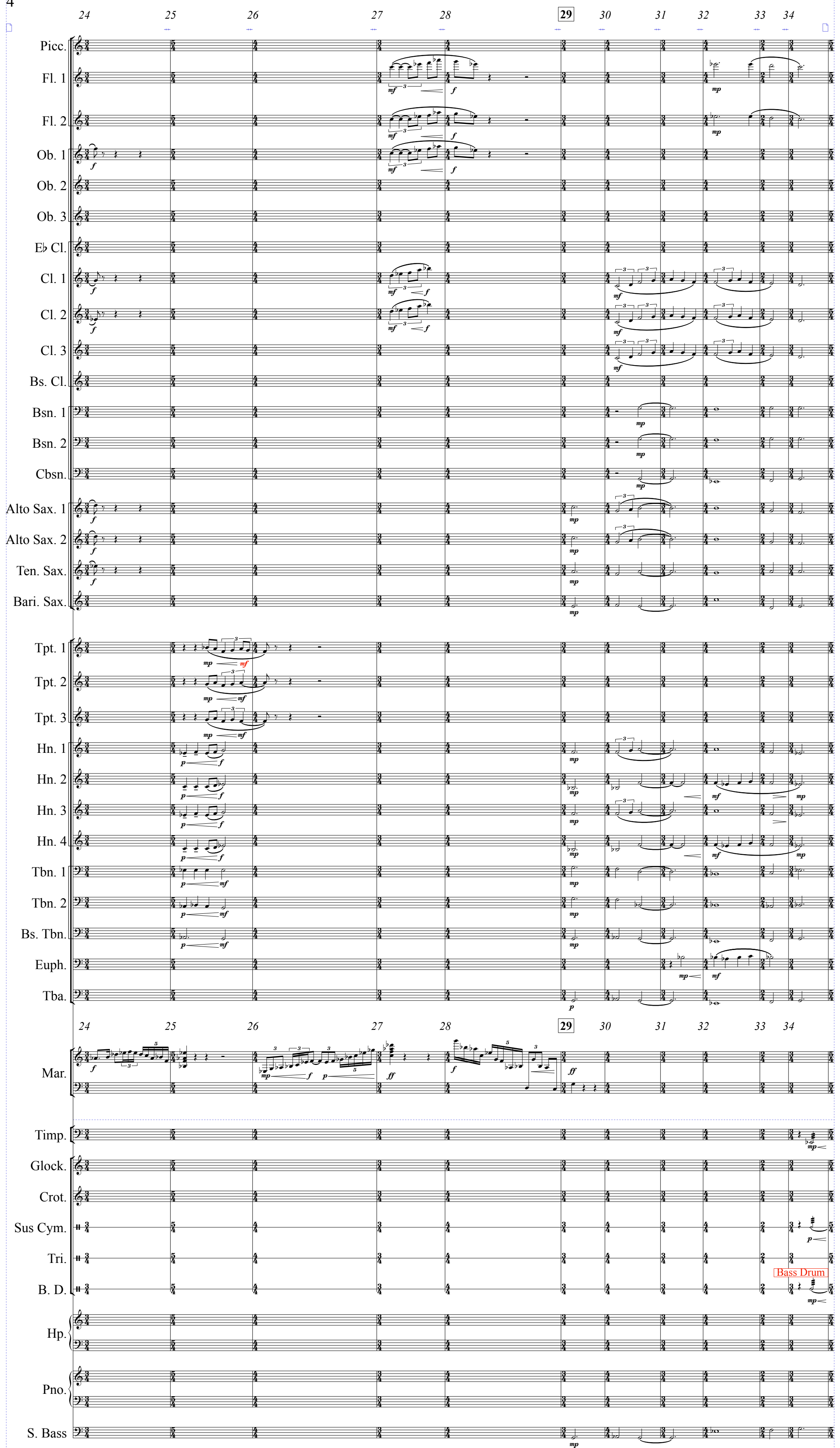


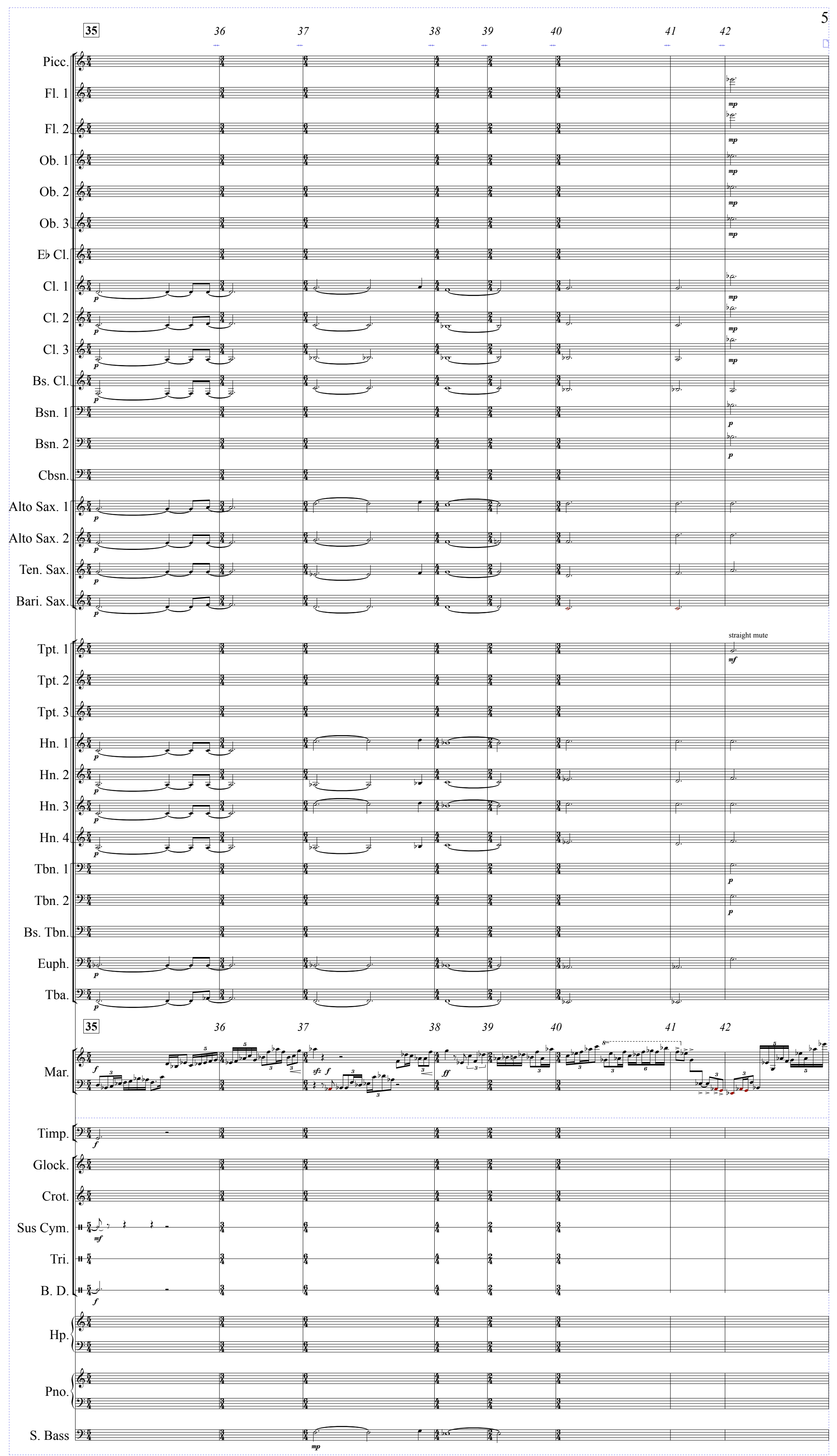



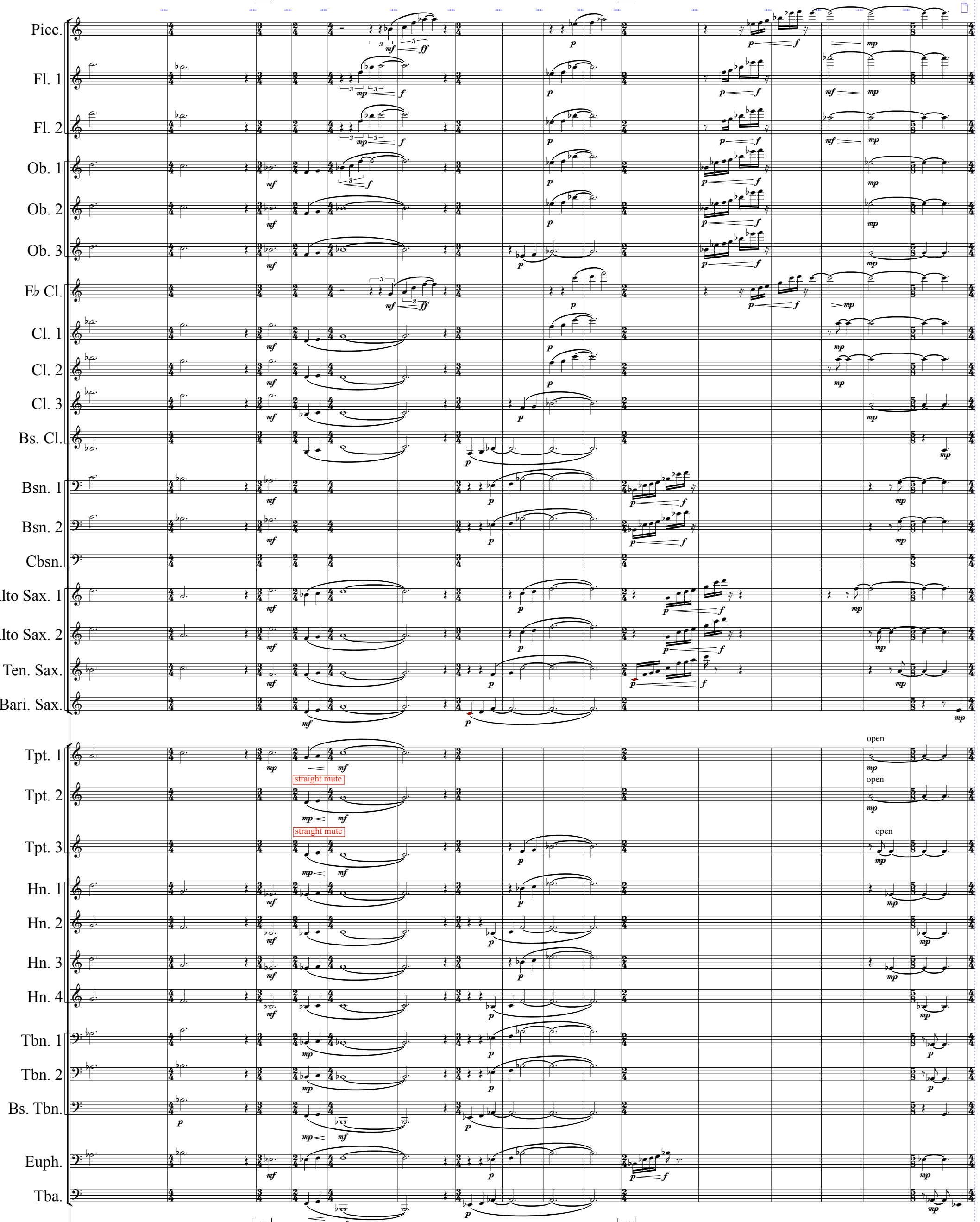

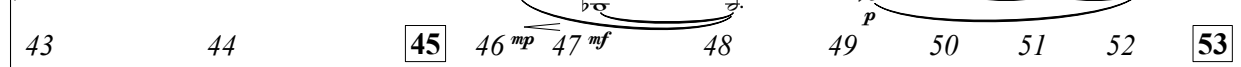

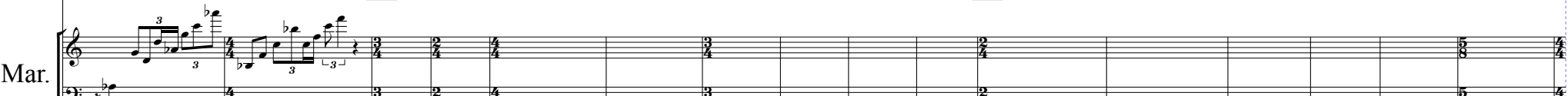

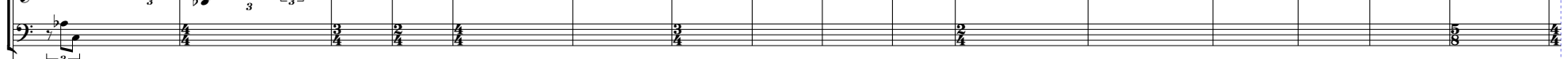

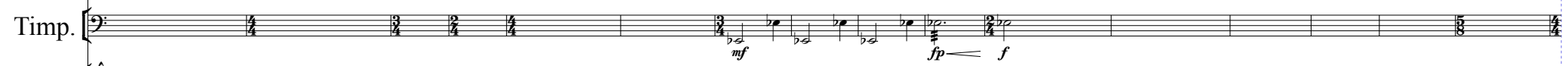

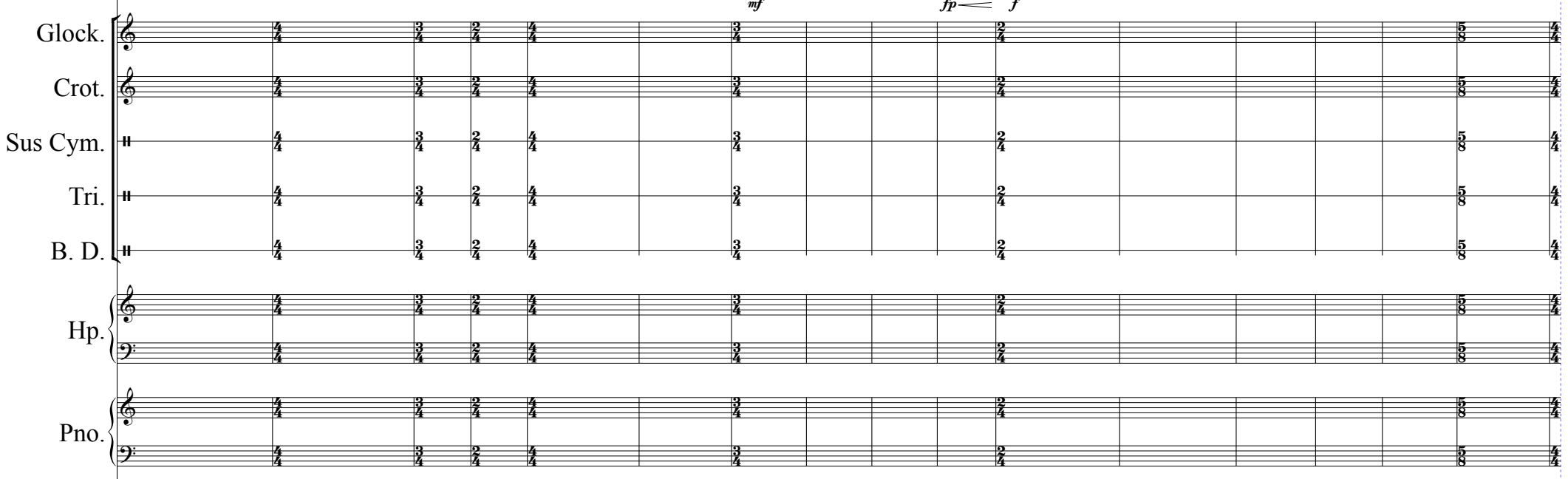

S. Bass 


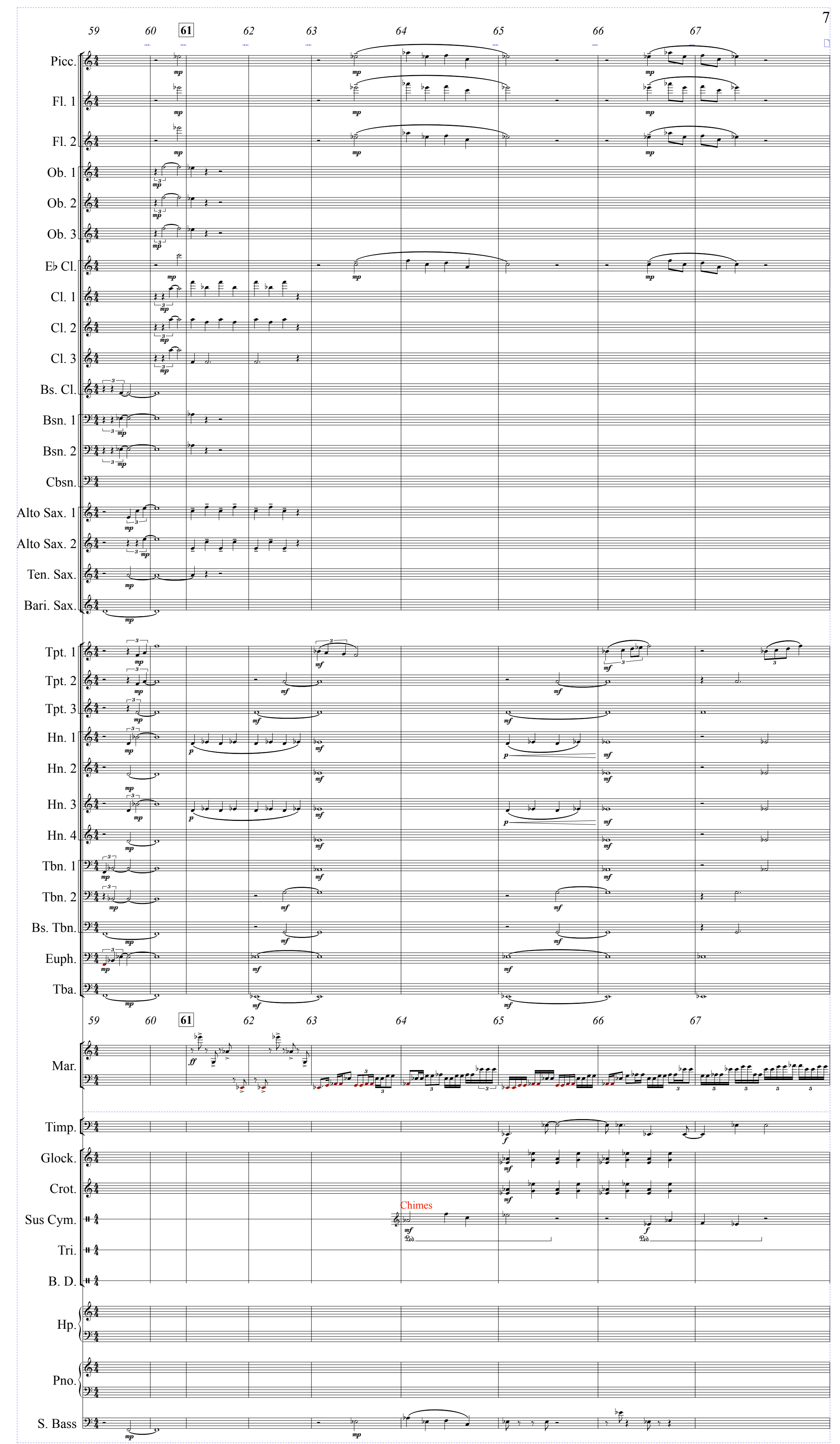



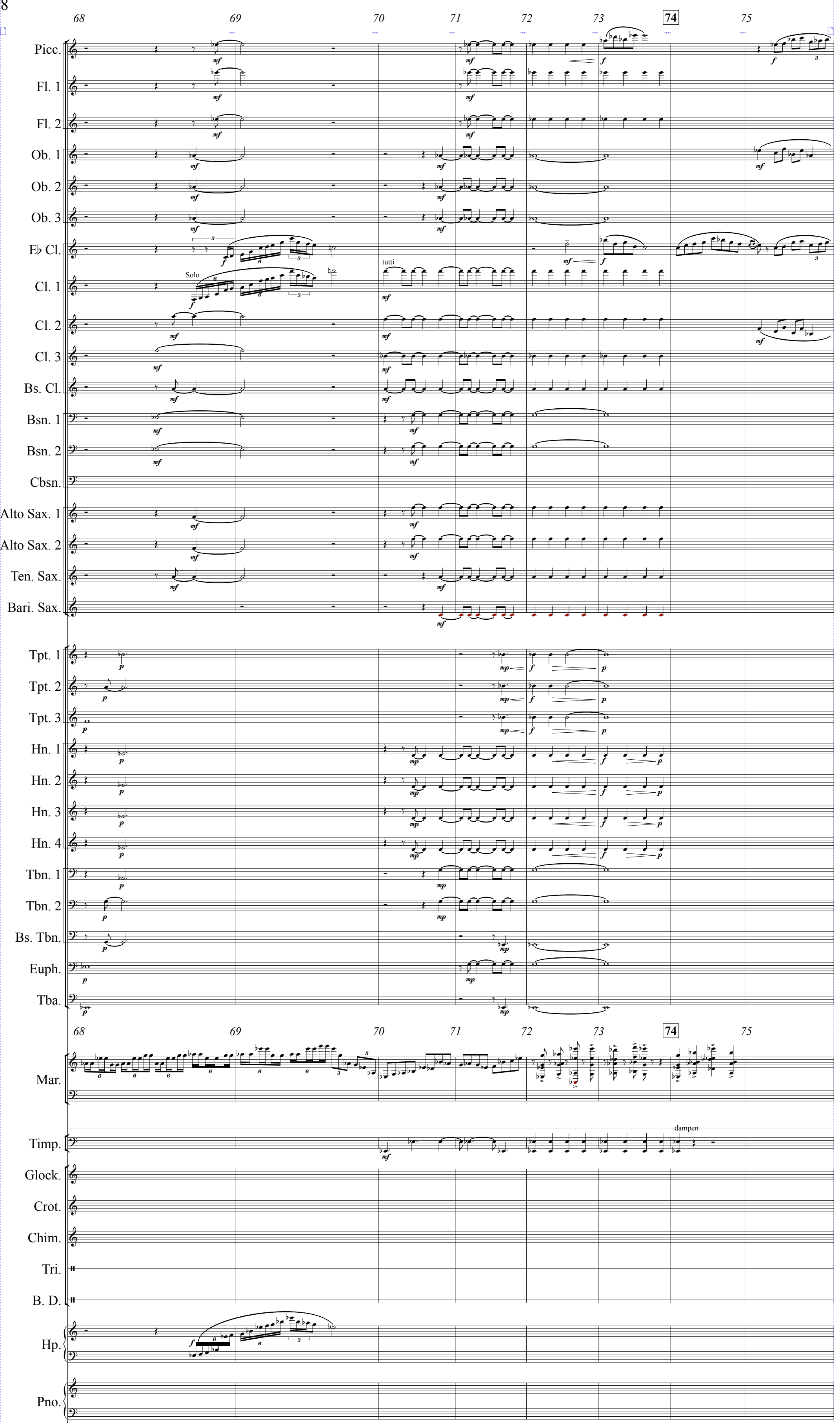

S. Bass 


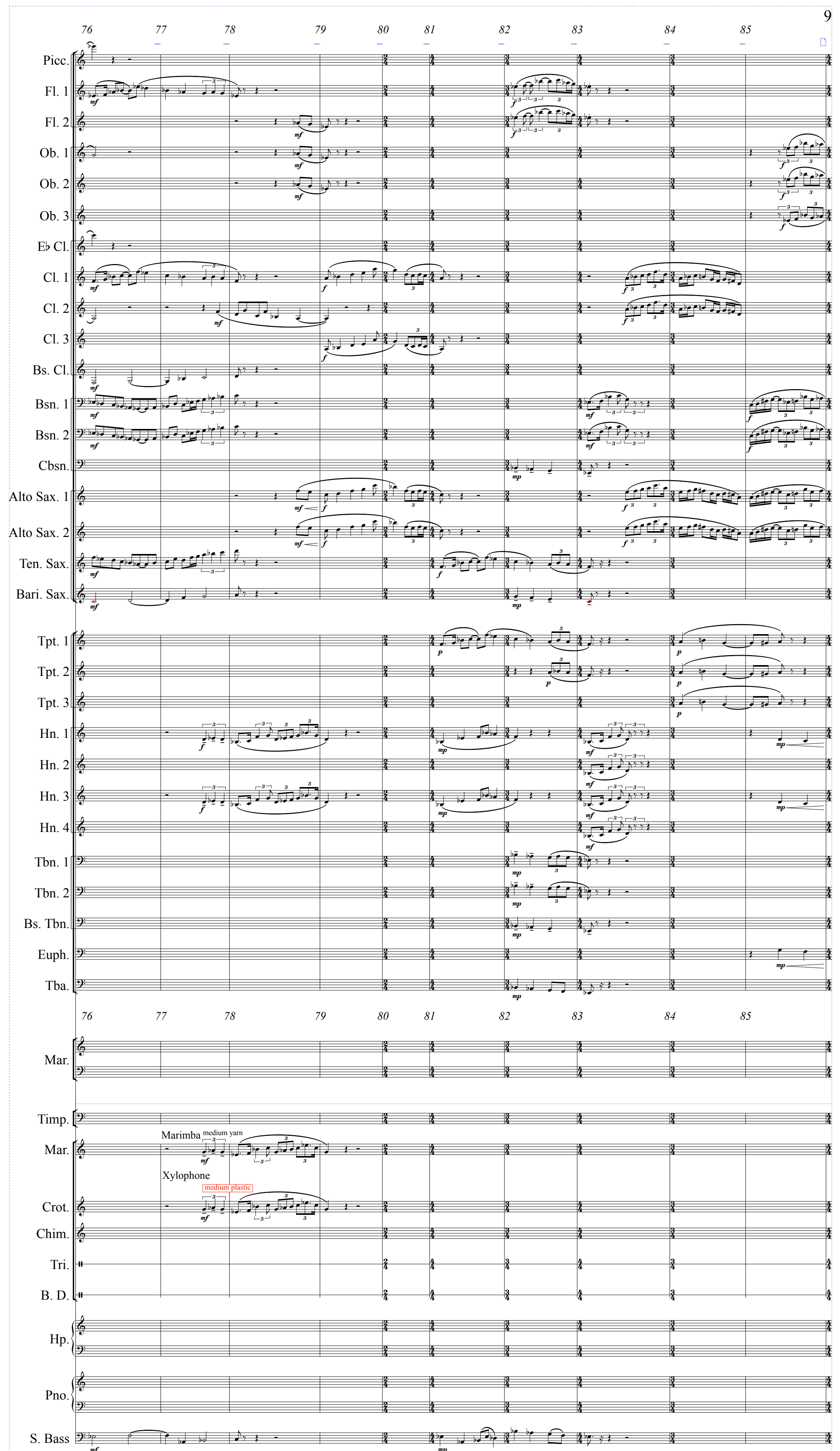



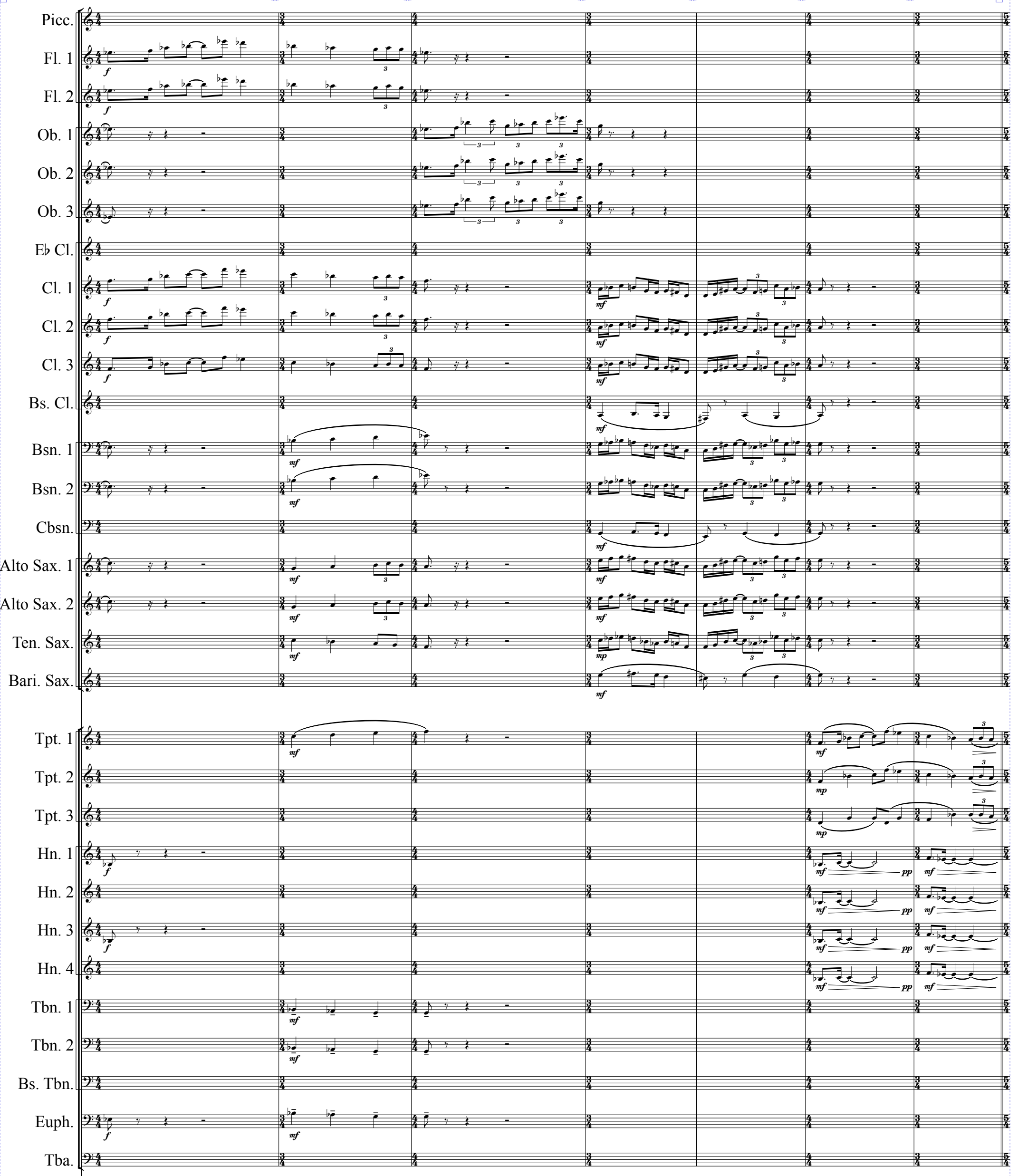
86
87
88
92

89

90

91

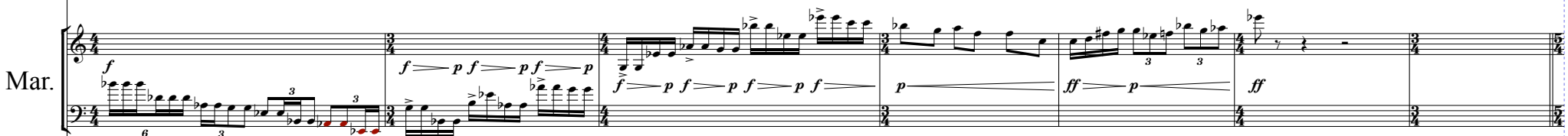

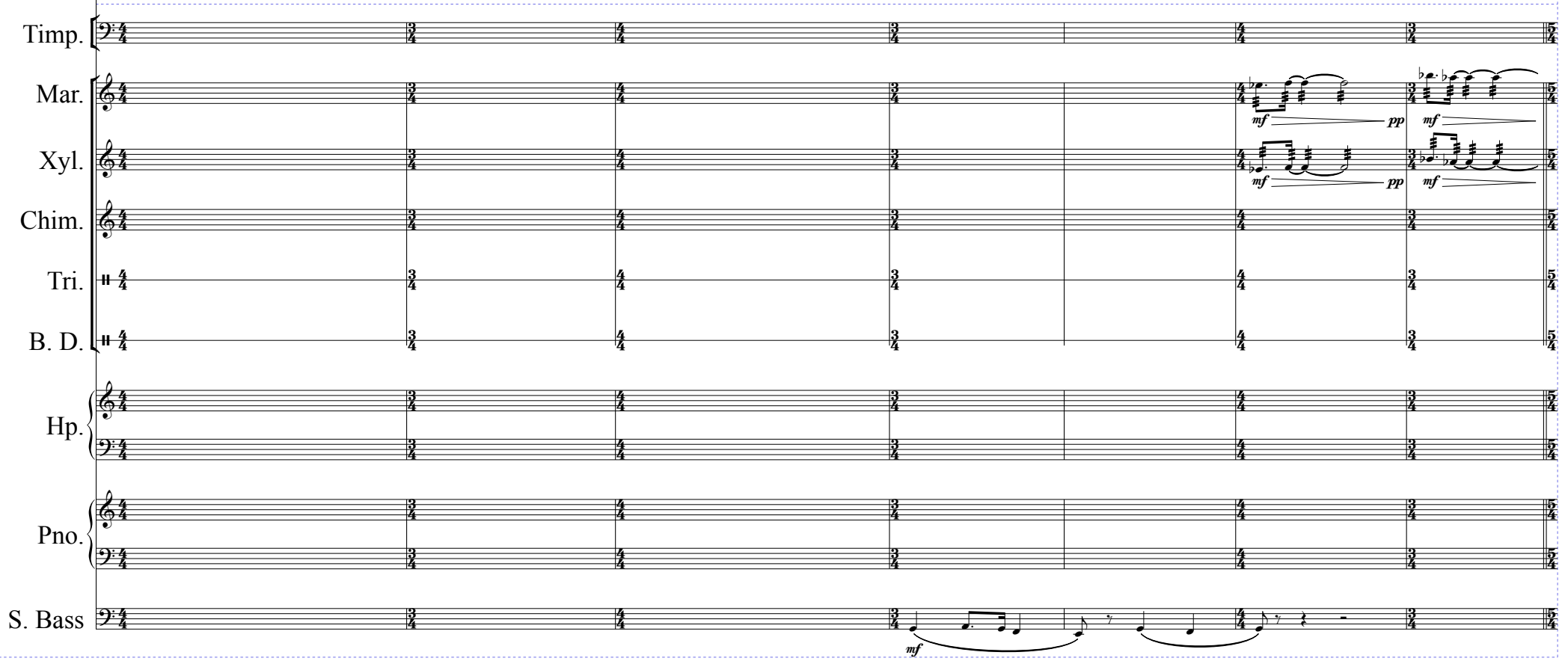




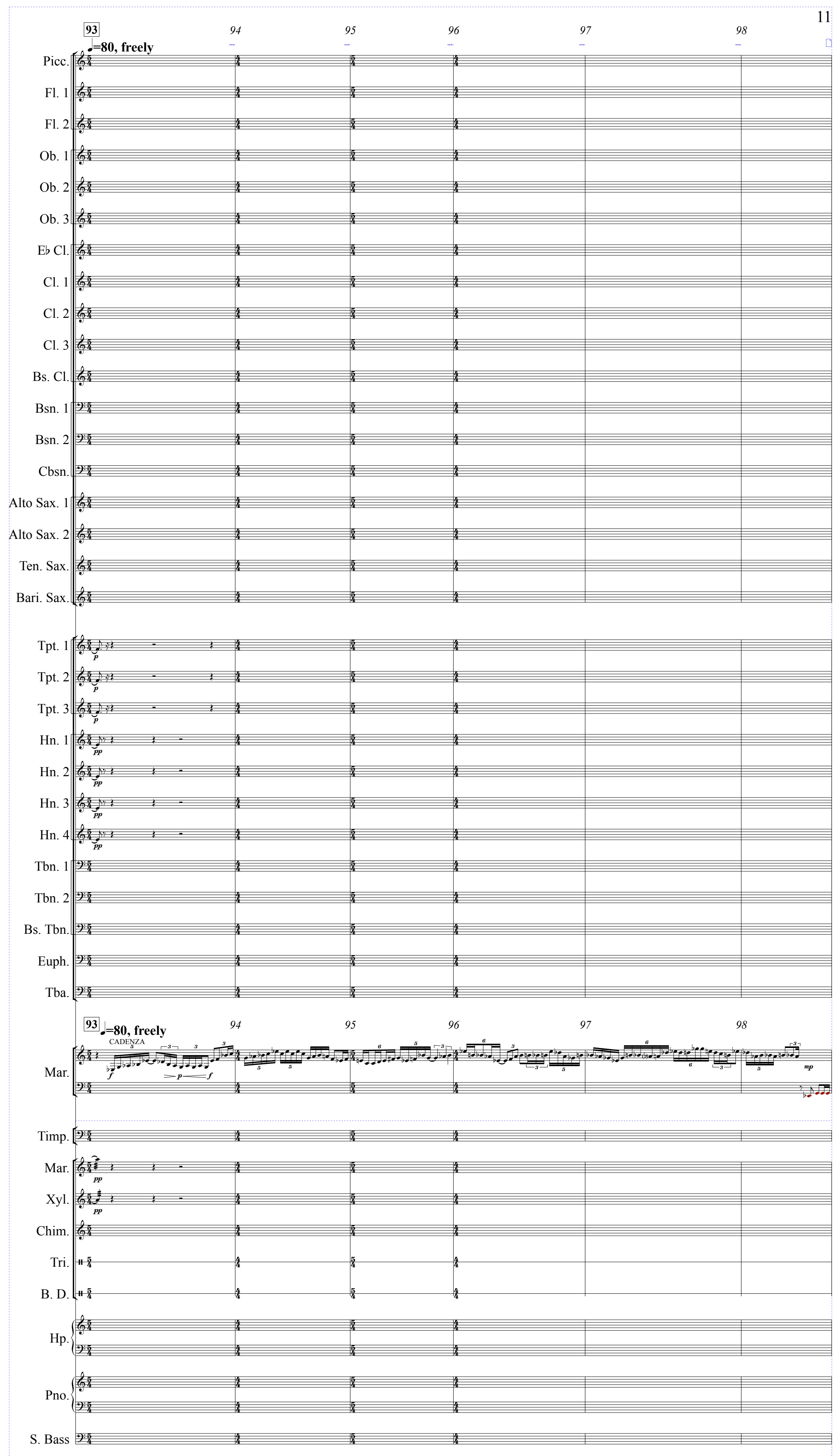


$\begin{array}{llllllllll}99 & 100 & 101 & 102 & 103 & 104 & 105 & 106 & 107 & 108\end{array}$
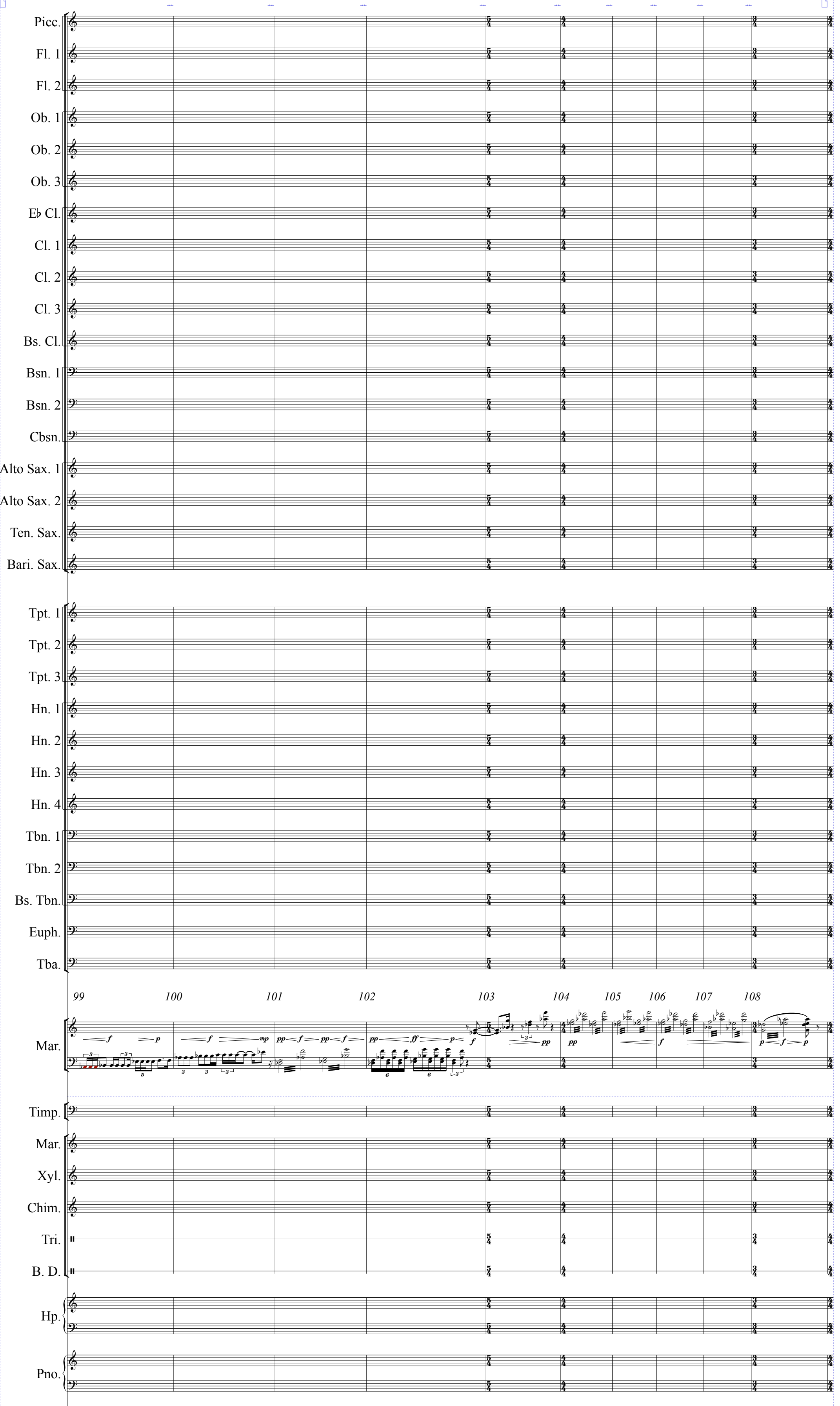

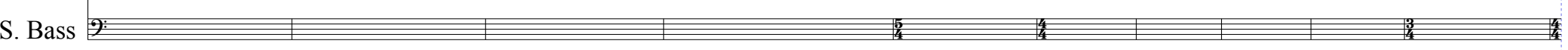




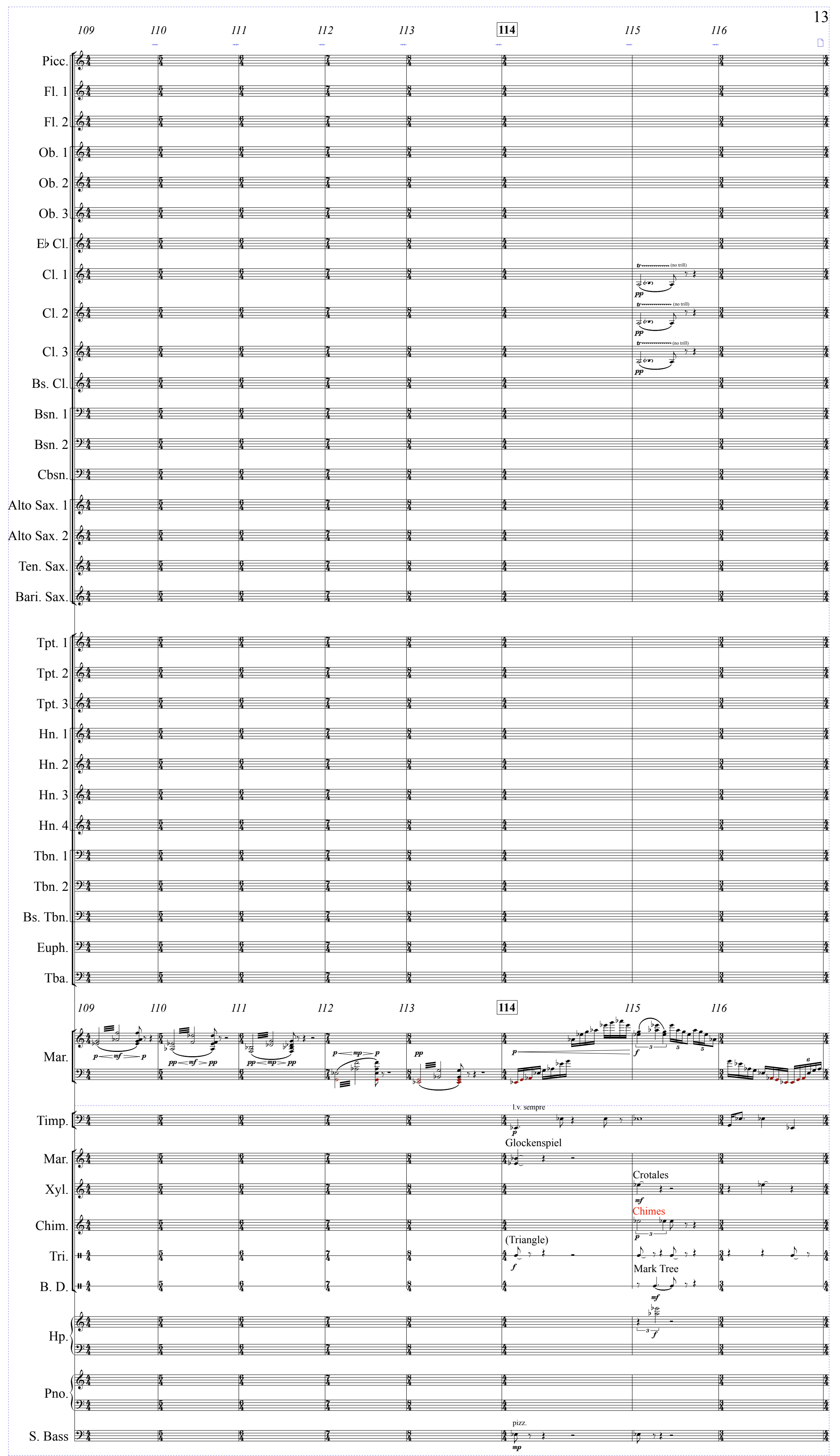



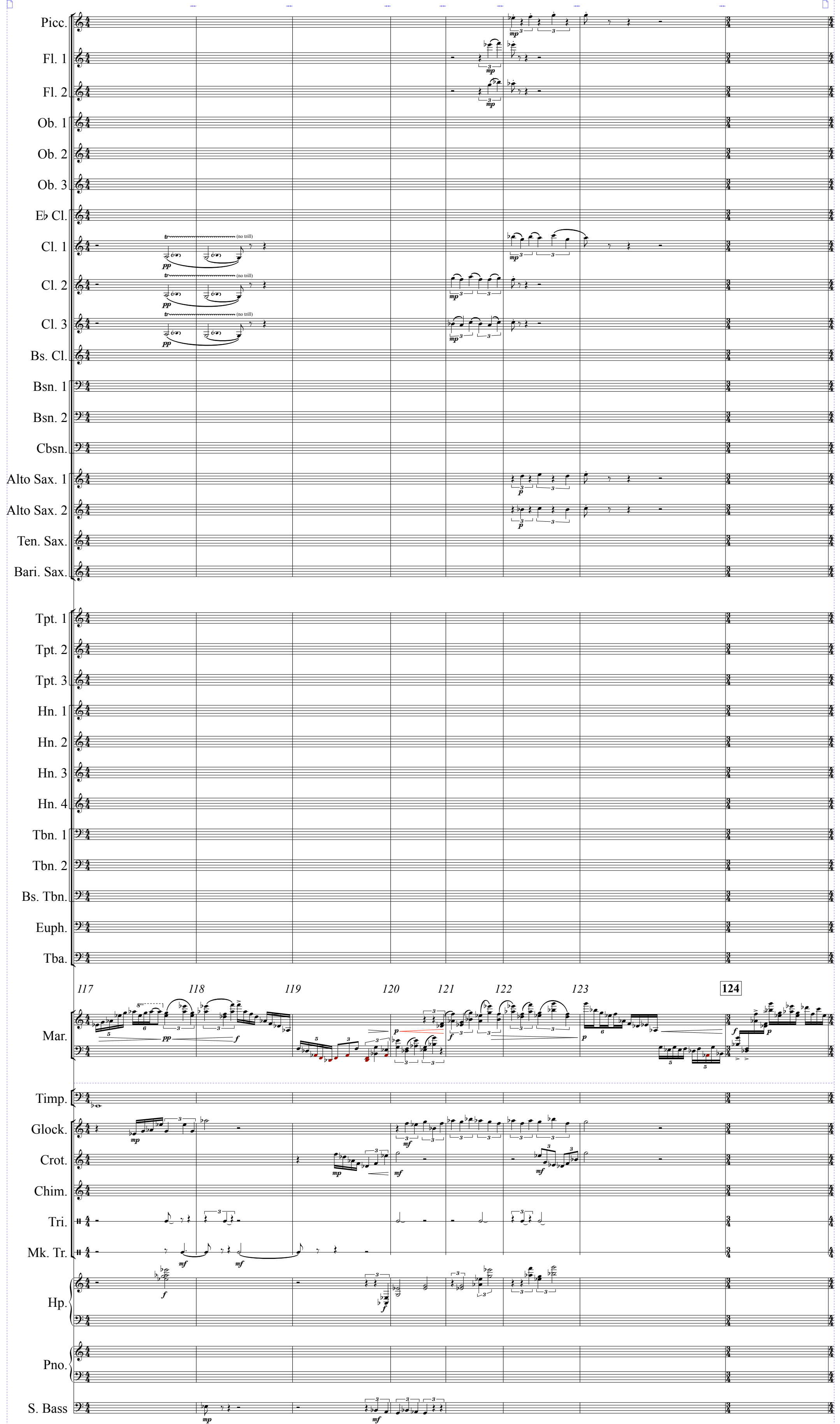


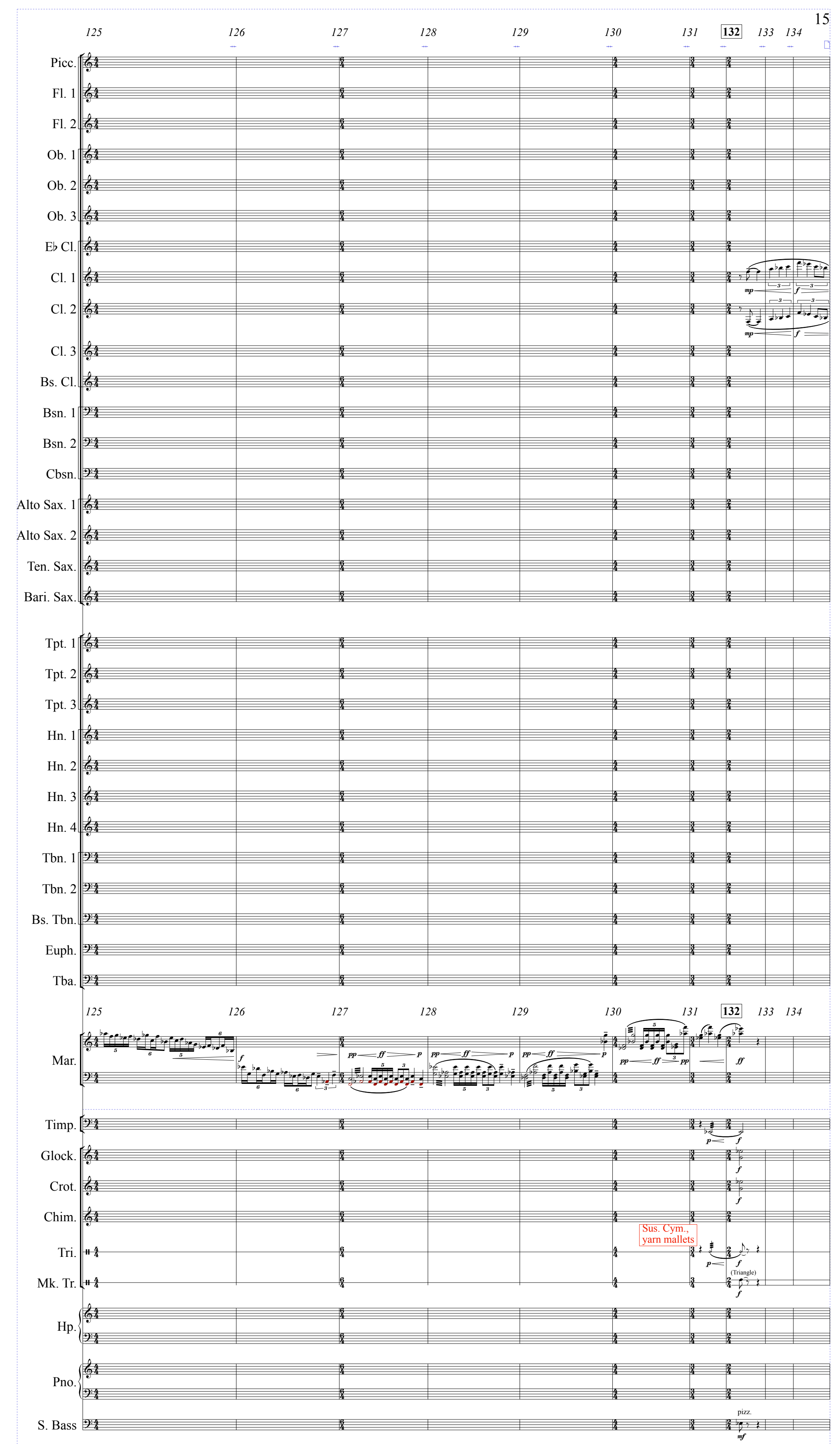



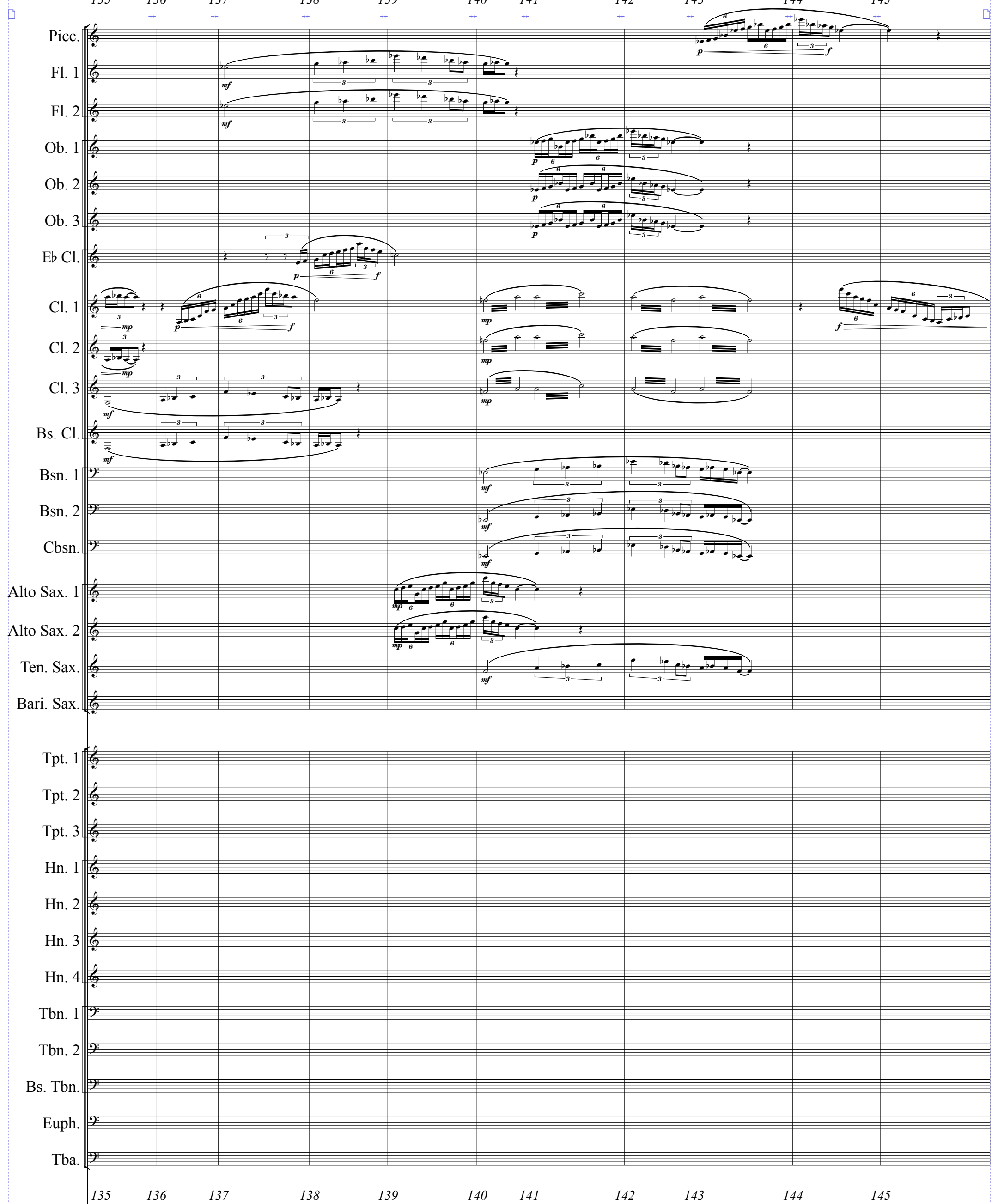

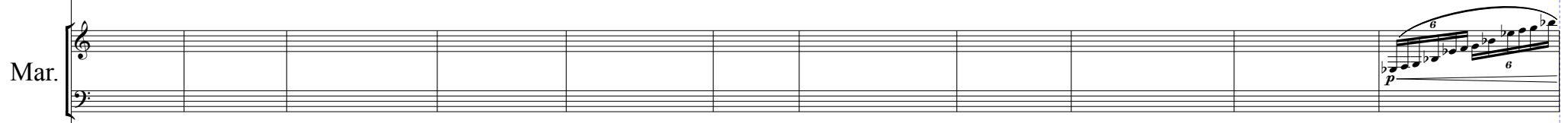

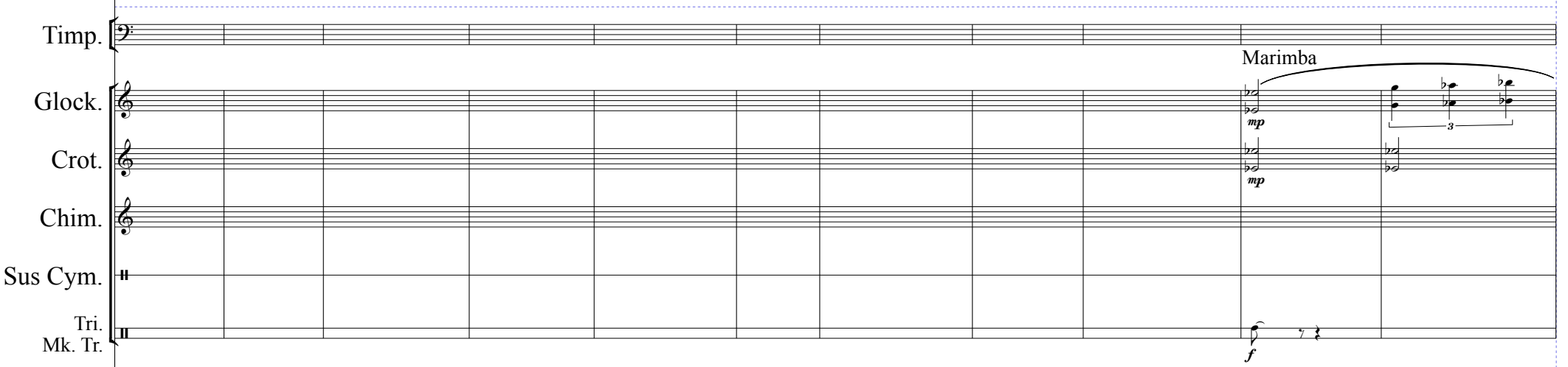

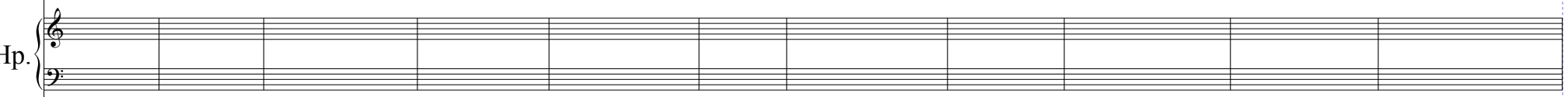

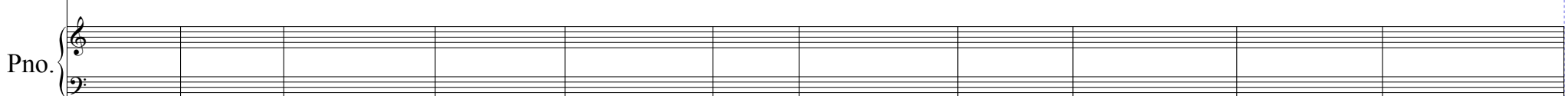
S. Bass 


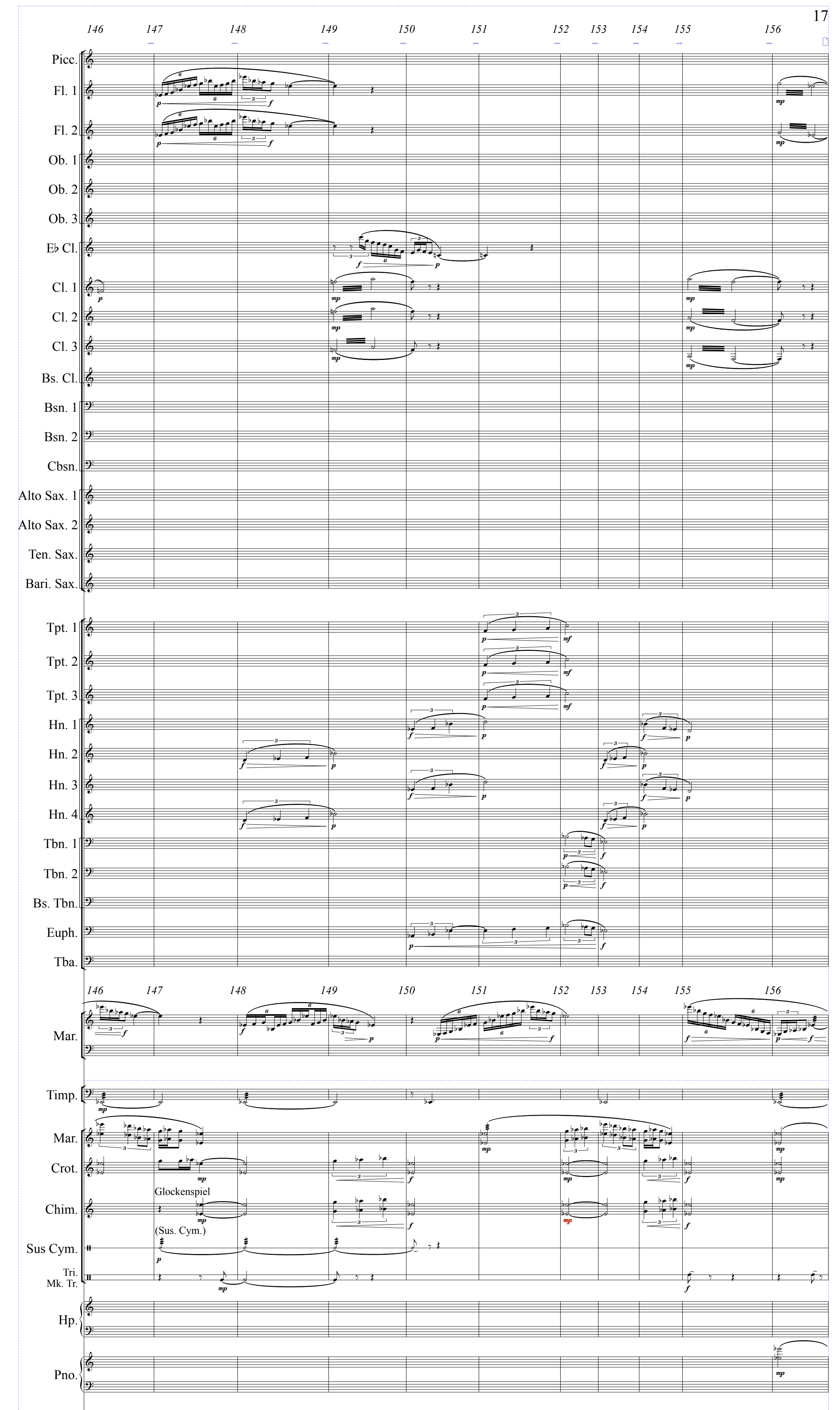

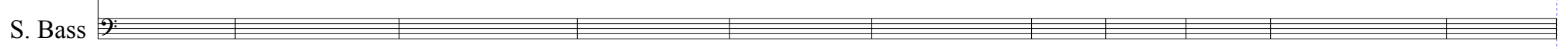


$\begin{array}{lllllllll}157 & 158 & 159 & 160 & 161 & 162 & 163 & 164 & 165\end{array}$
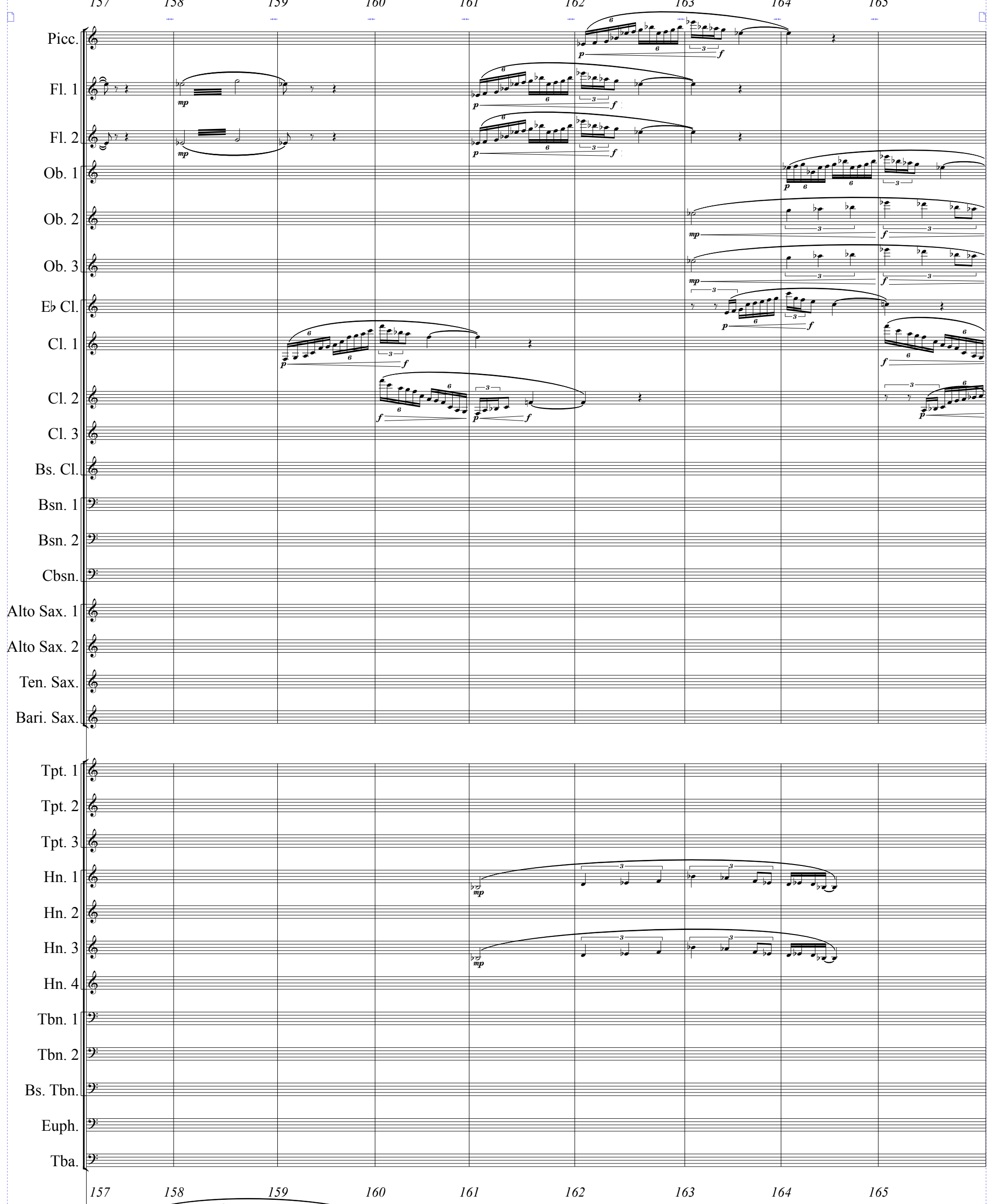

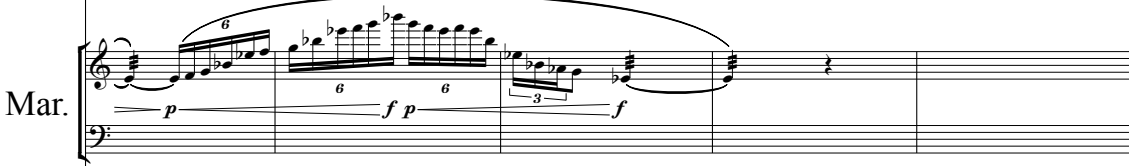

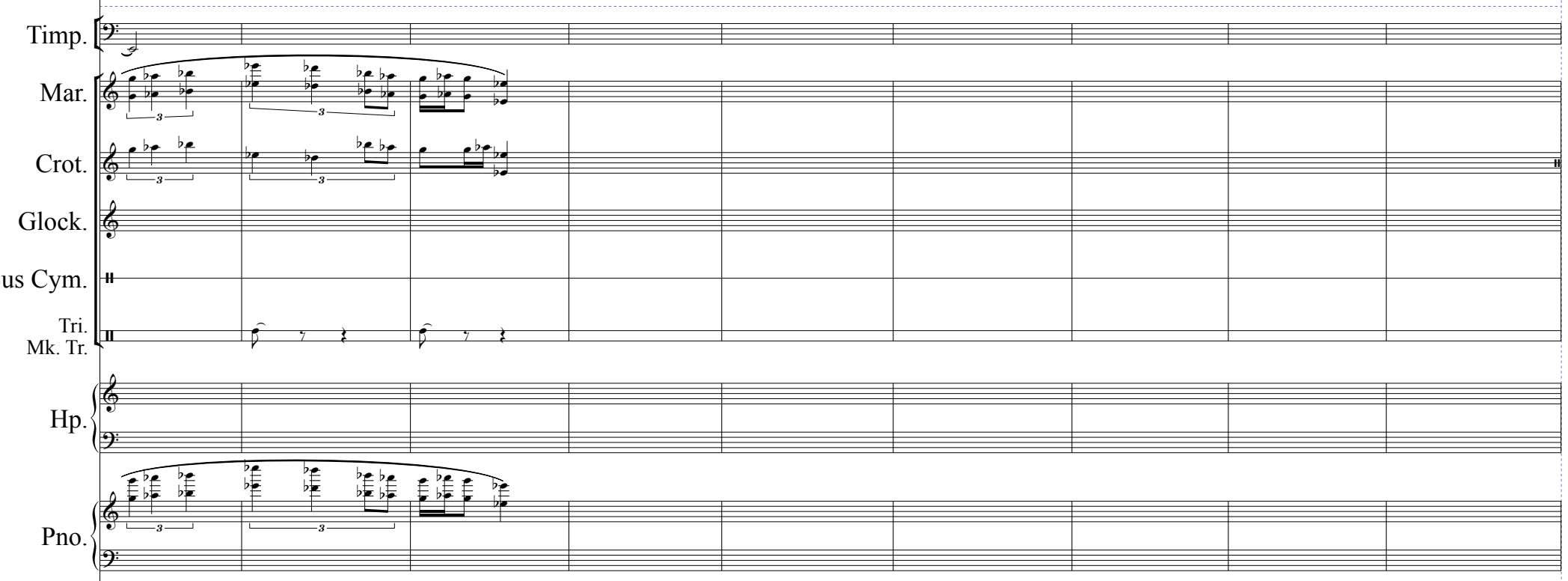

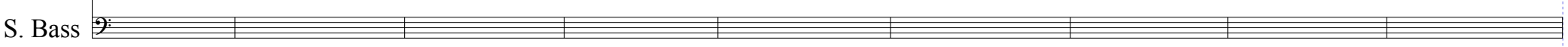




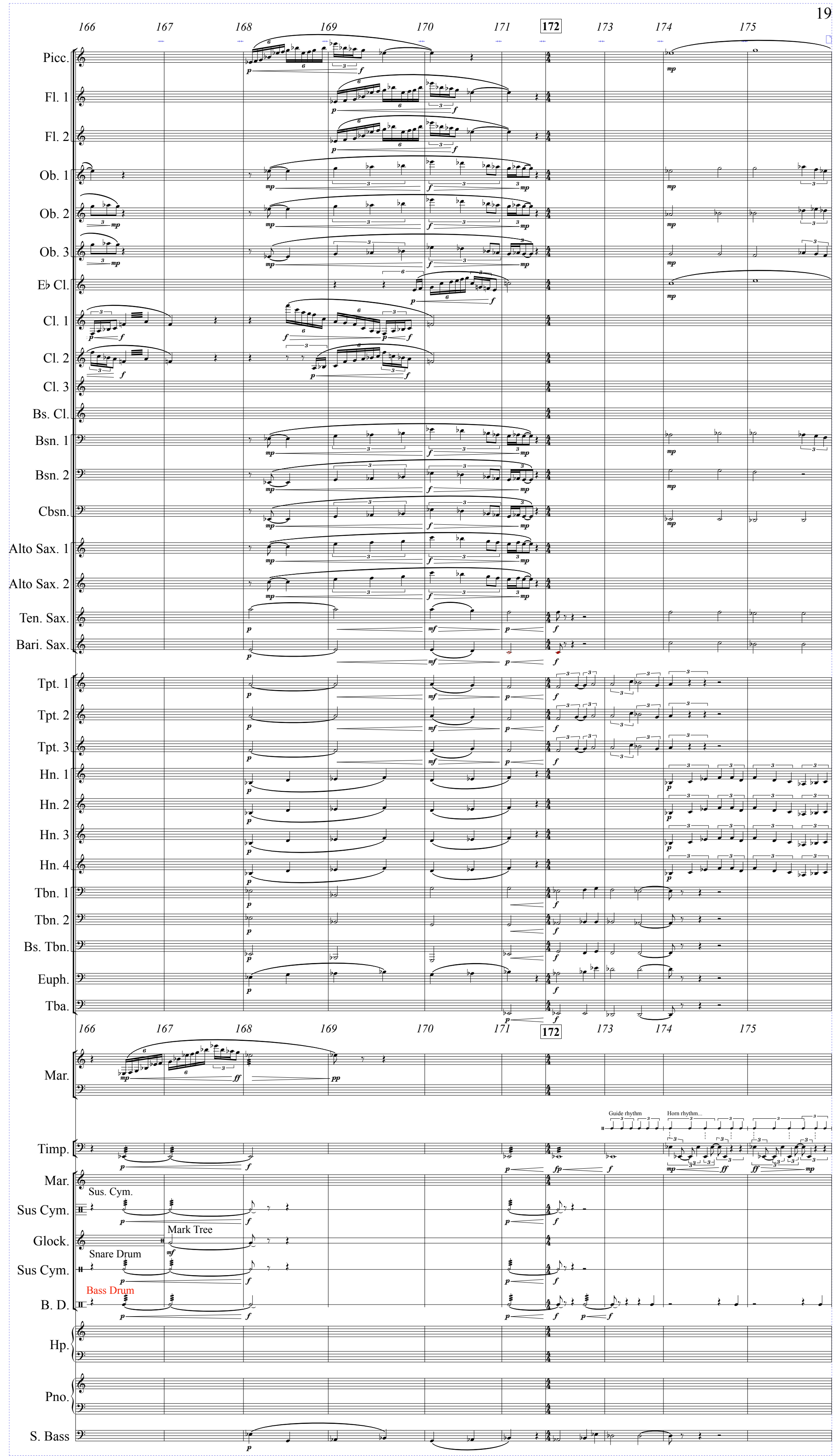



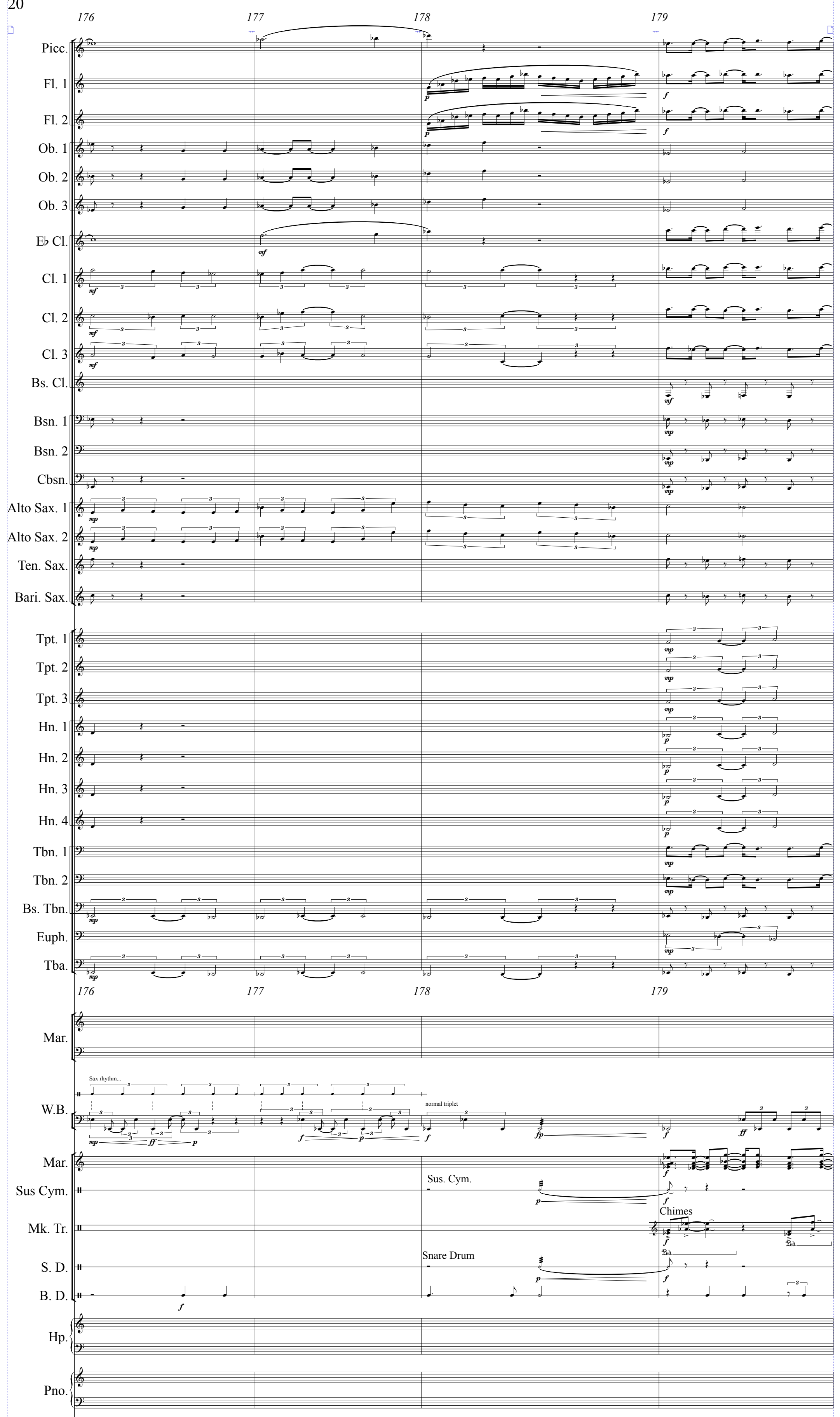

S. Bass 

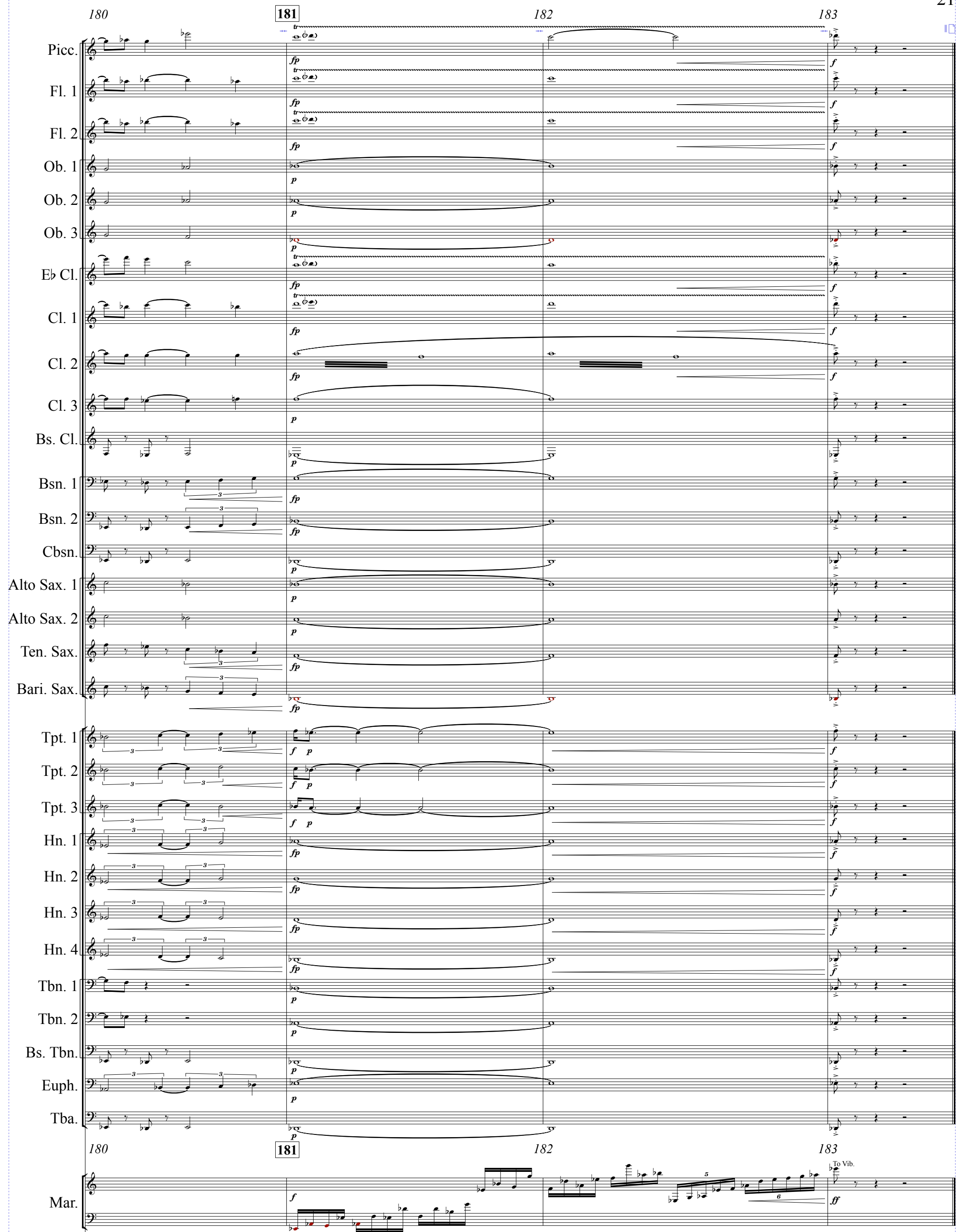

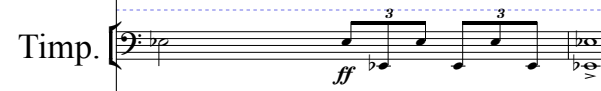
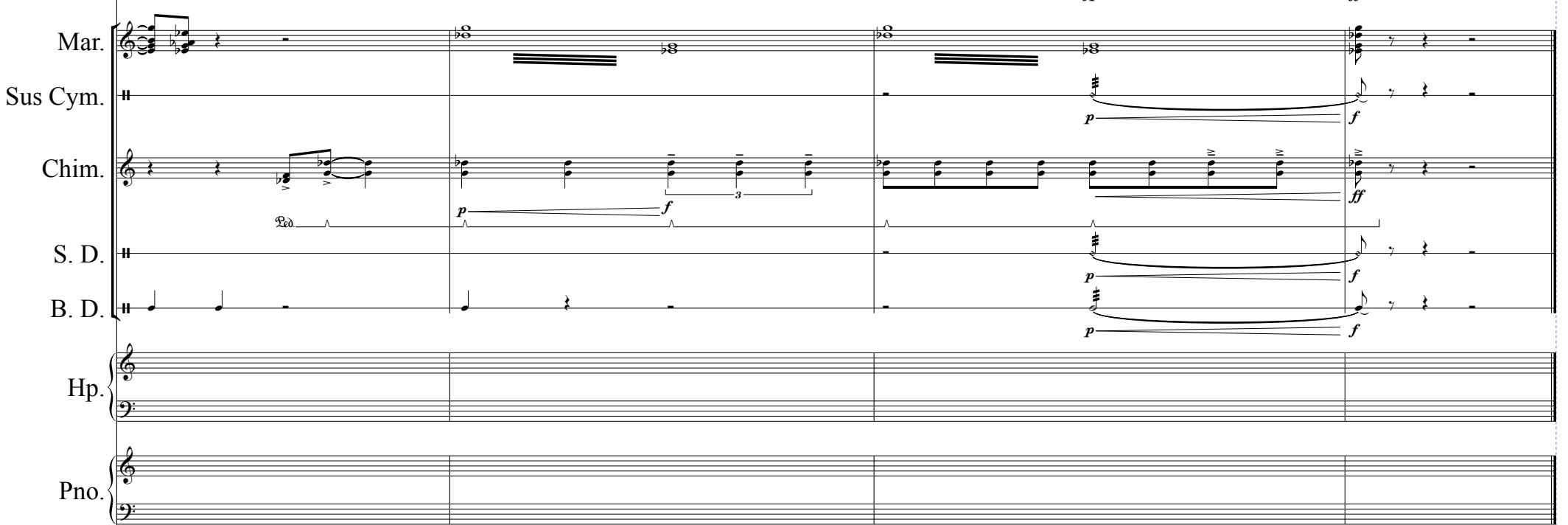

S. Bass 


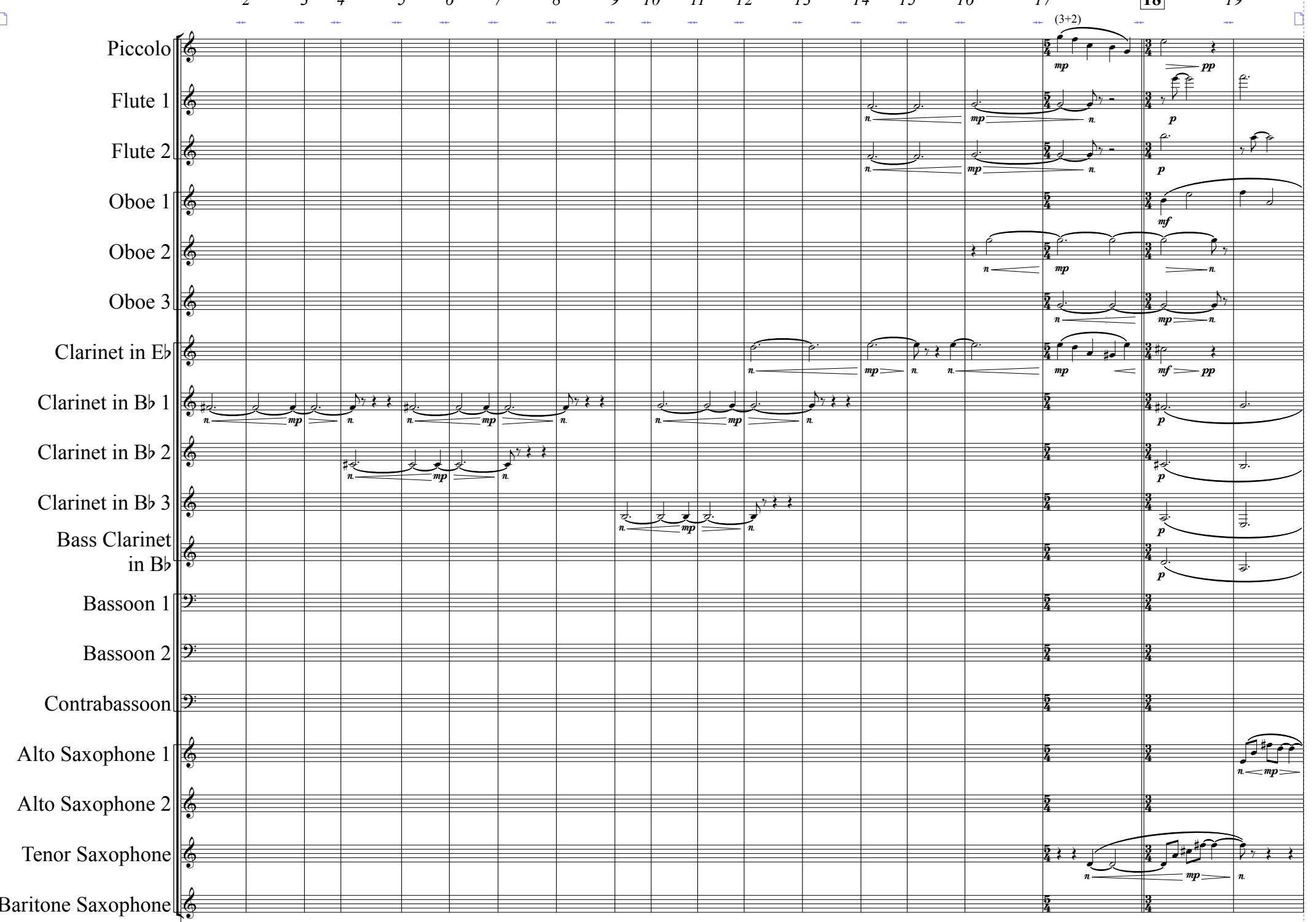

Baritone Saxophon

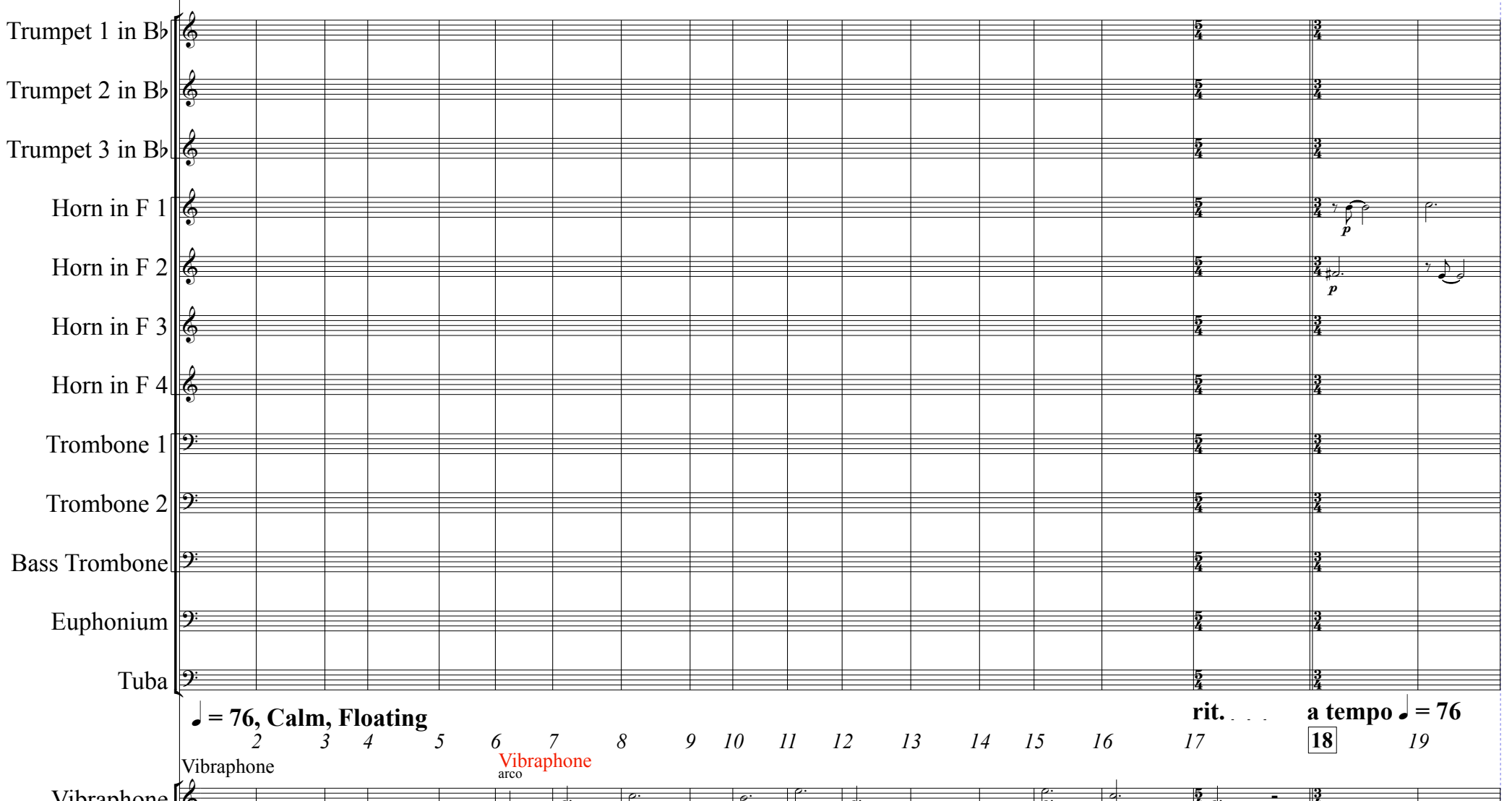

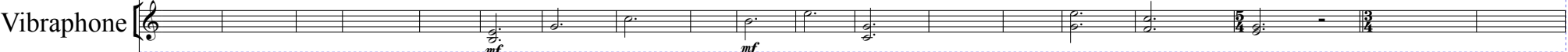

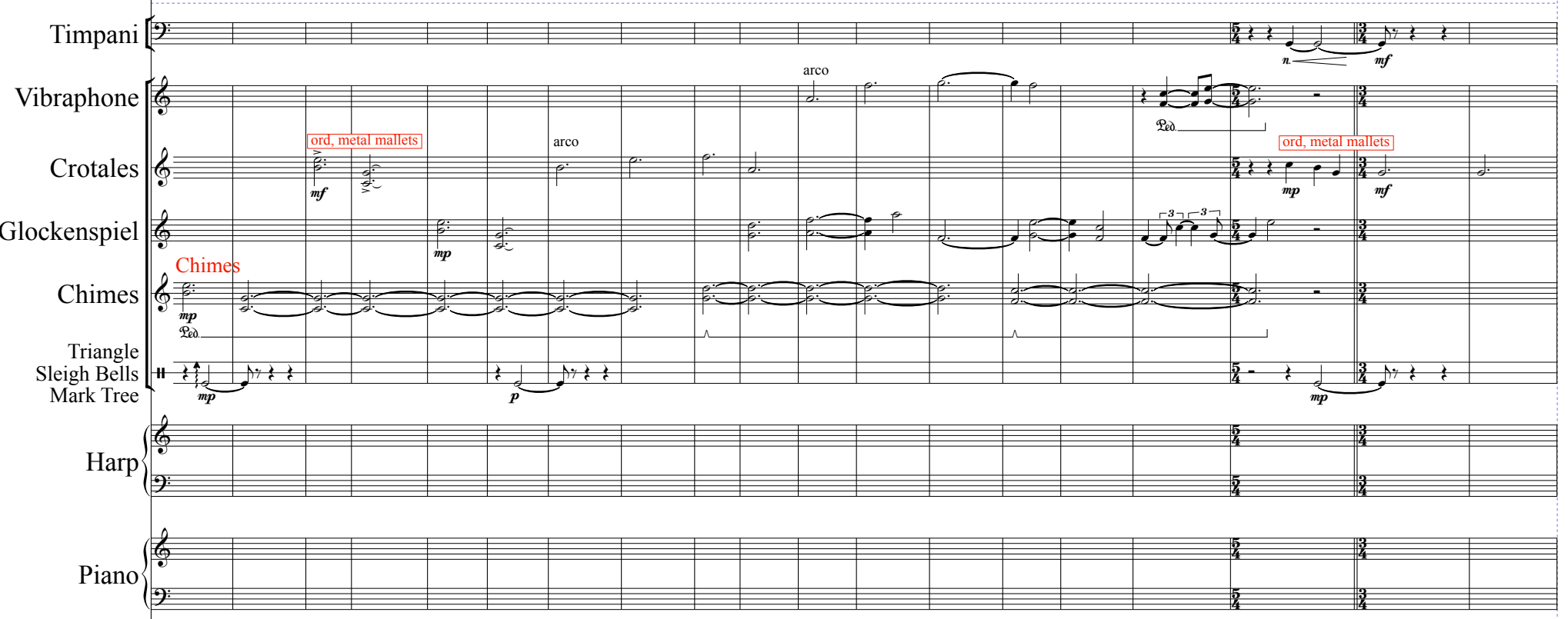

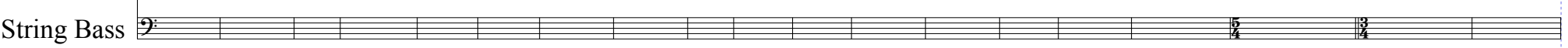


$\begin{array}{llllllllllllllll}20 & 21 & 22 & 23 & 24 & 25 & 26 & 27 & 28 & 29 & 30 & 31 & 32 & 33 & 34\end{array}$
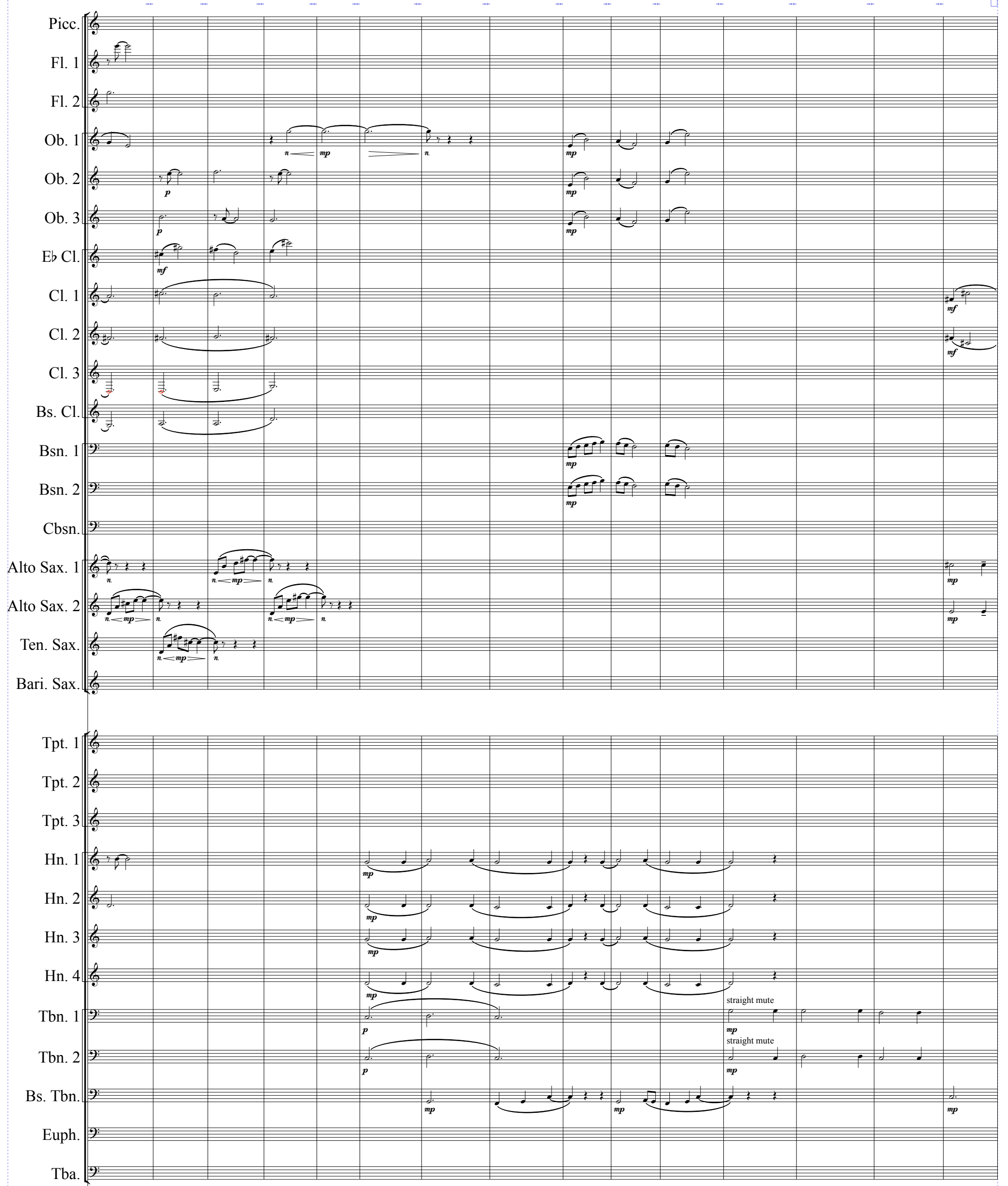

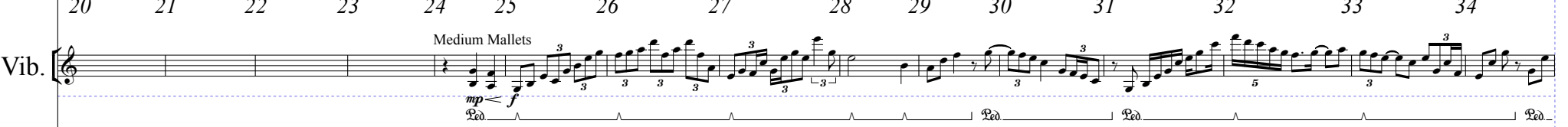

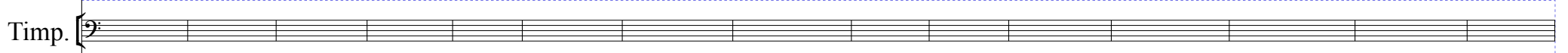

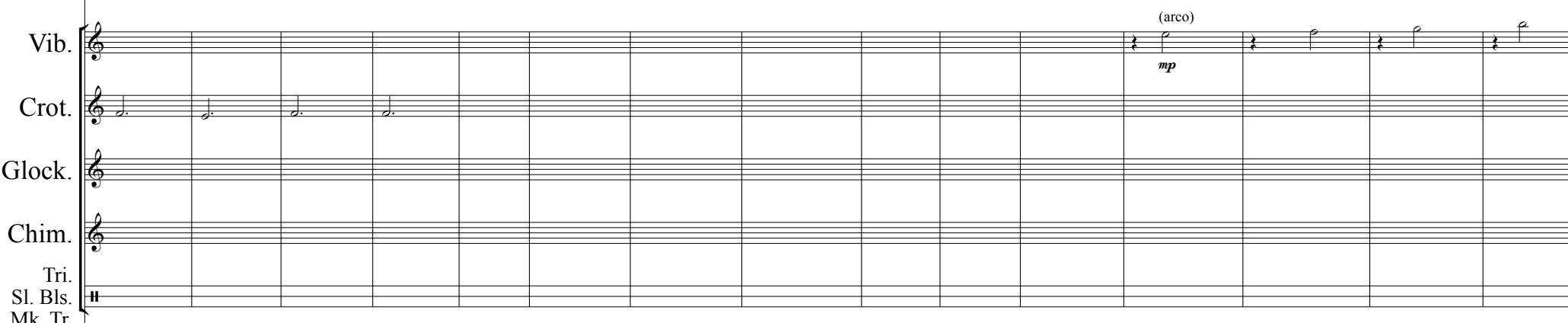
S1. Bls.
Mk. Tr.

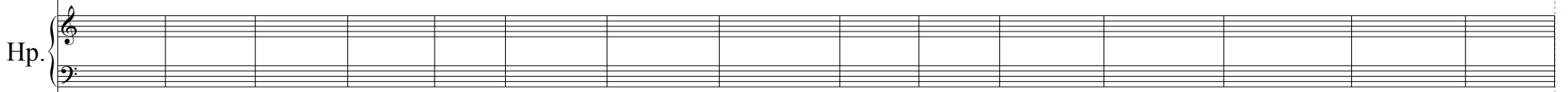

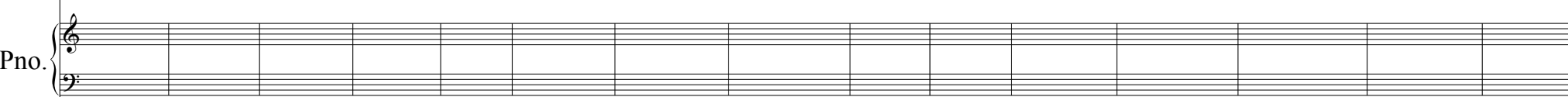

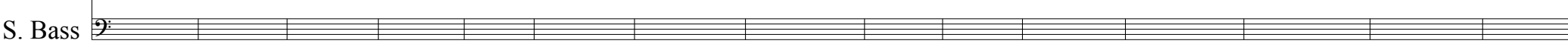



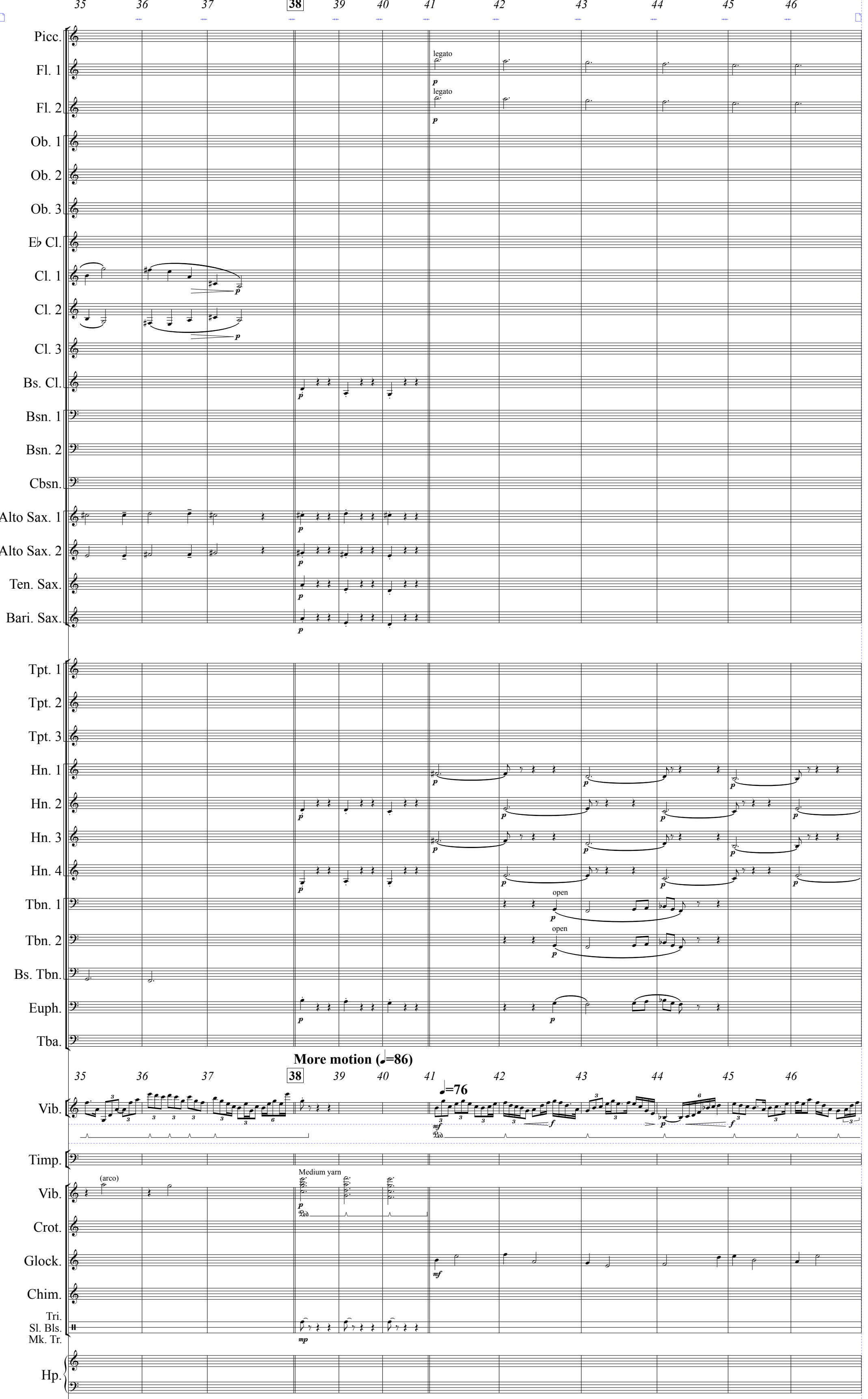

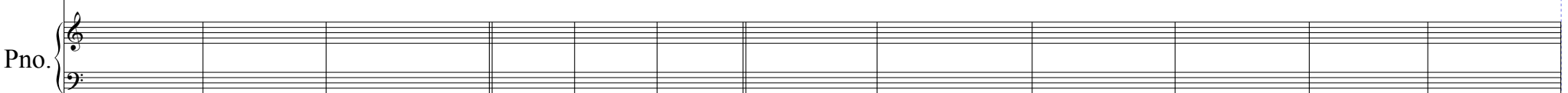

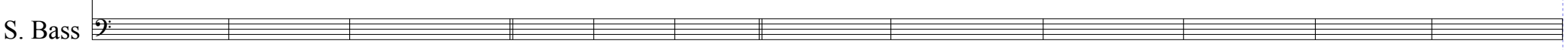



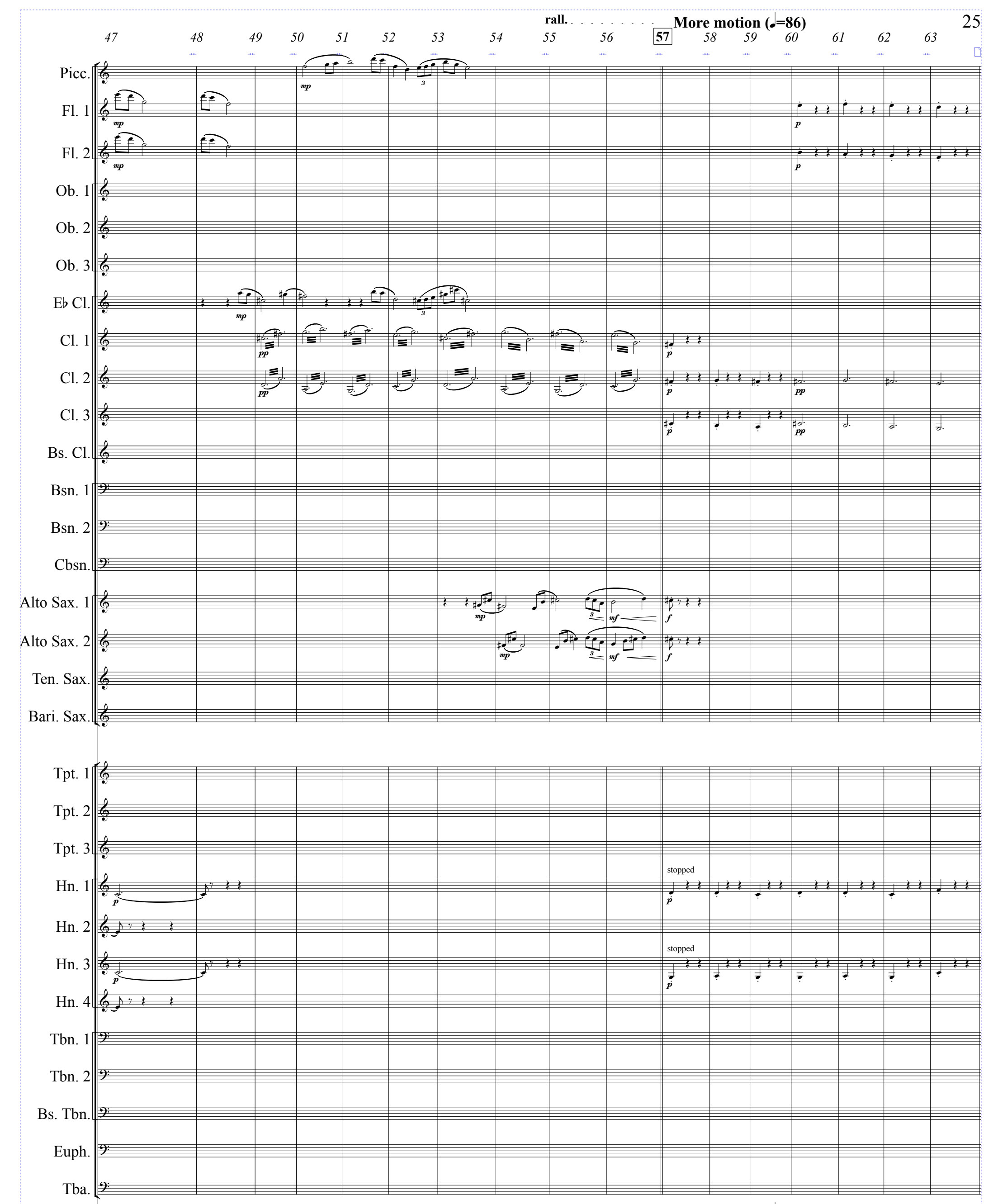

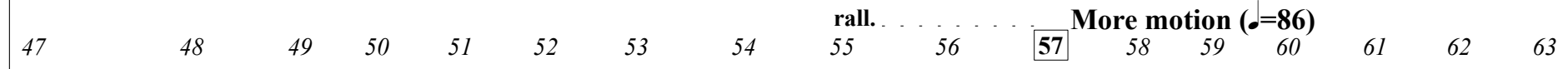

Vib.

Timp.

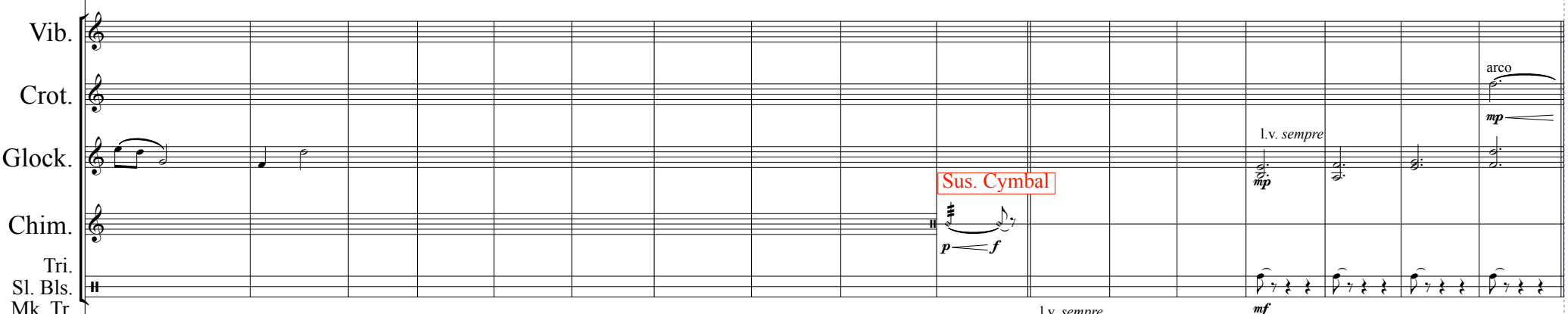
Mk. Tr.

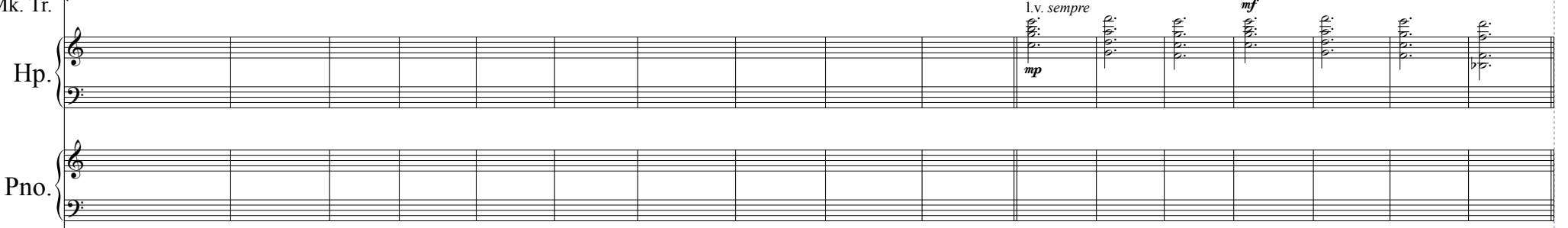

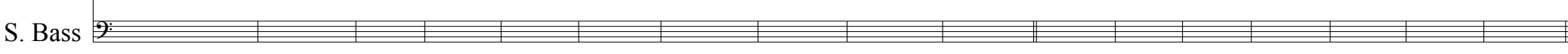



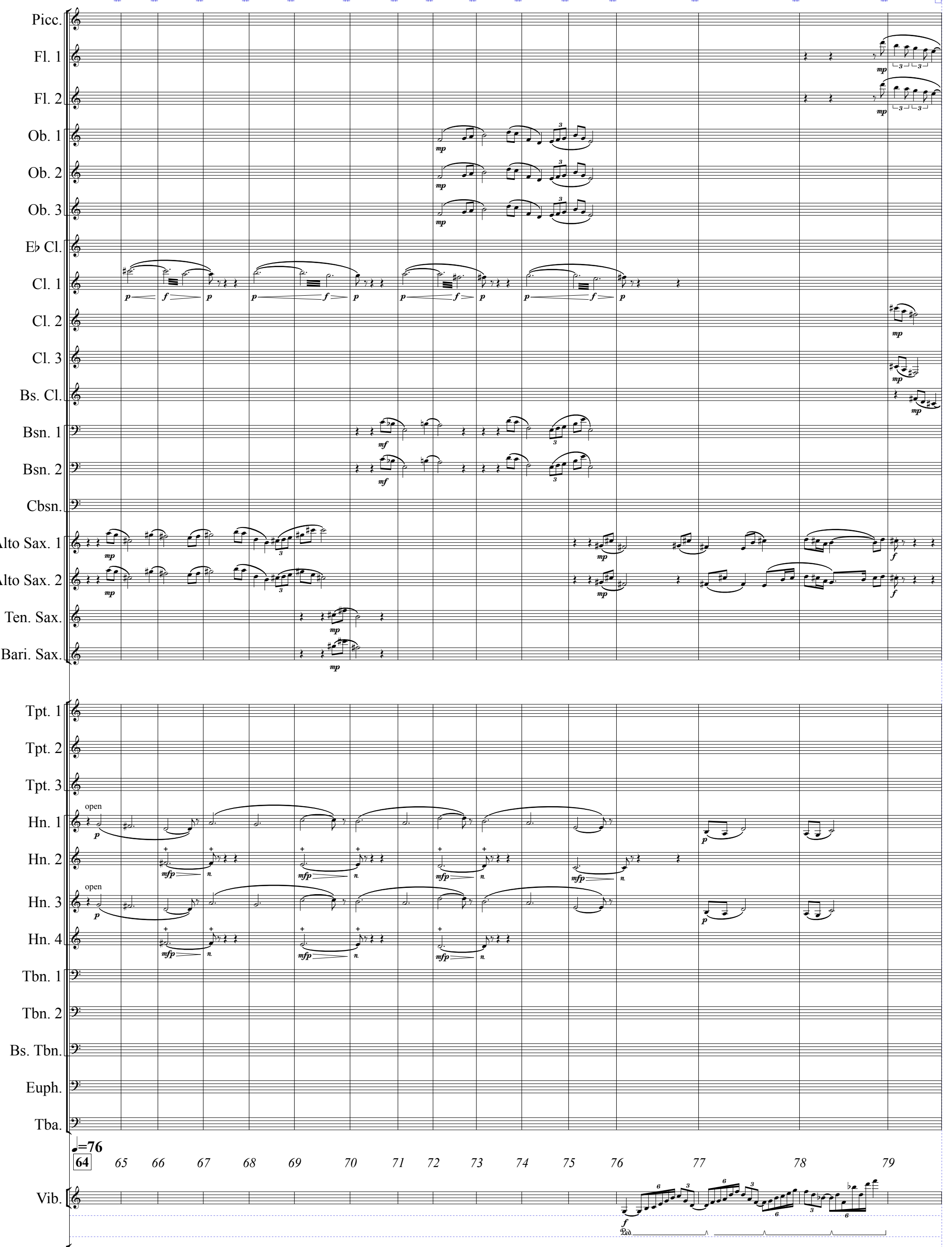

Timp.

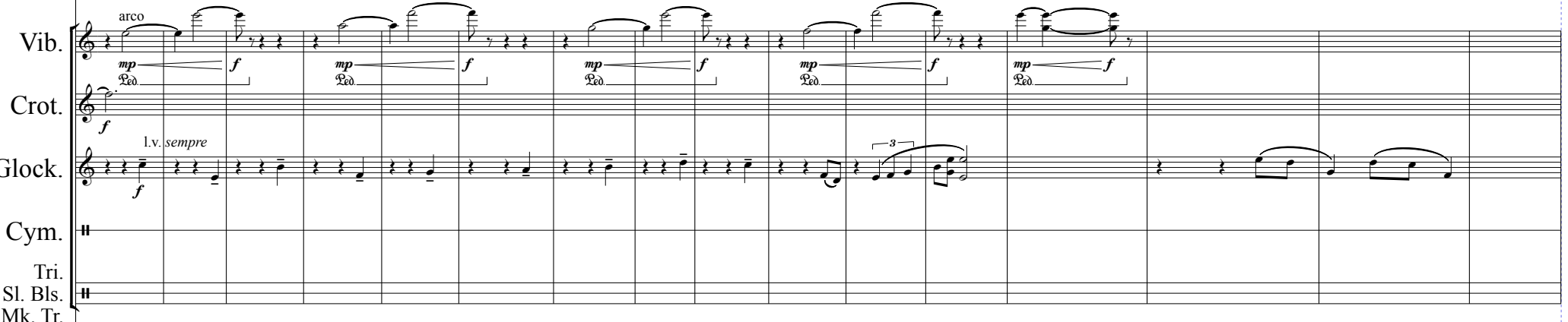

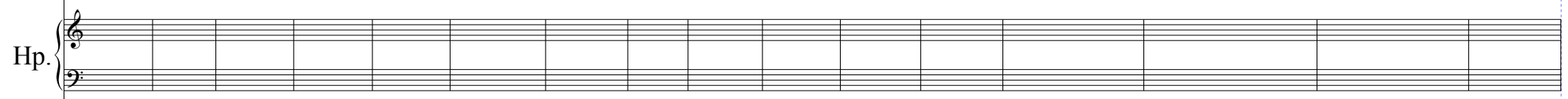

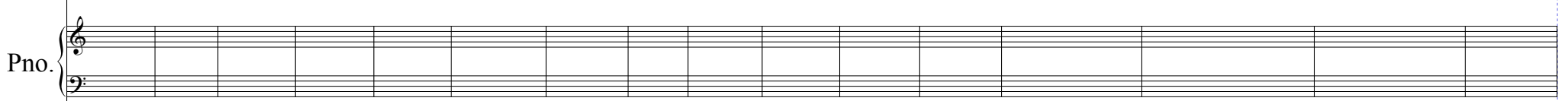

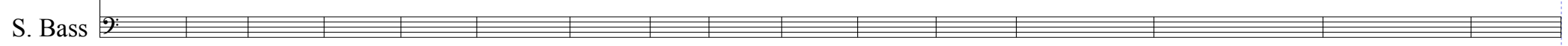



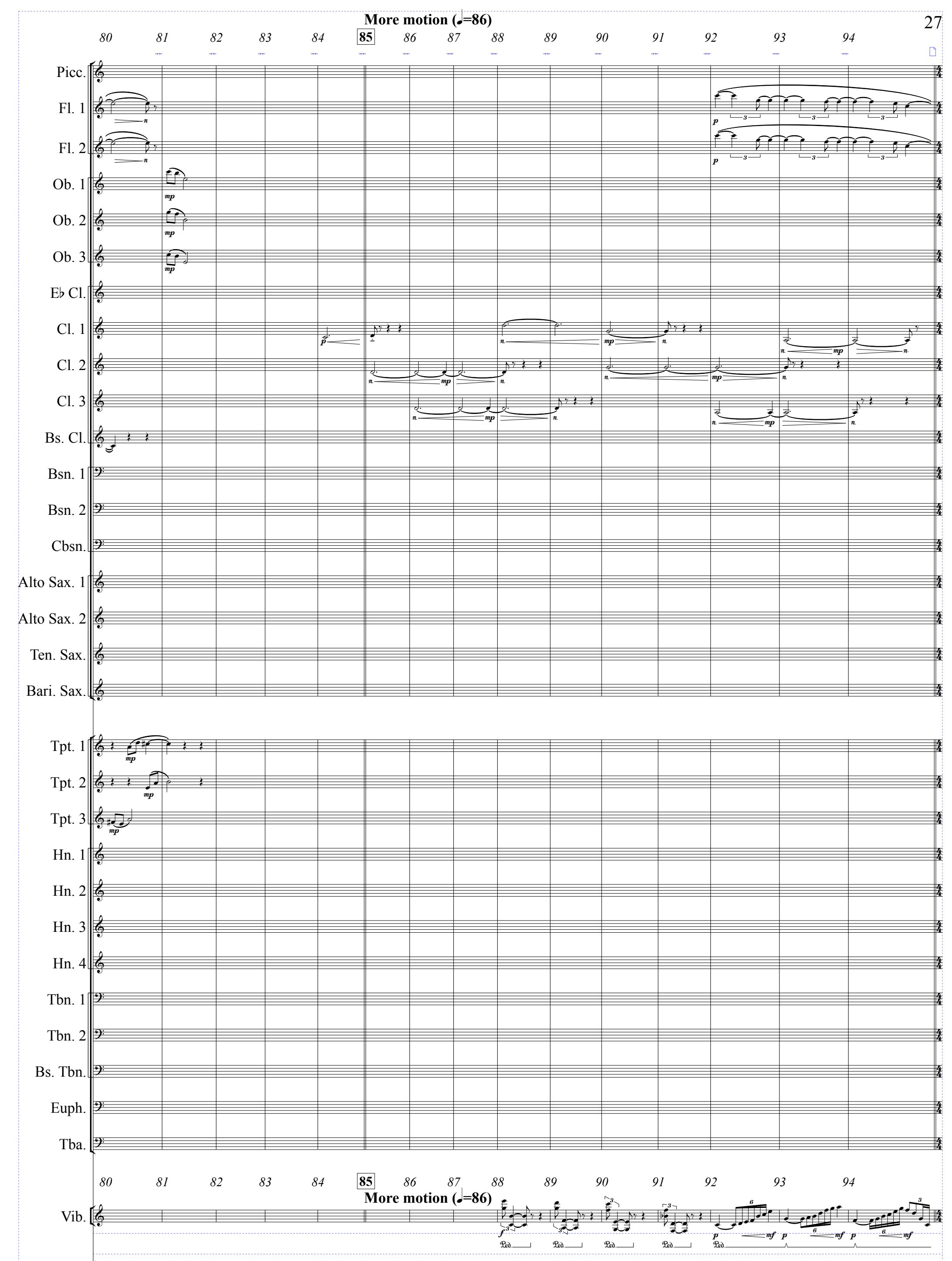

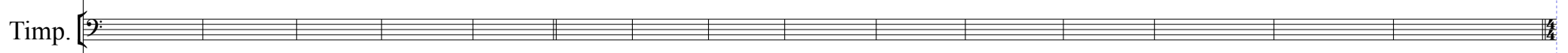

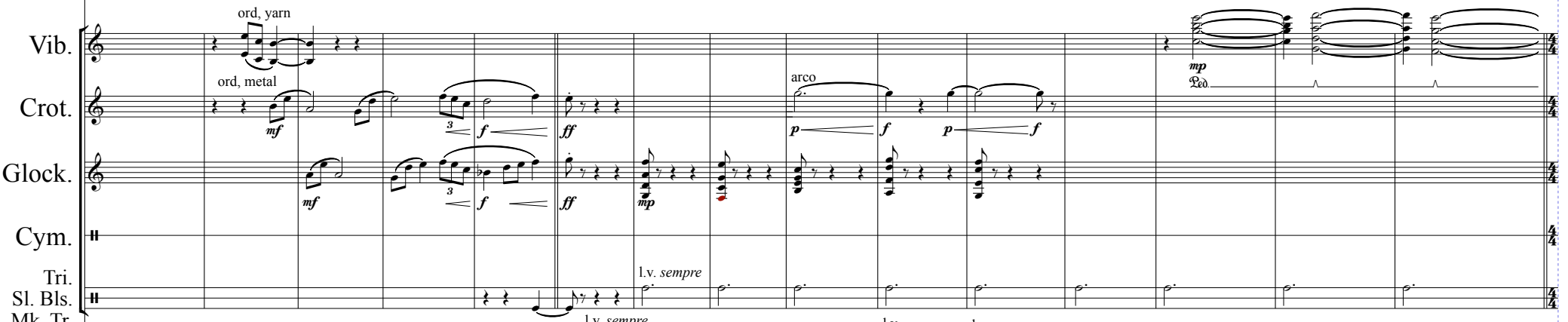

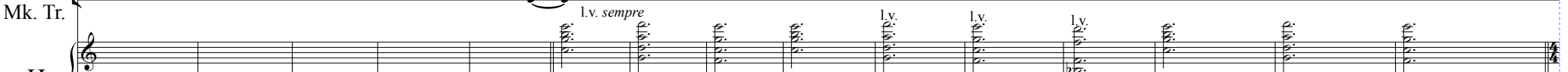

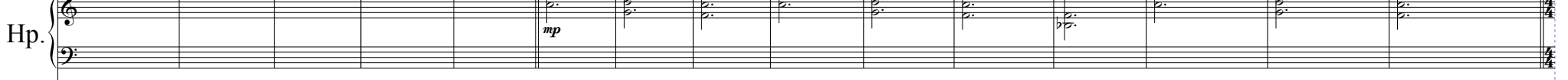

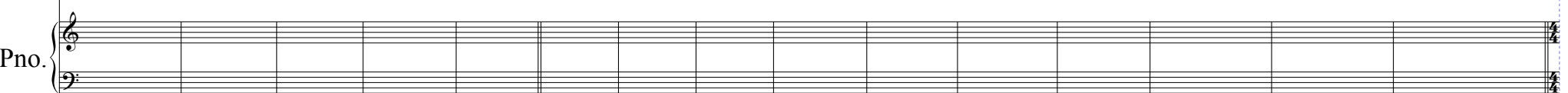

S. Bass 

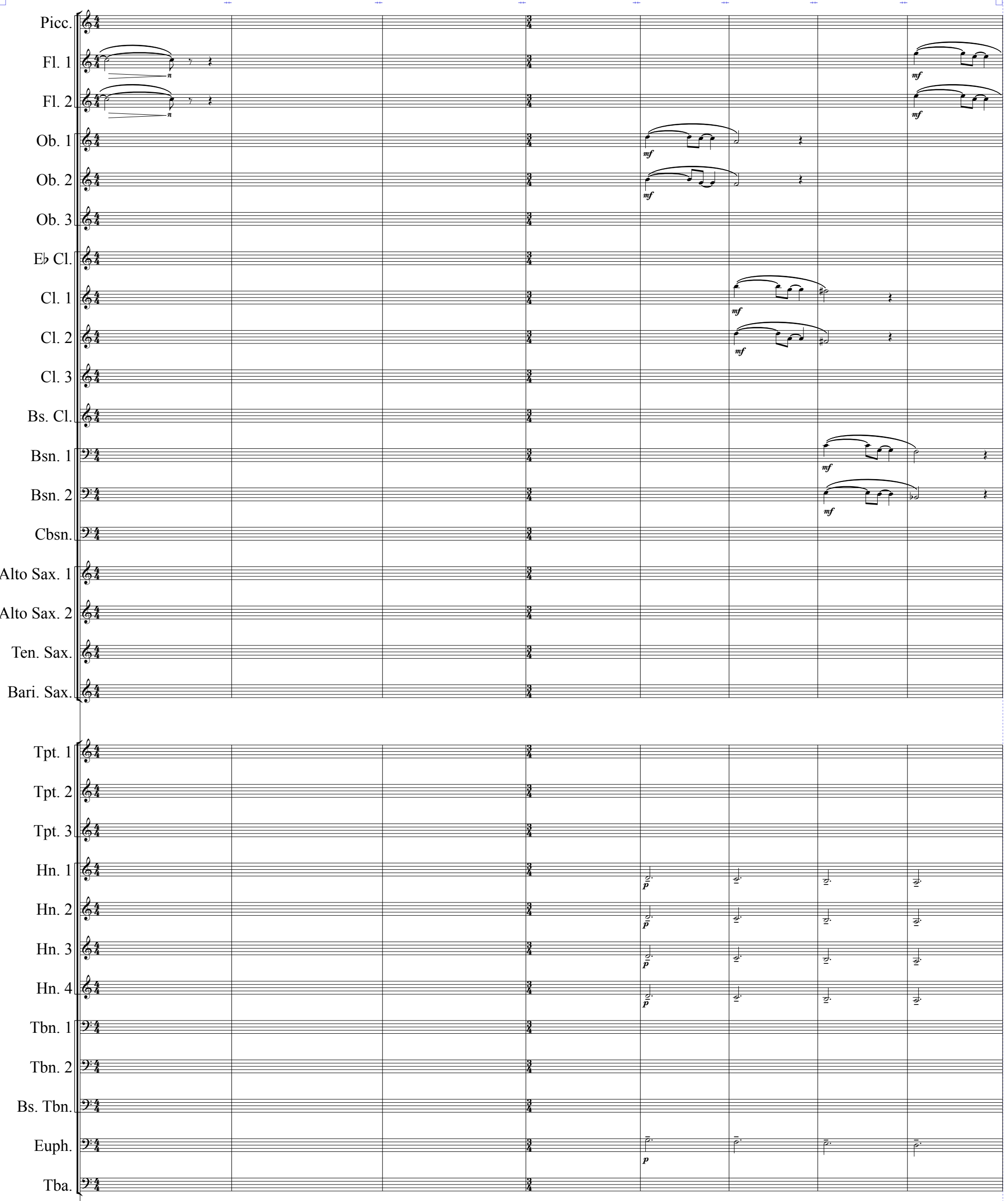

$\begin{array}{llllllll}95 & 96 & 97 & 98 & 99 & 100 & 101 & 102\end{array}$

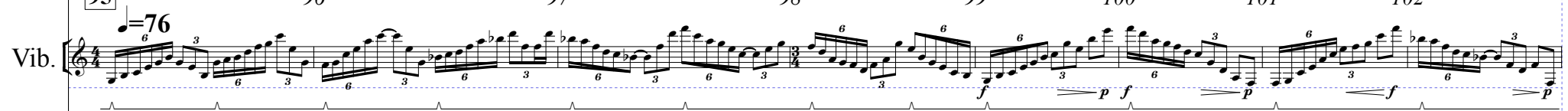

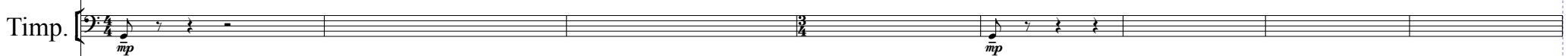

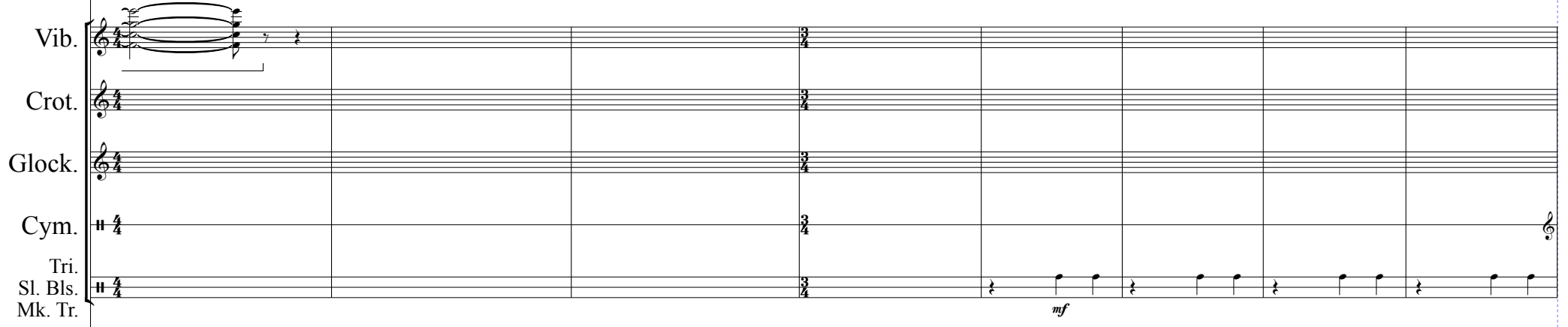

Hp.

p. $\left\{\begin{array}{l}\frac{24}{34} \\ 254\end{array}\right.$

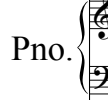

3

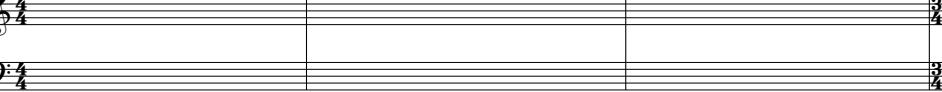

S. Bass 

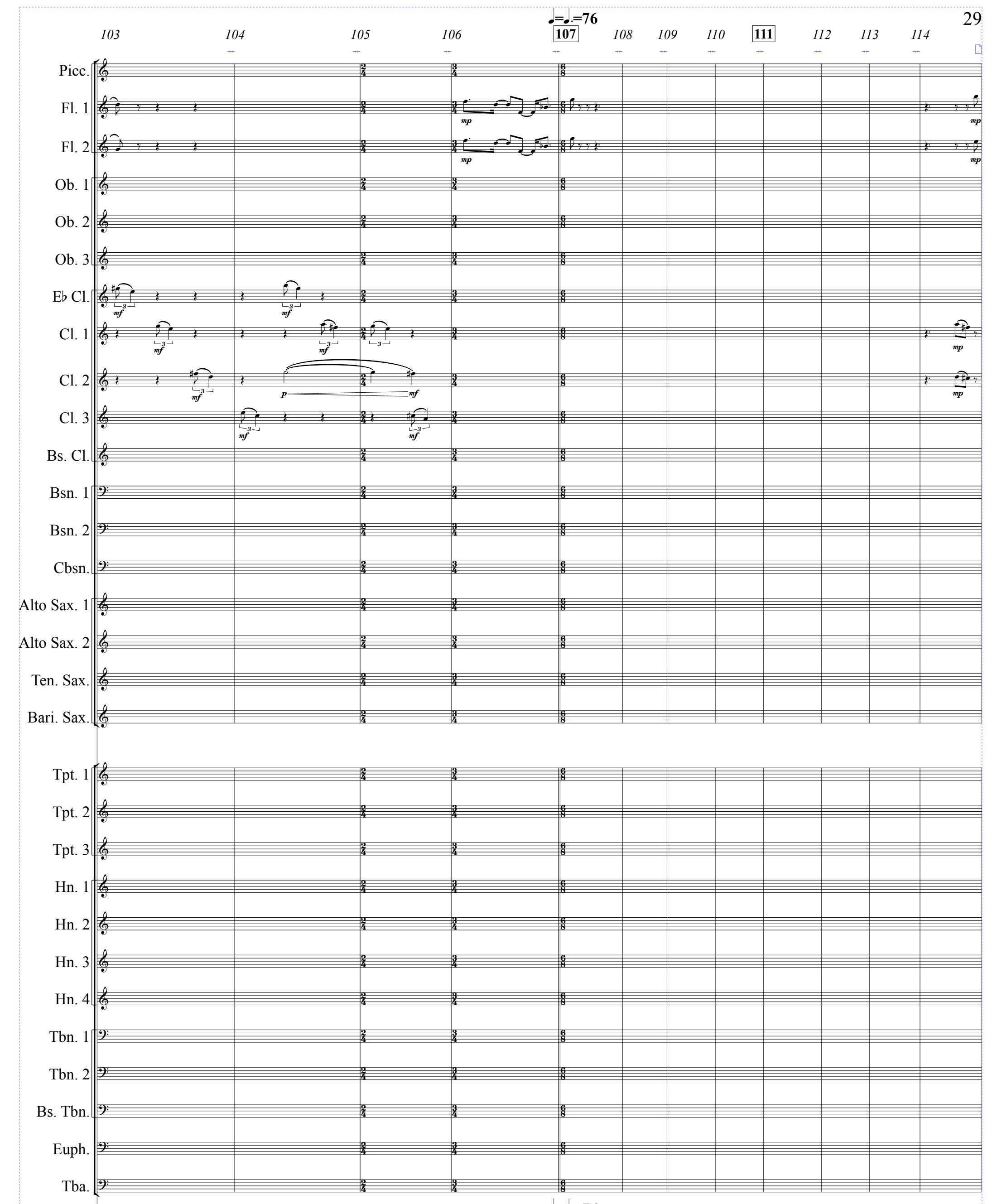

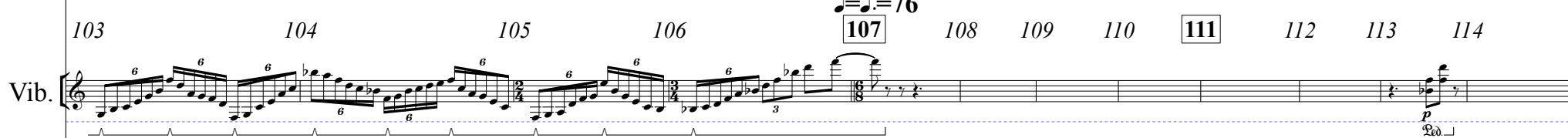
Timp.

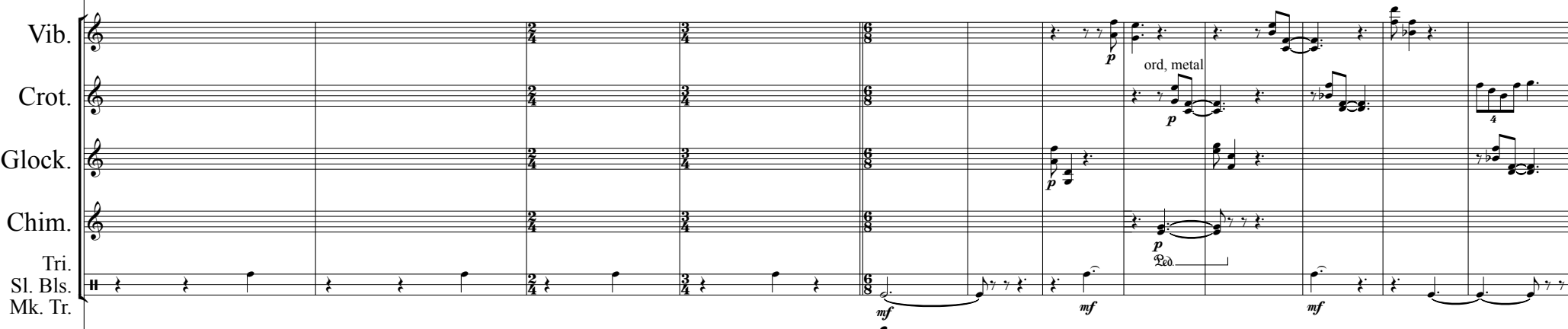

Hр.

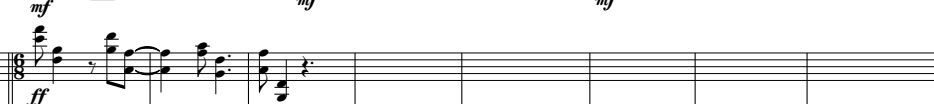

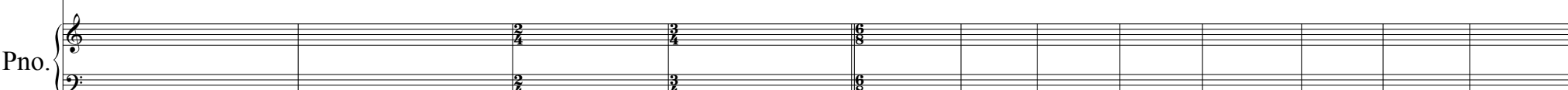

S. Bass 

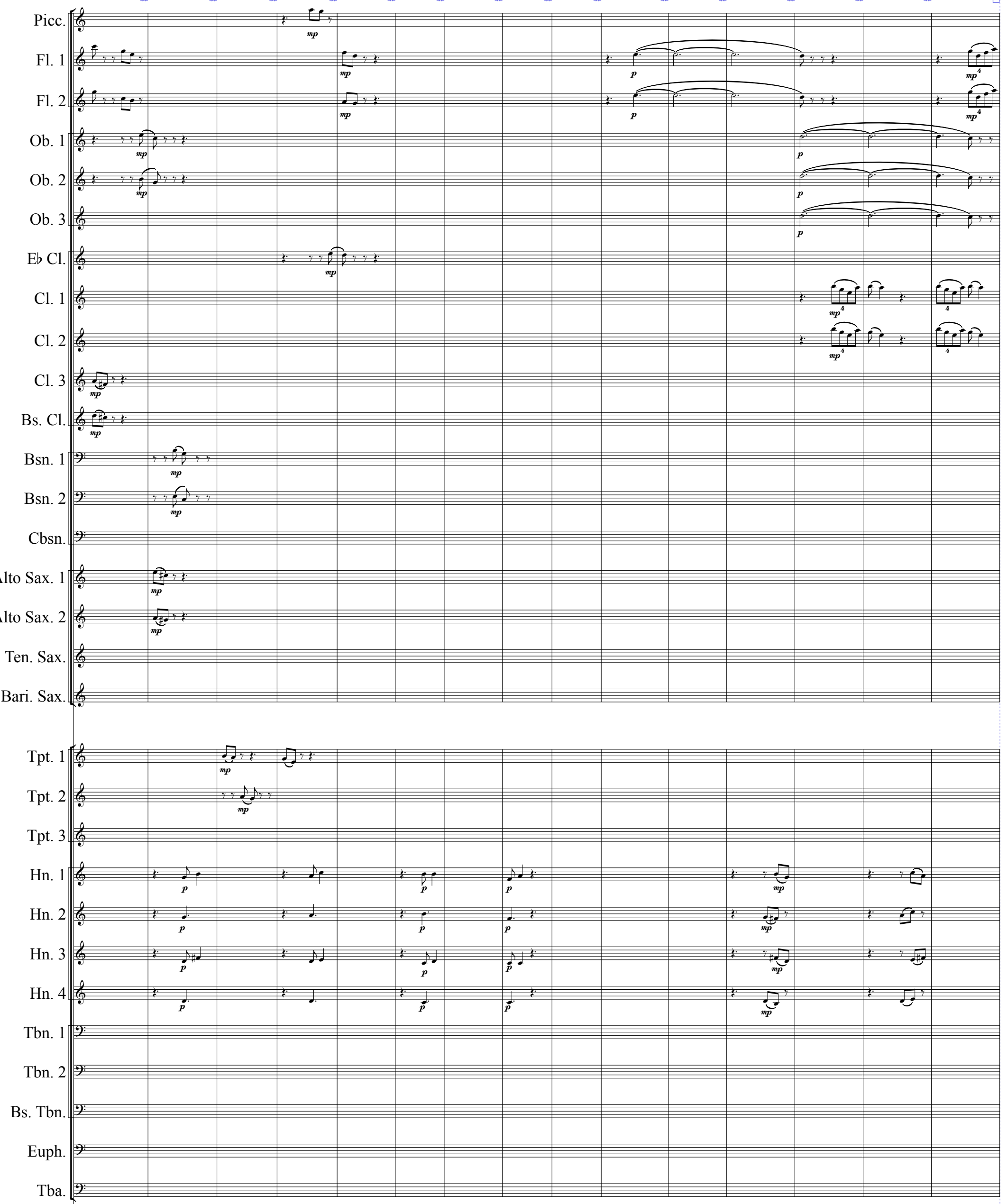

$\begin{array}{lllllllllllllll}115 & 116 & 117 & 118 & 119 & 120 & 121 & 122 & 123 & 124 & 125 & 126 & 127 & 128 & 129\end{array}$

Vib.

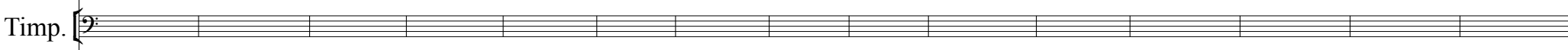

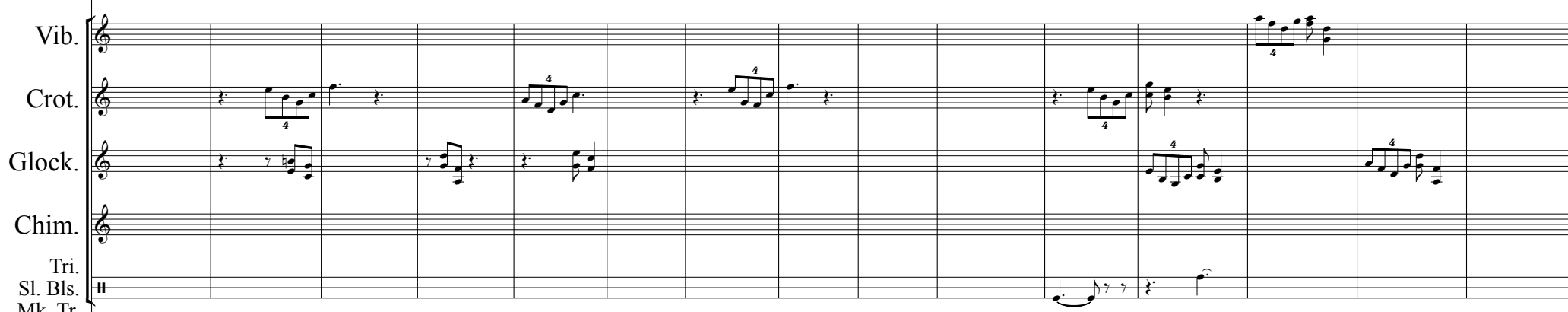

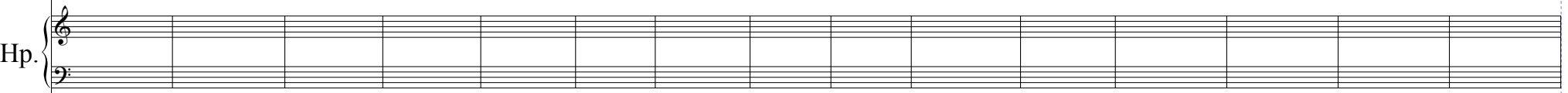

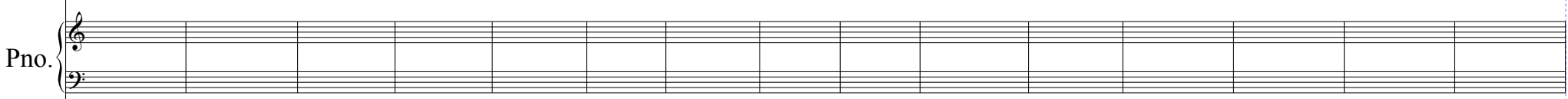

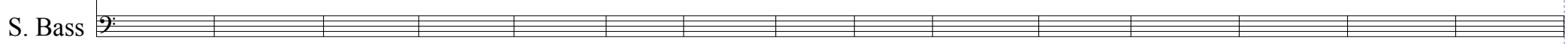



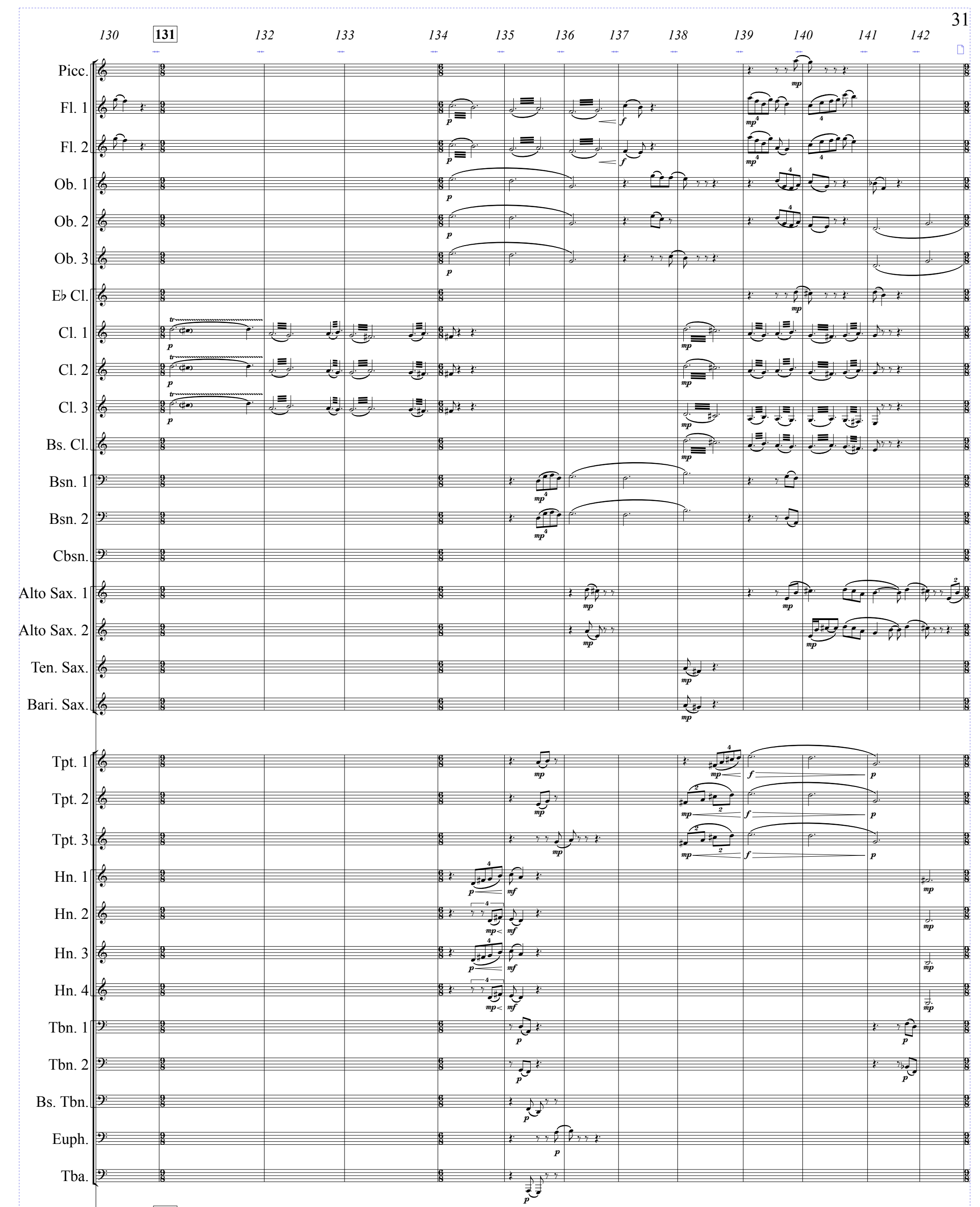

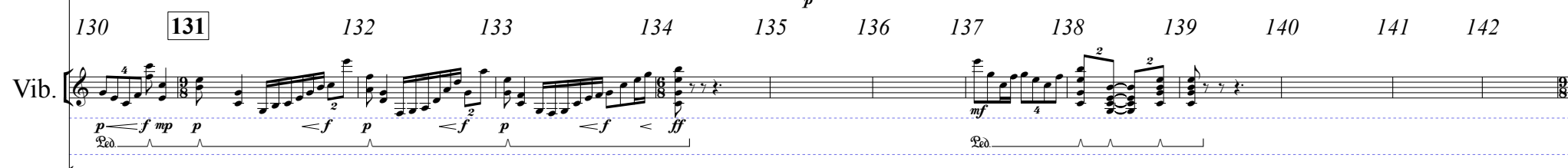

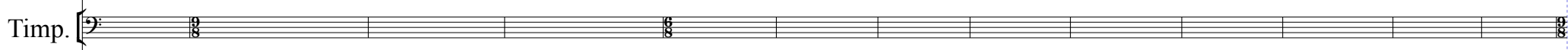

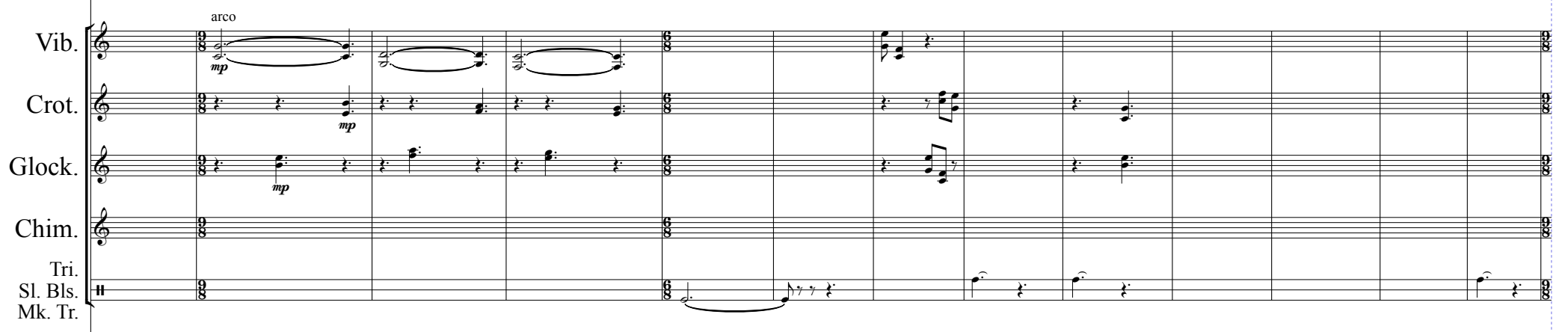

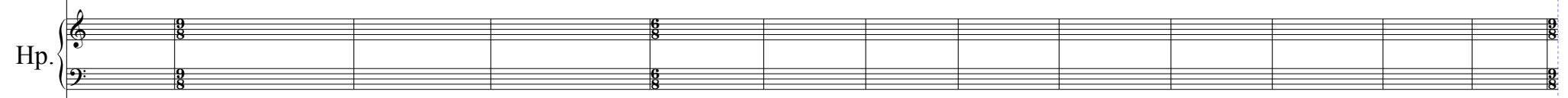

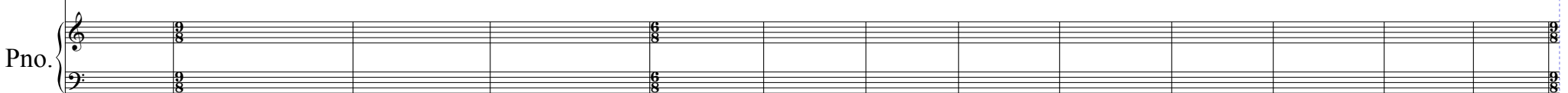

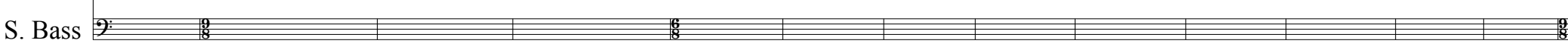



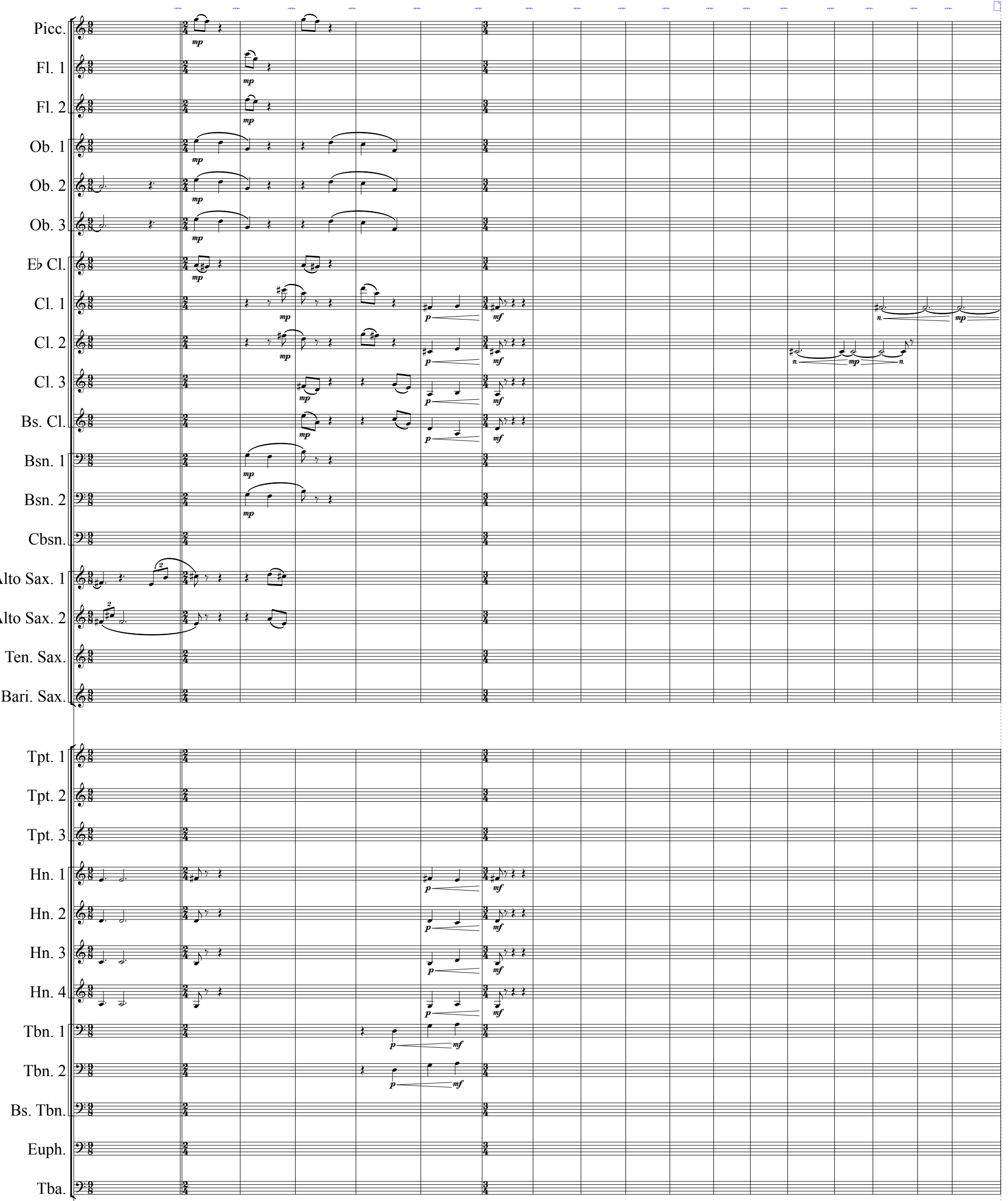

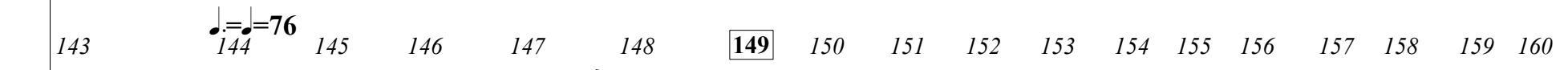

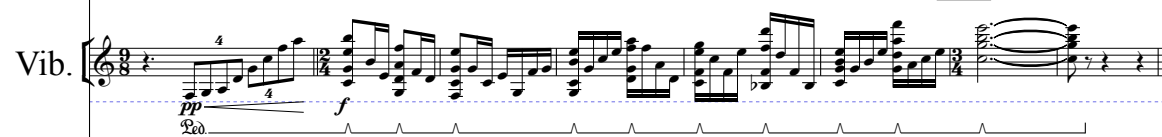

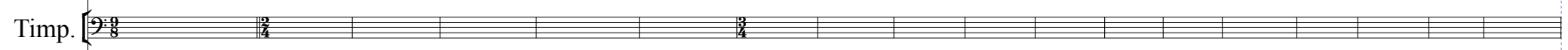

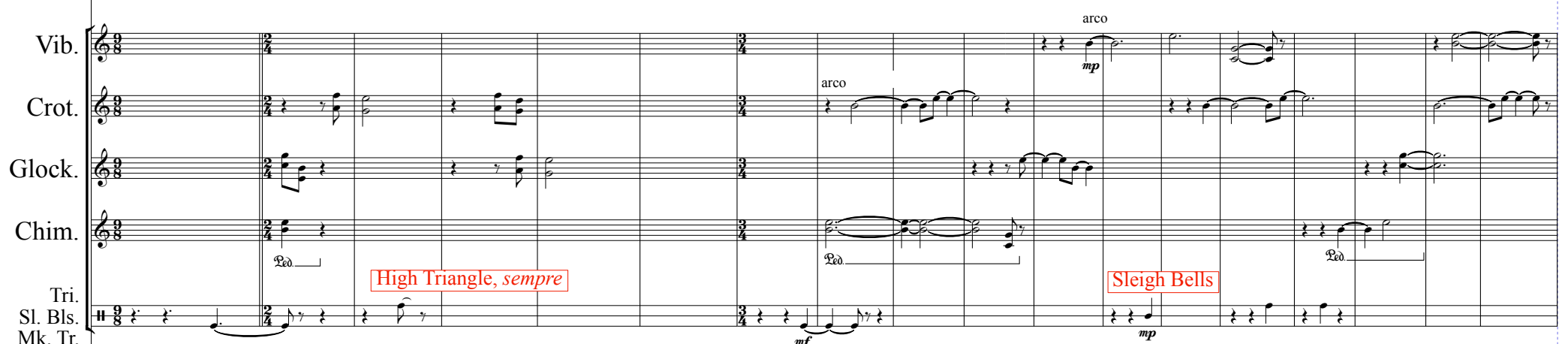

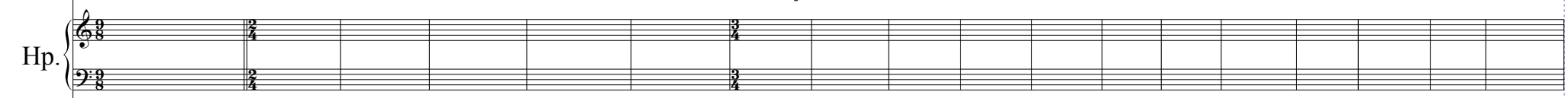

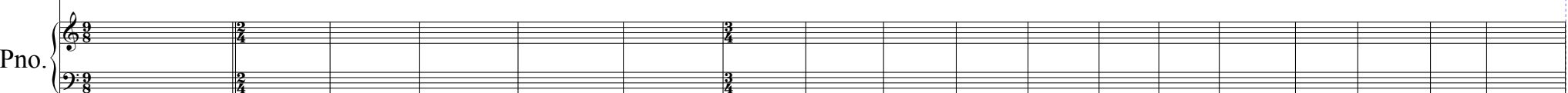

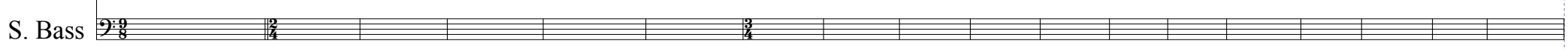



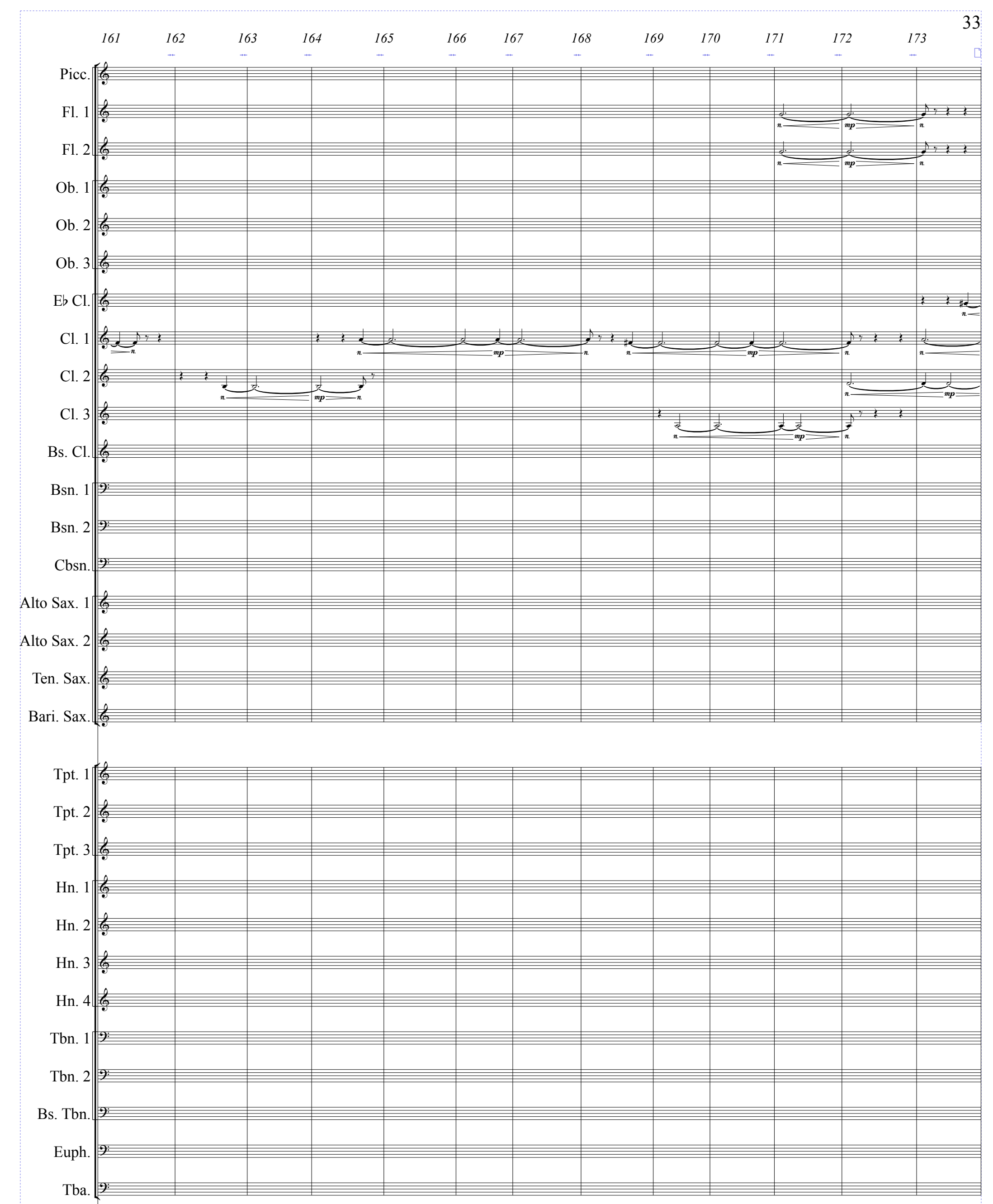
161

Vib.

Timp.

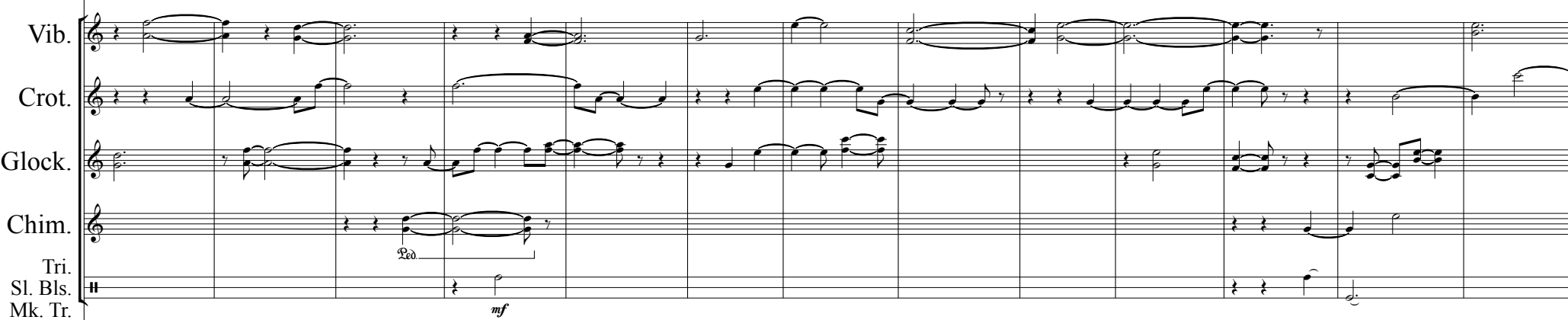

Hp. $\{$.

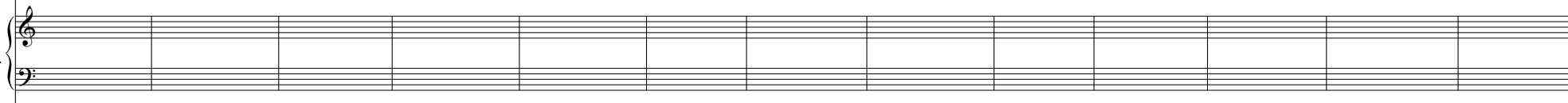

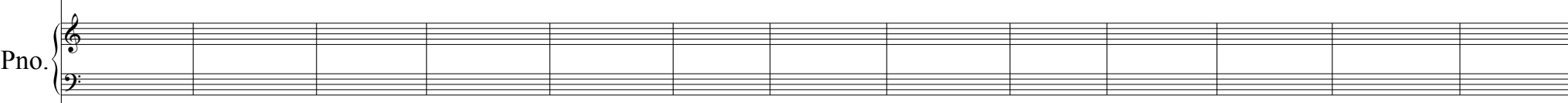

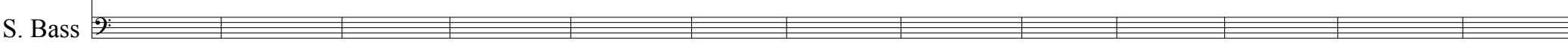



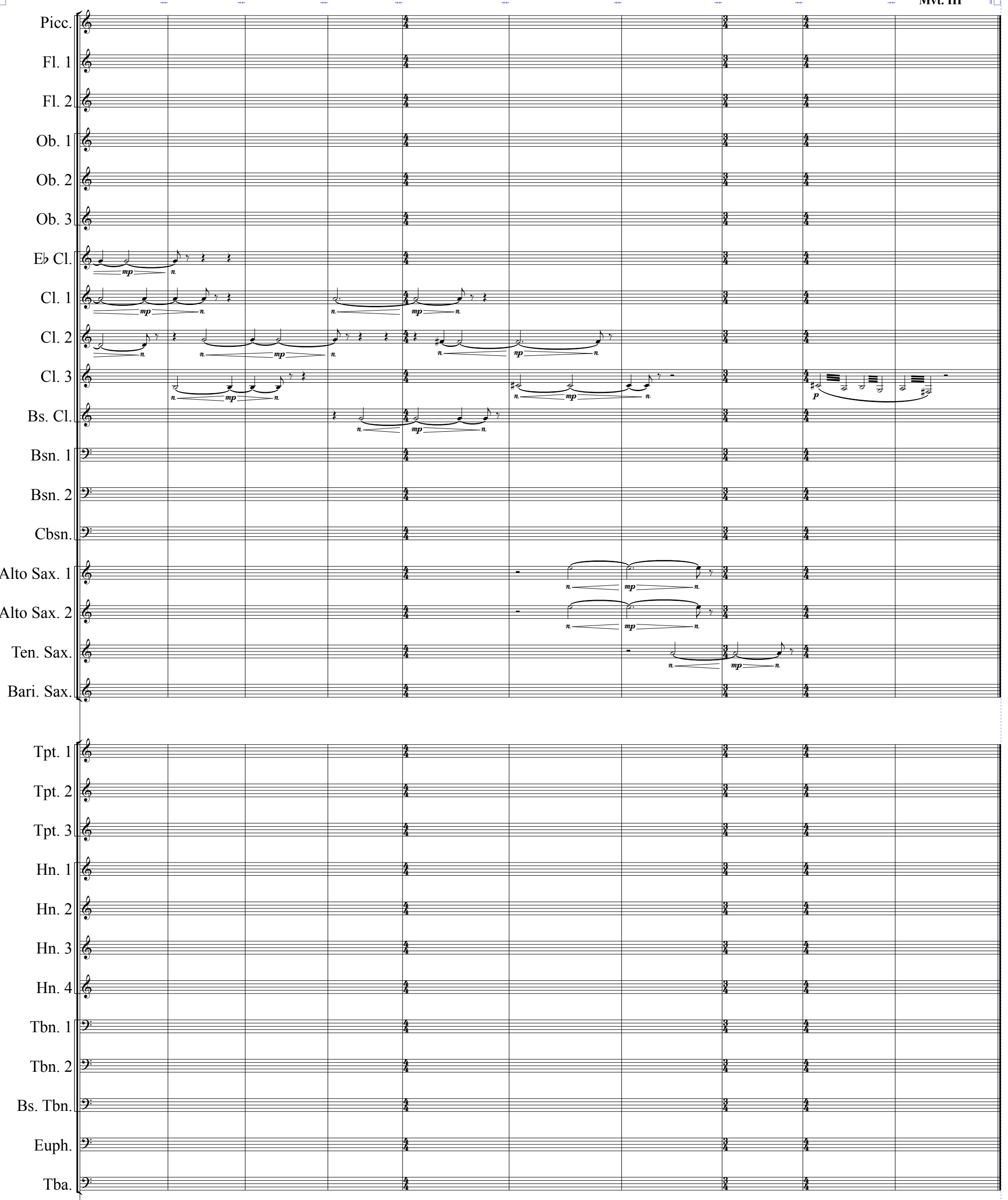
$\mathrm{Vib} .\left(\begin{array}{lllllllllll}174 & 175 & 176 & 177 & 178 & 179 & 180 & 181 & 183 & \text { Attacca subito } \\ \text { Mvt. III }\end{array}\right.$

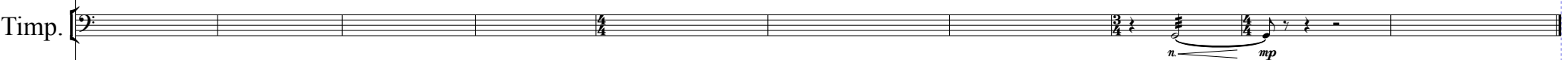

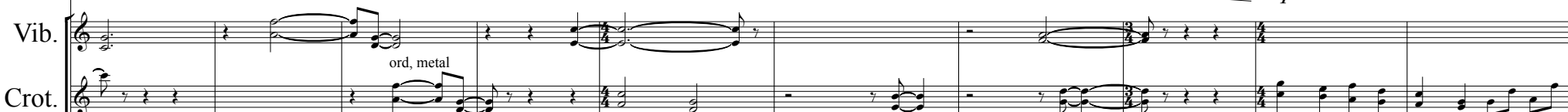

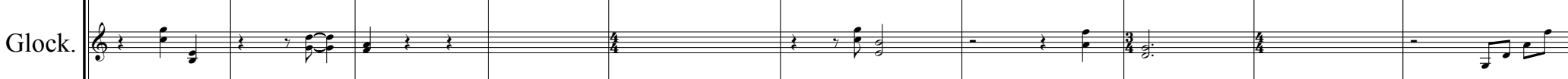
Chim. Sl. Bri.
Mk. Tr.

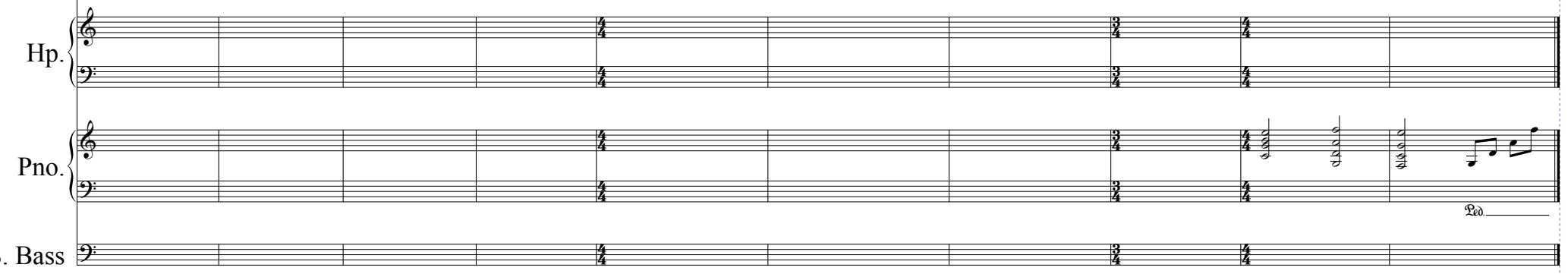



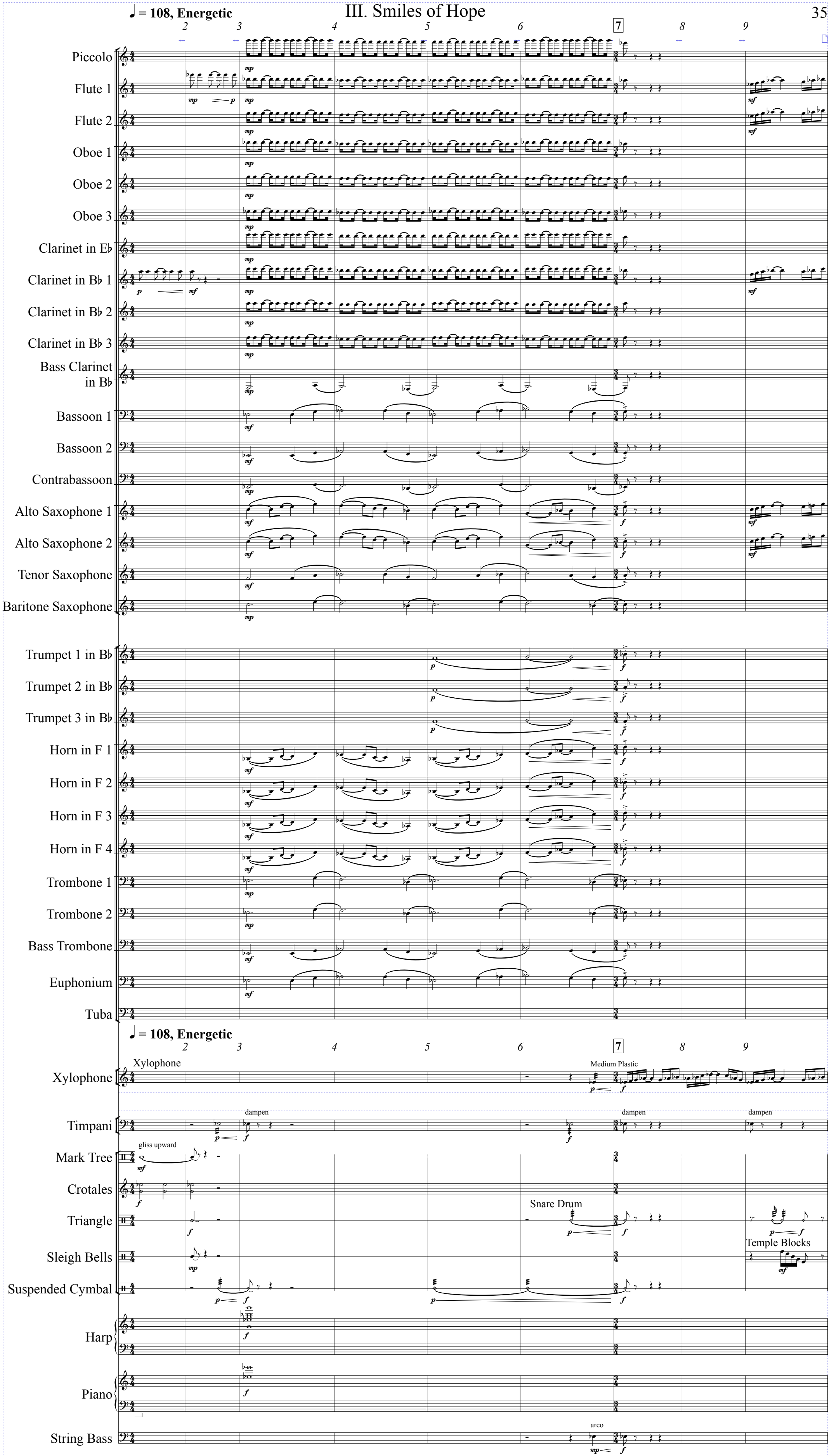

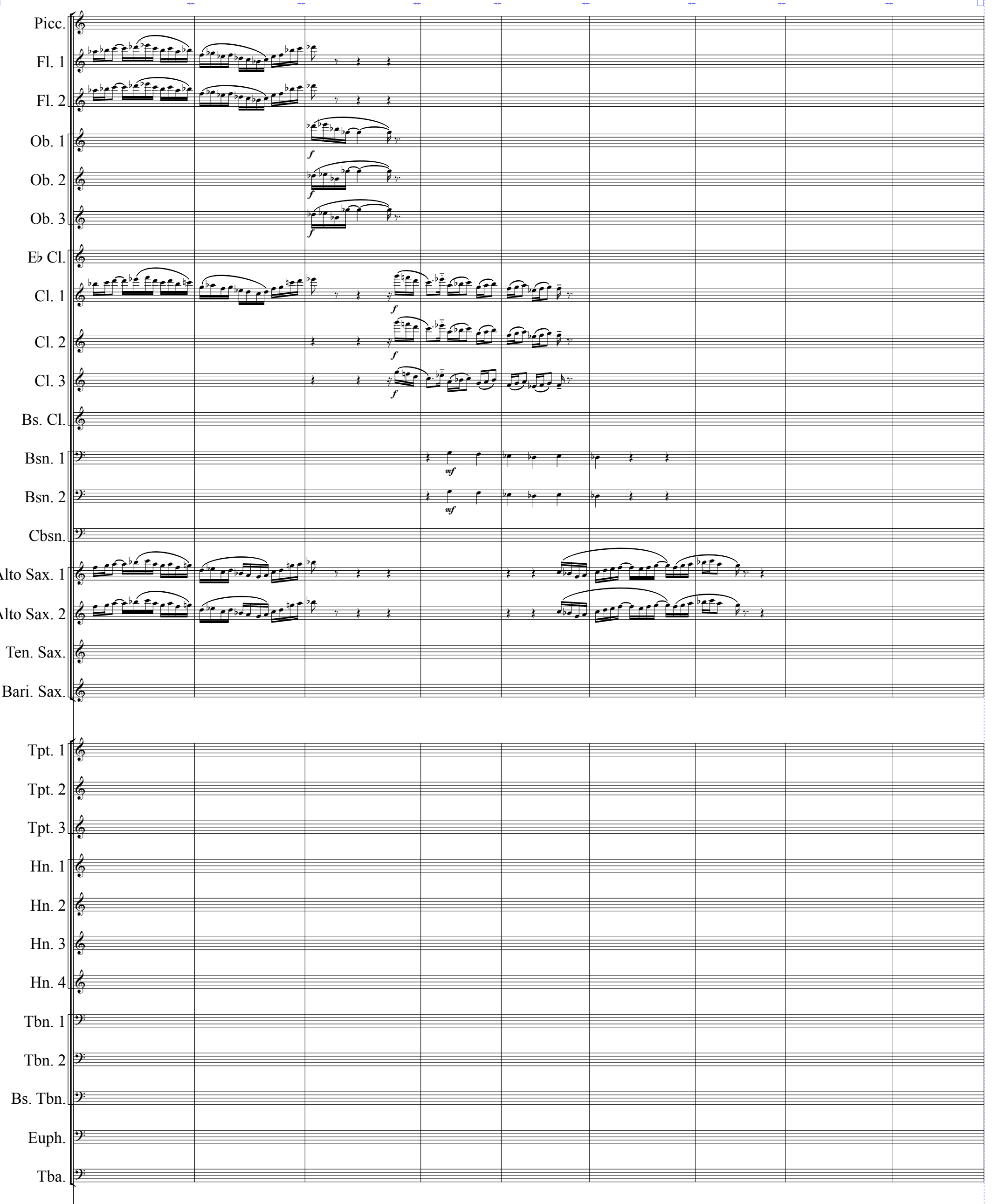

Xyl. $f=0.0000000$

Timp.

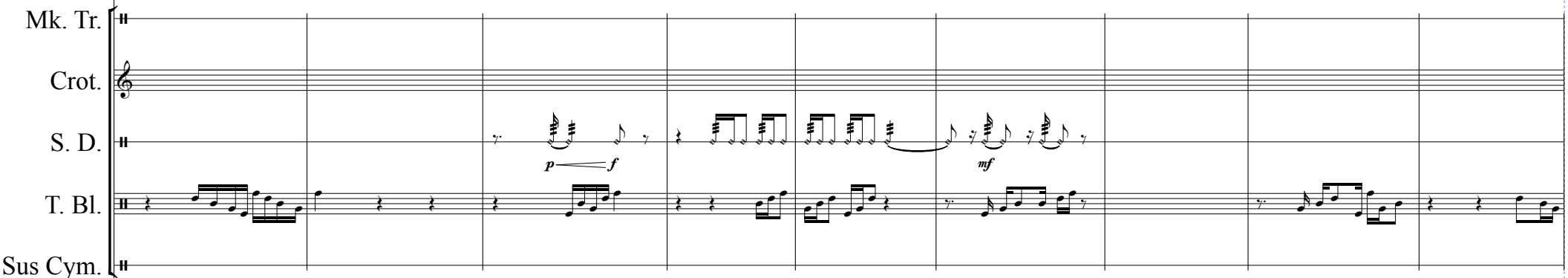
Sus Cym.

Hp.

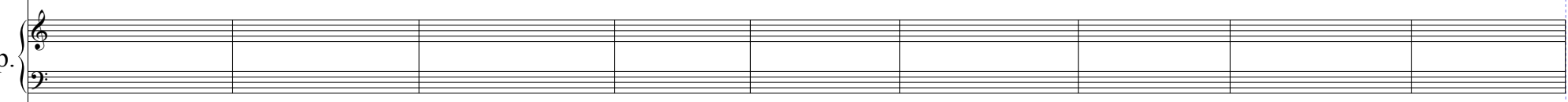

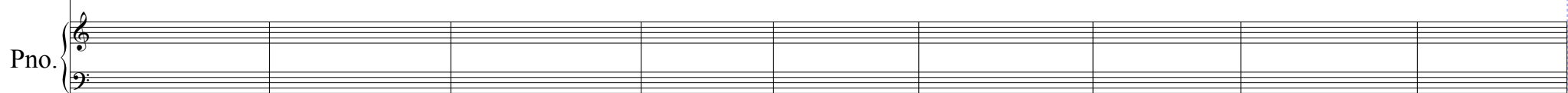

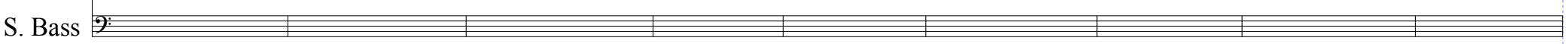




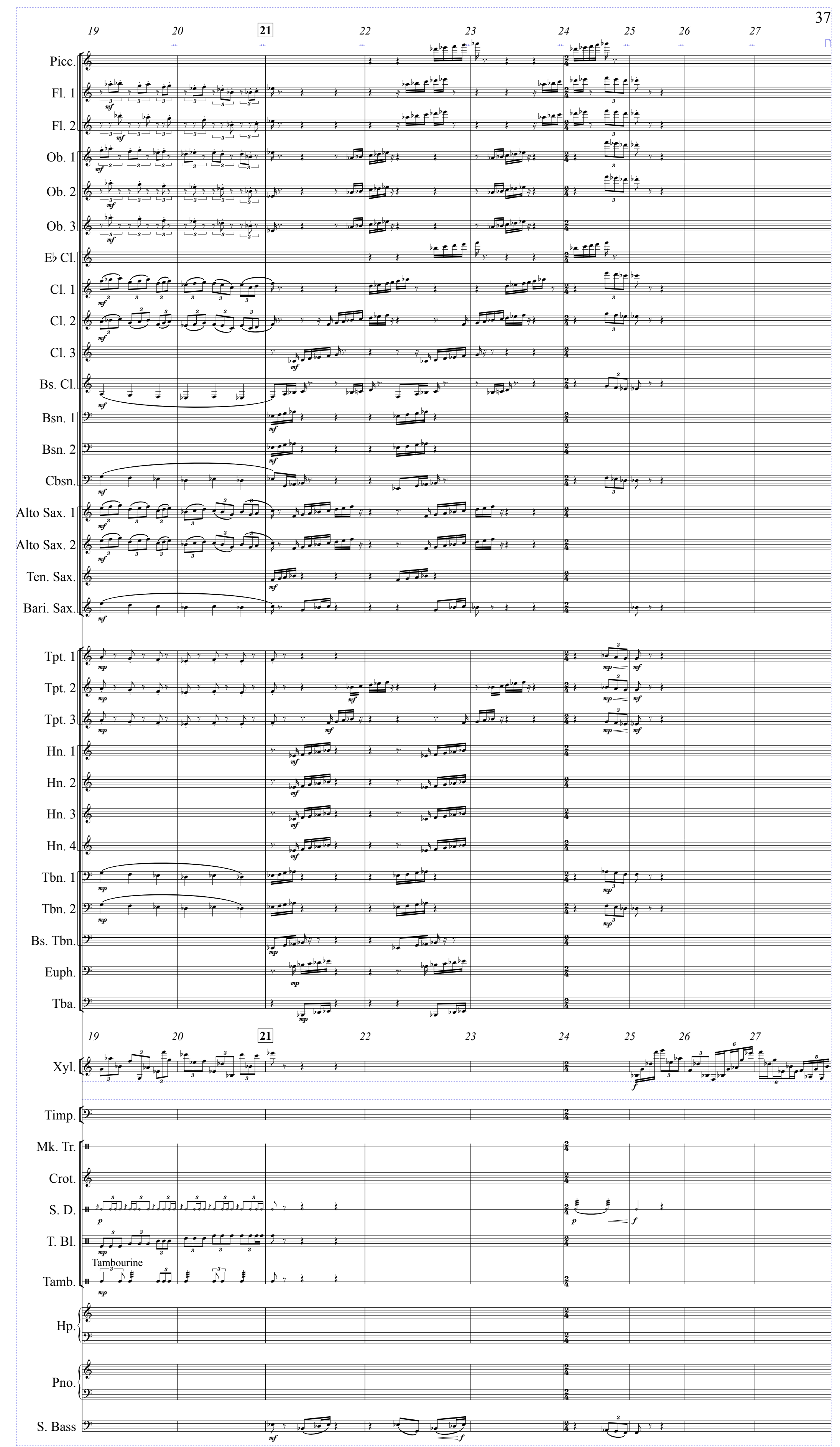



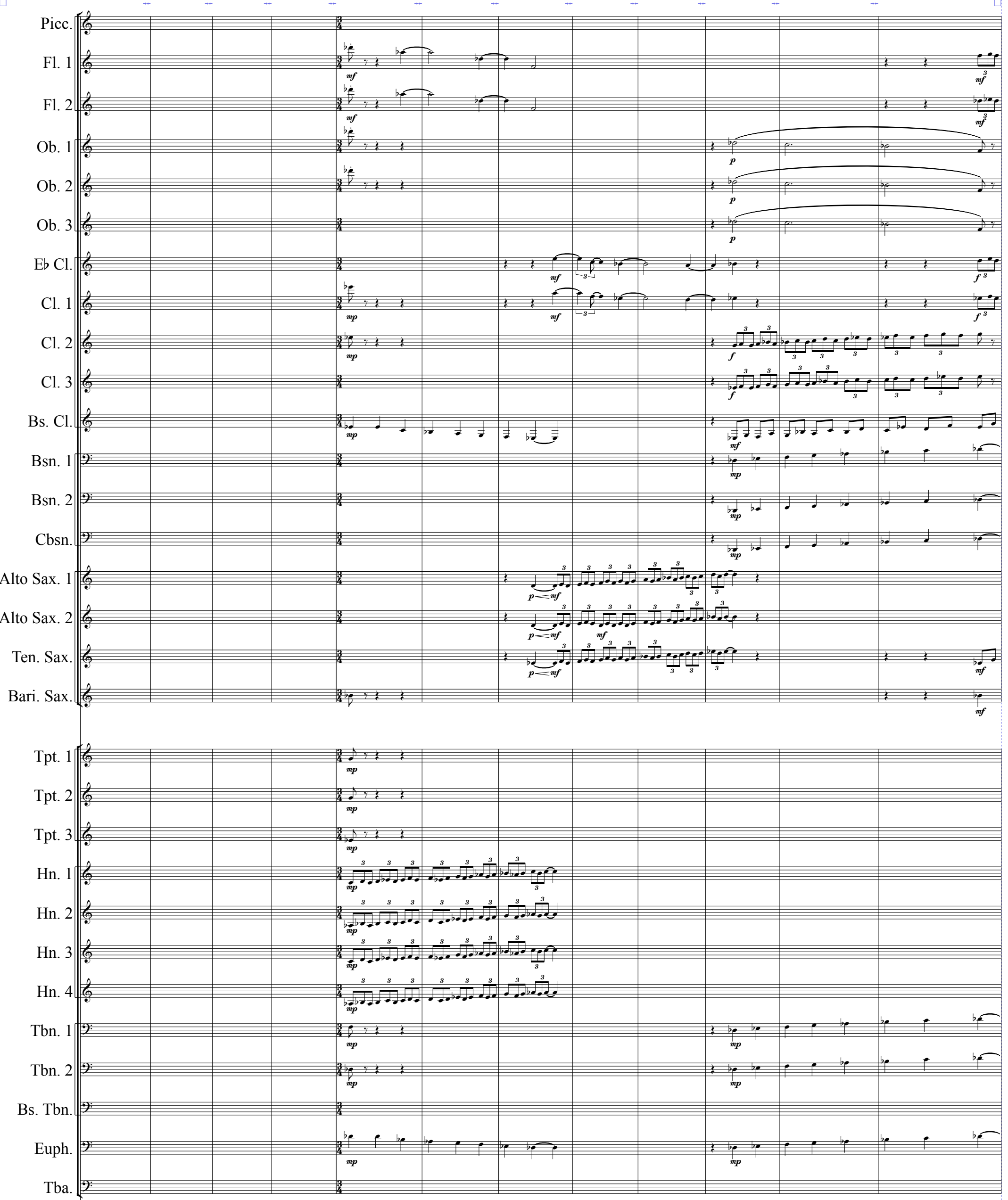

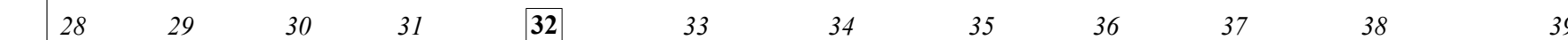

$\mathrm{Xyl}$ (6. Timp.

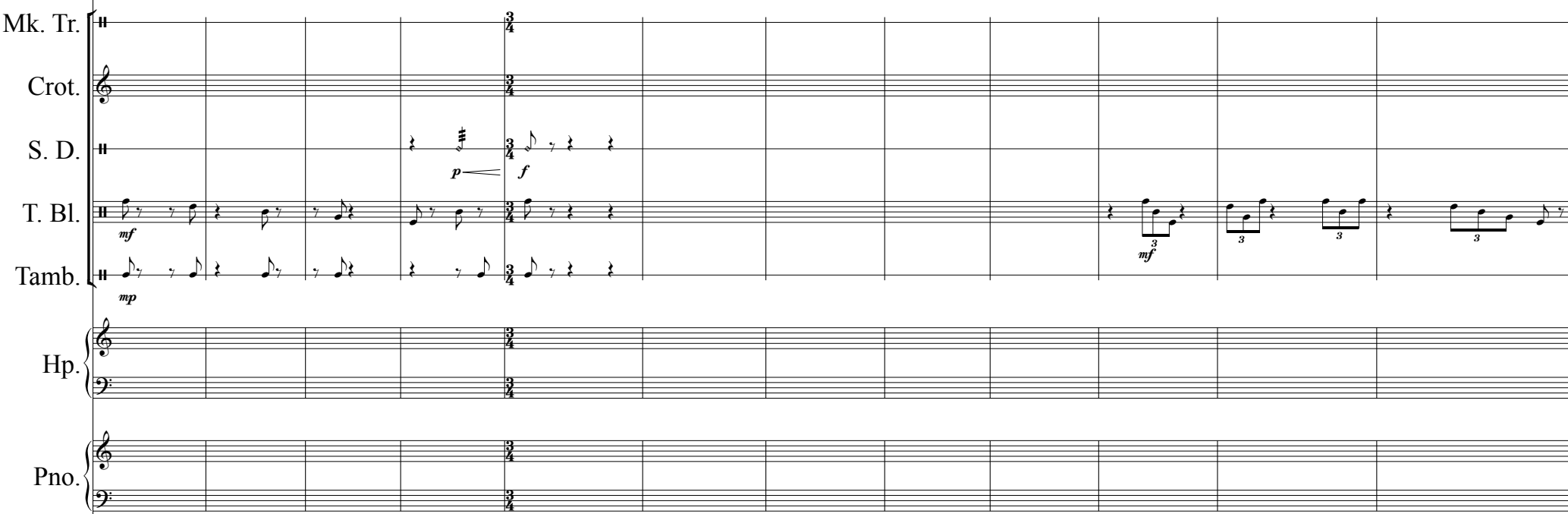

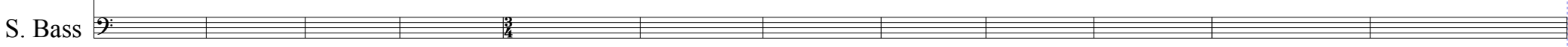




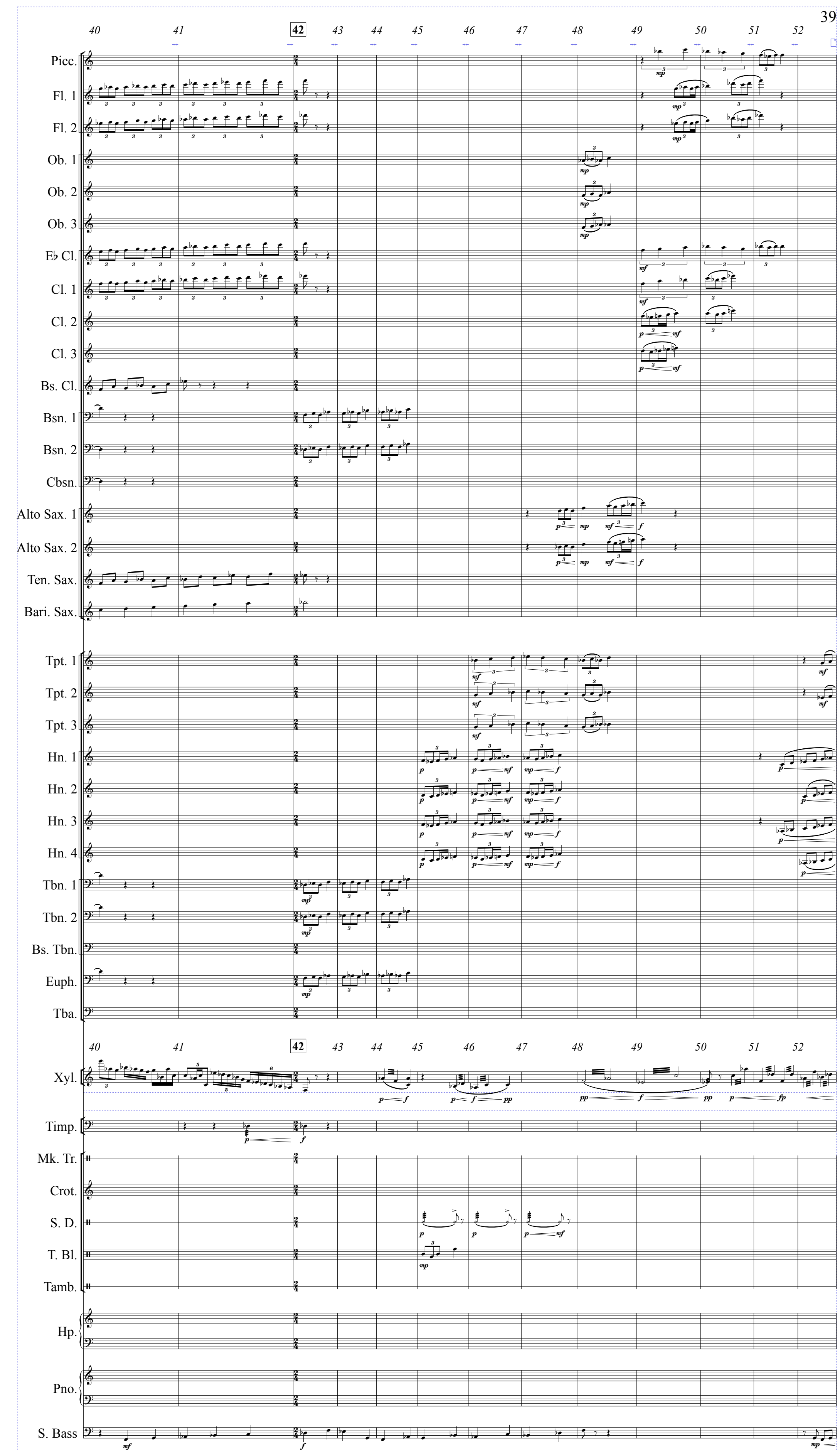



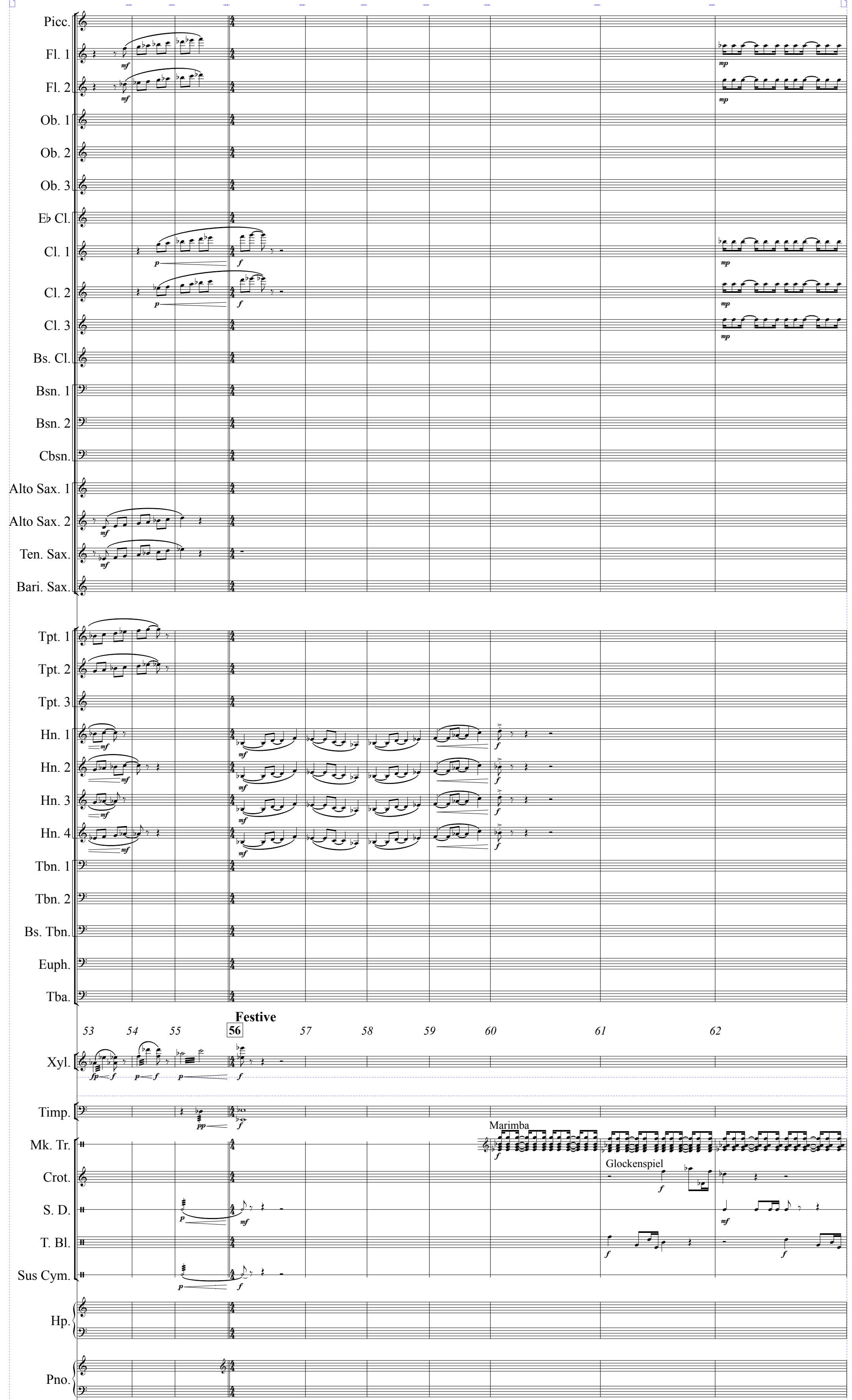

S. Bass 4 te 

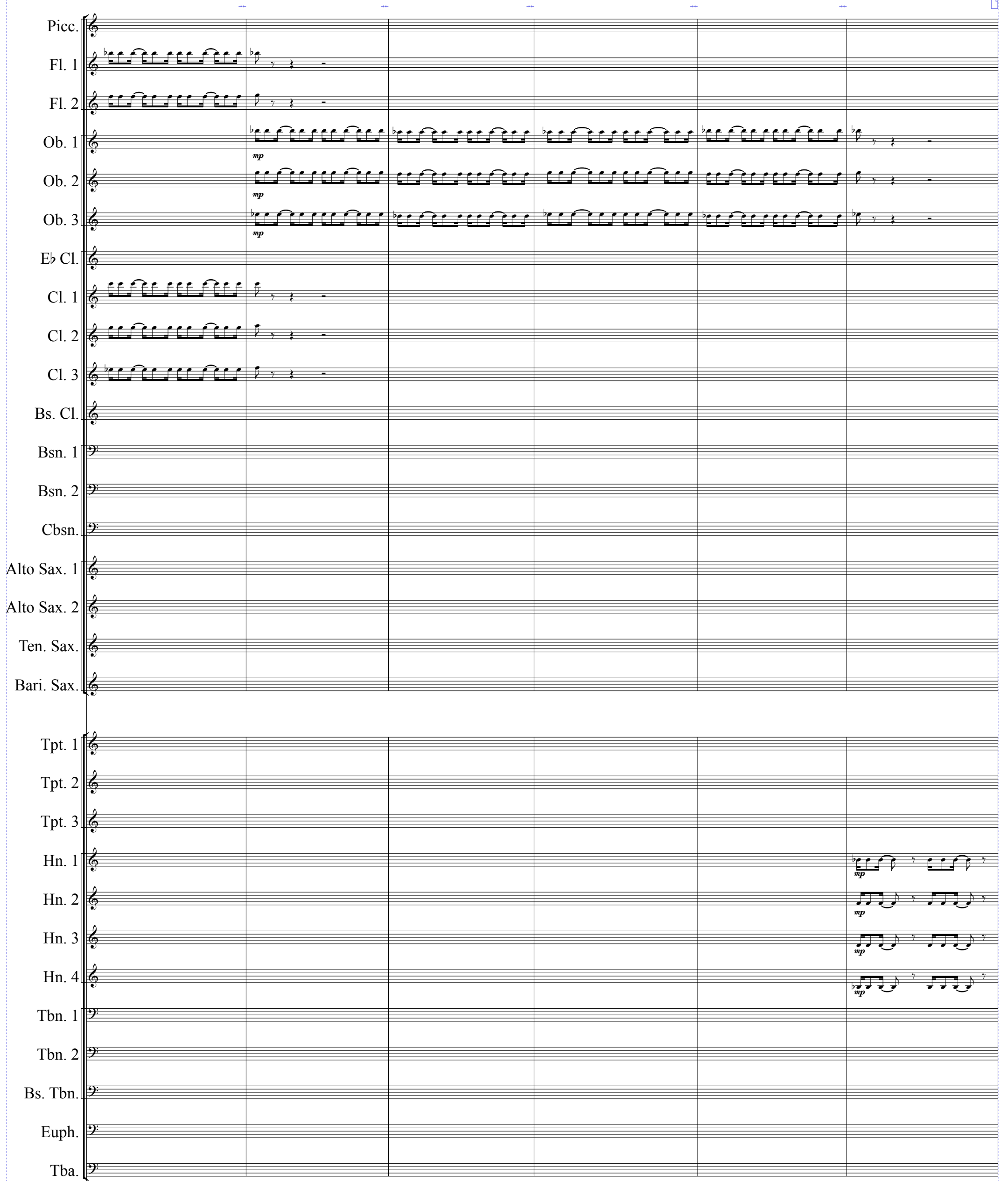
63
64
65
66
67
68

Xyl. $\frac{6}{6}$ (a)

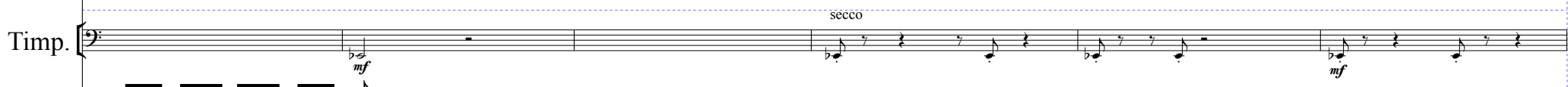

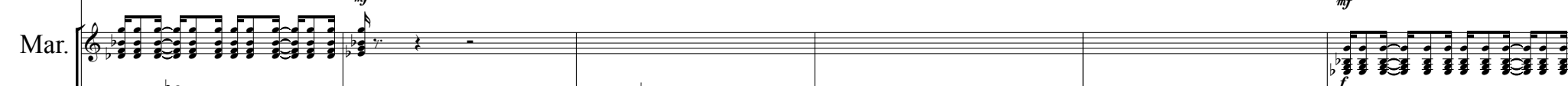

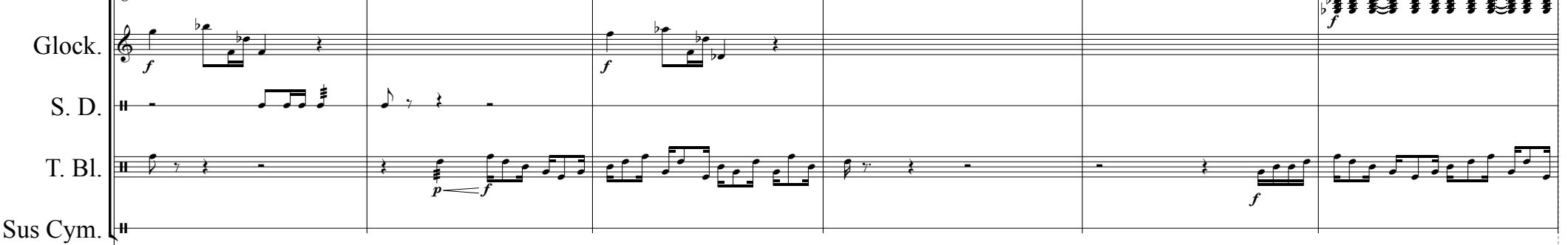

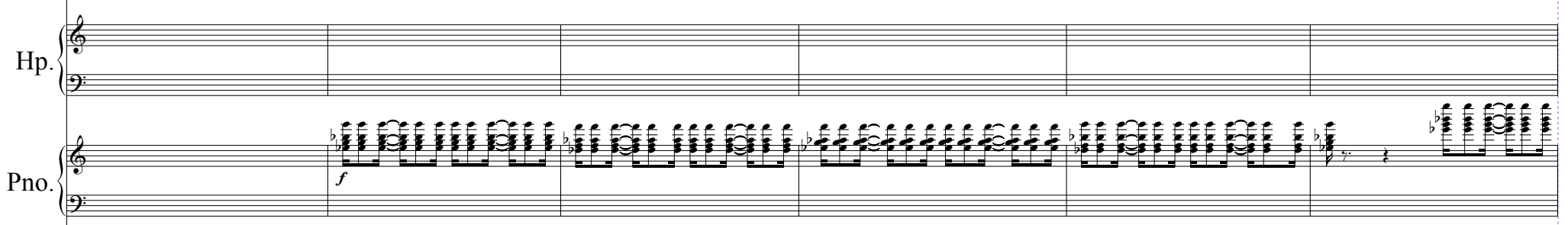



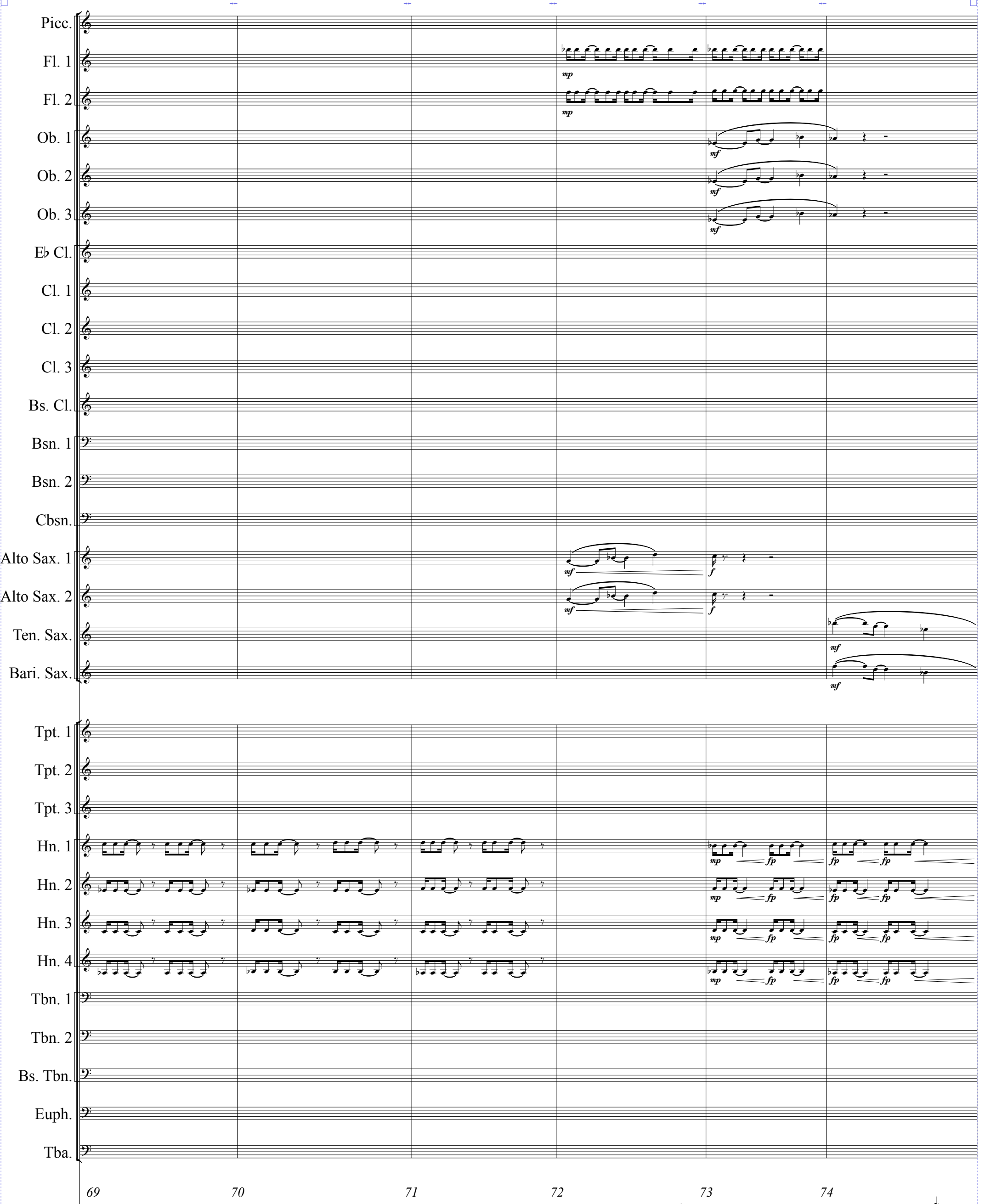

Xyl.

Timp.

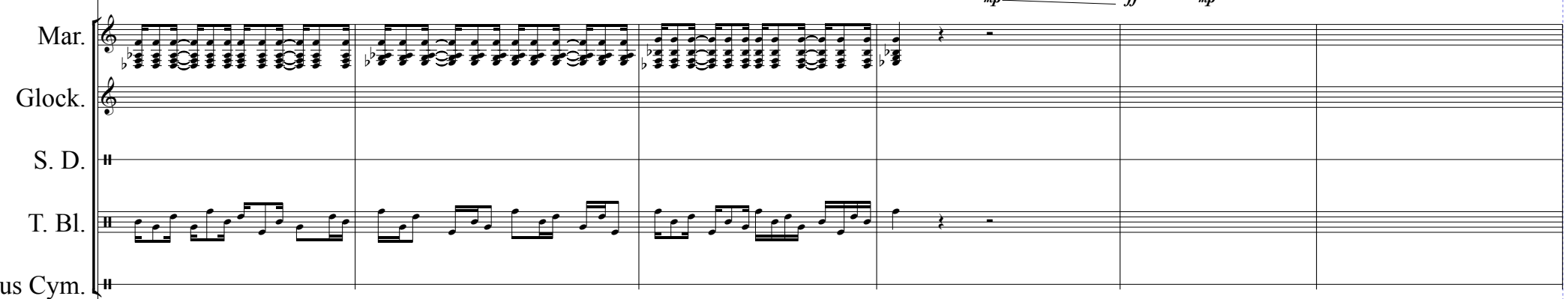

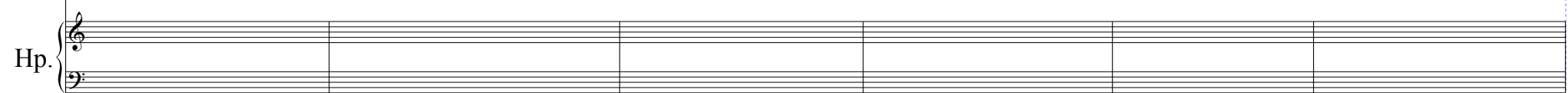

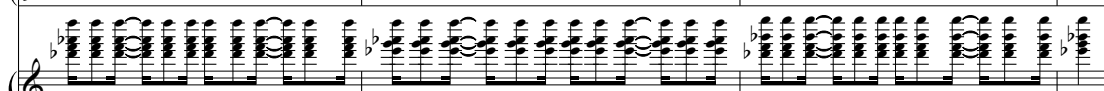

Pno.

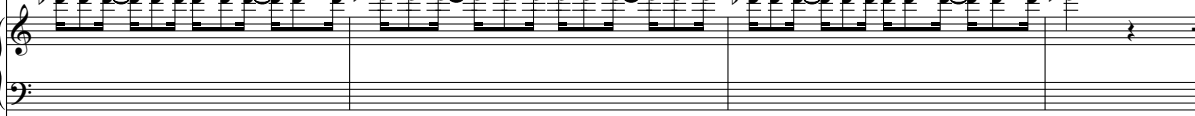

S. Bass 


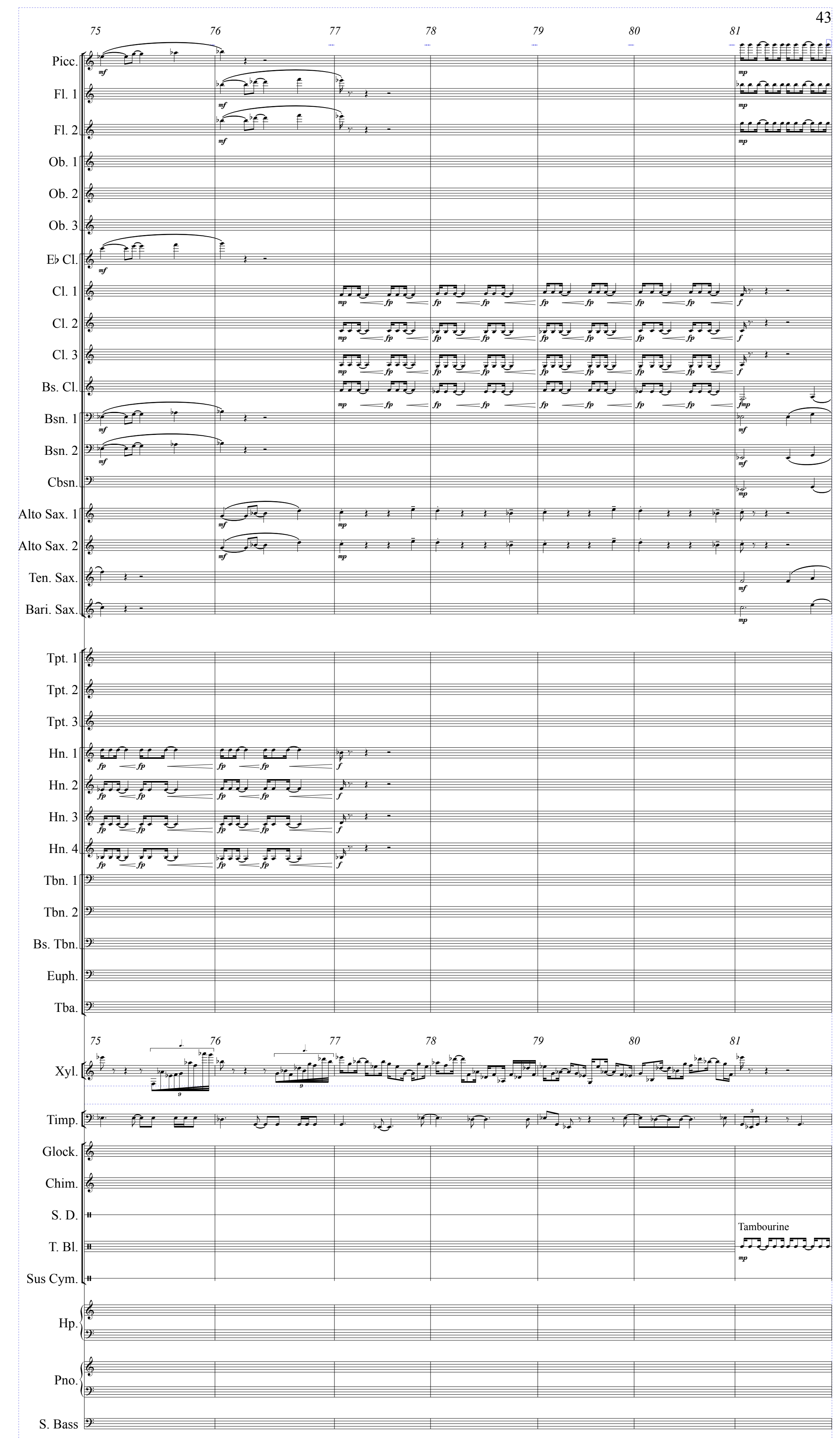


83

84

85

86

87

88

89
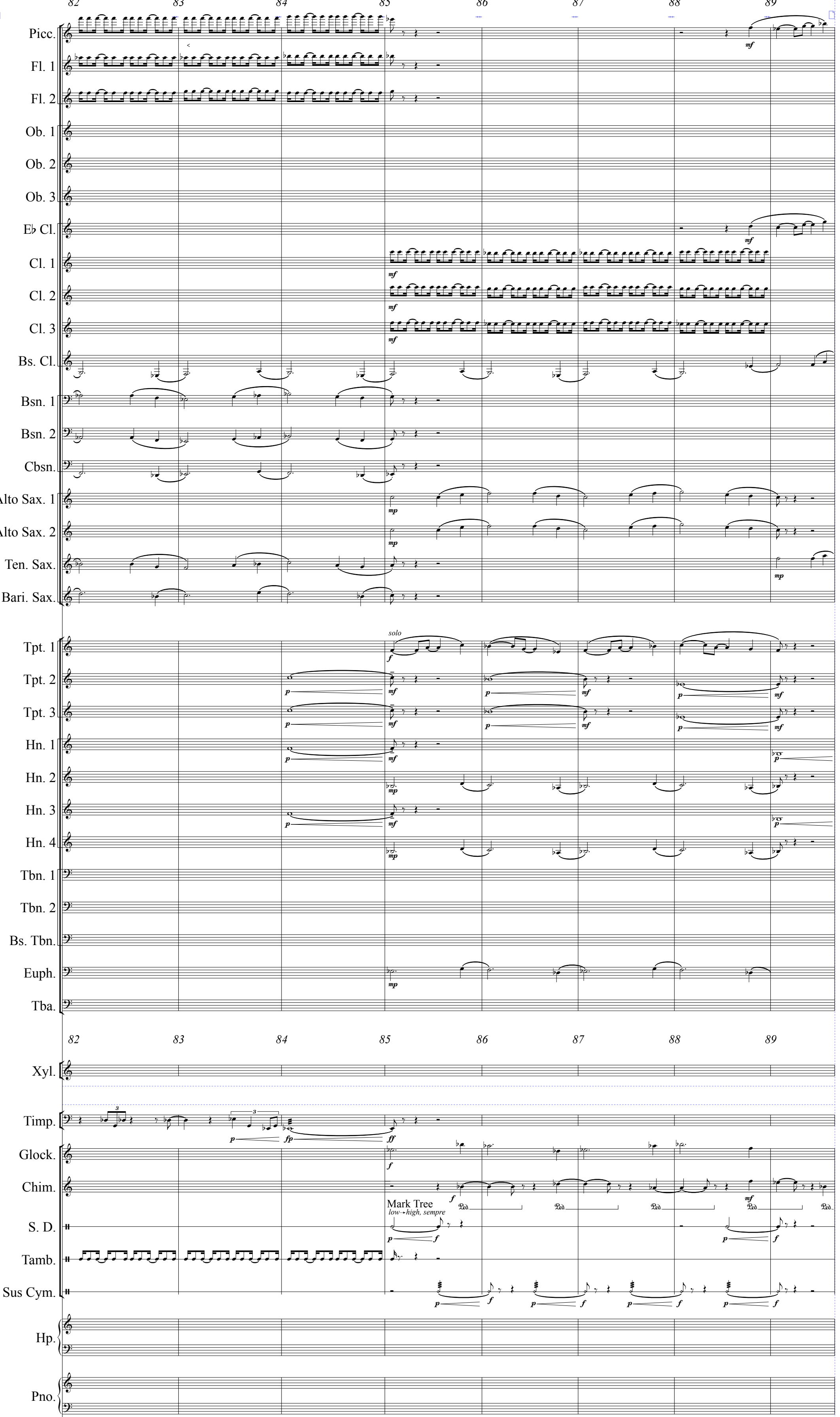

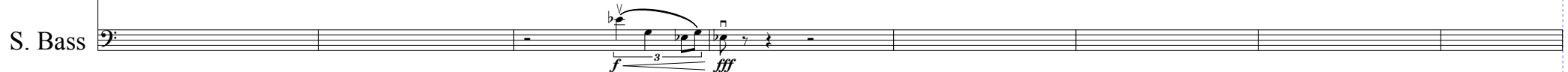



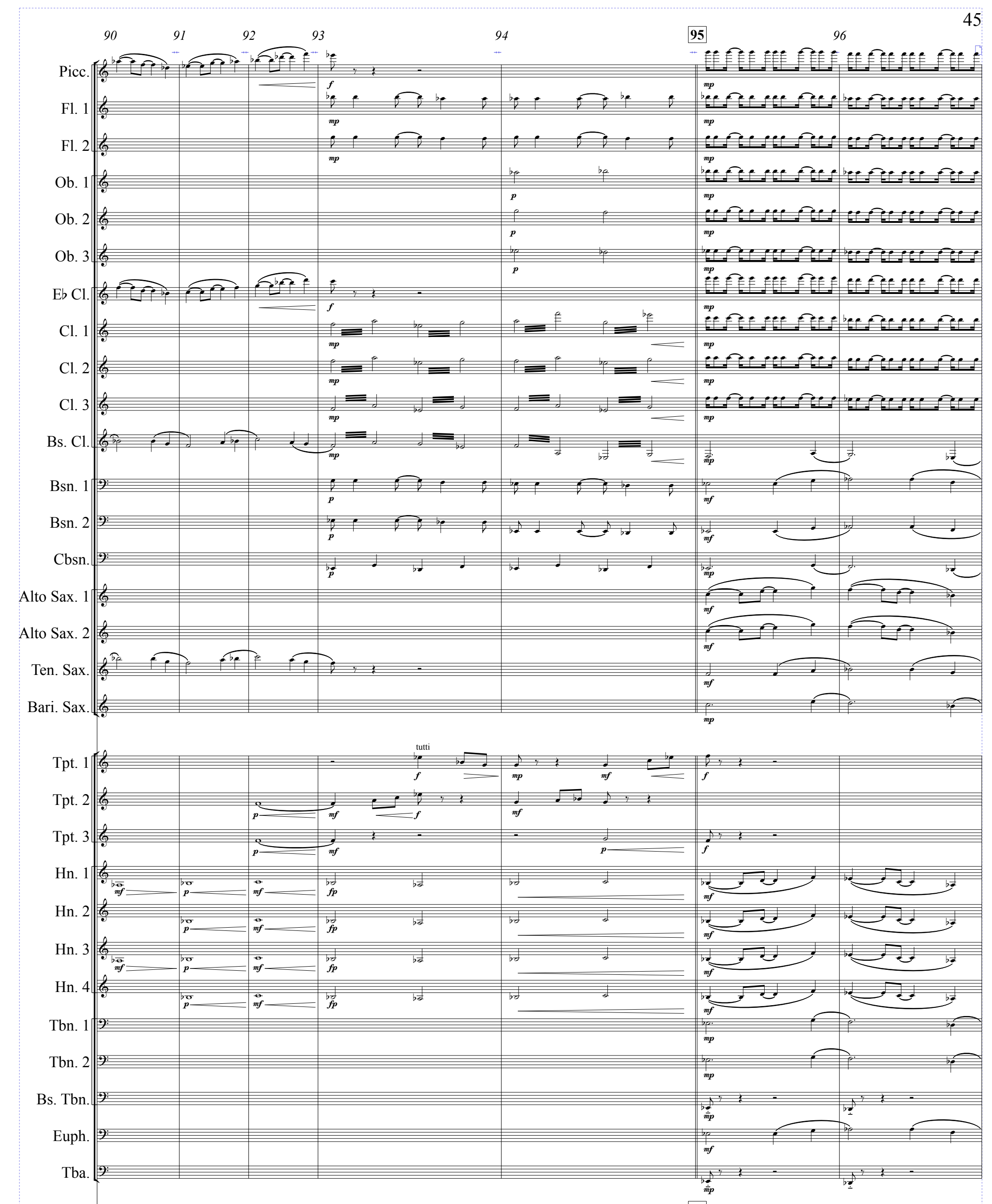
$92 \quad 93$
95
96

90

Xyl.

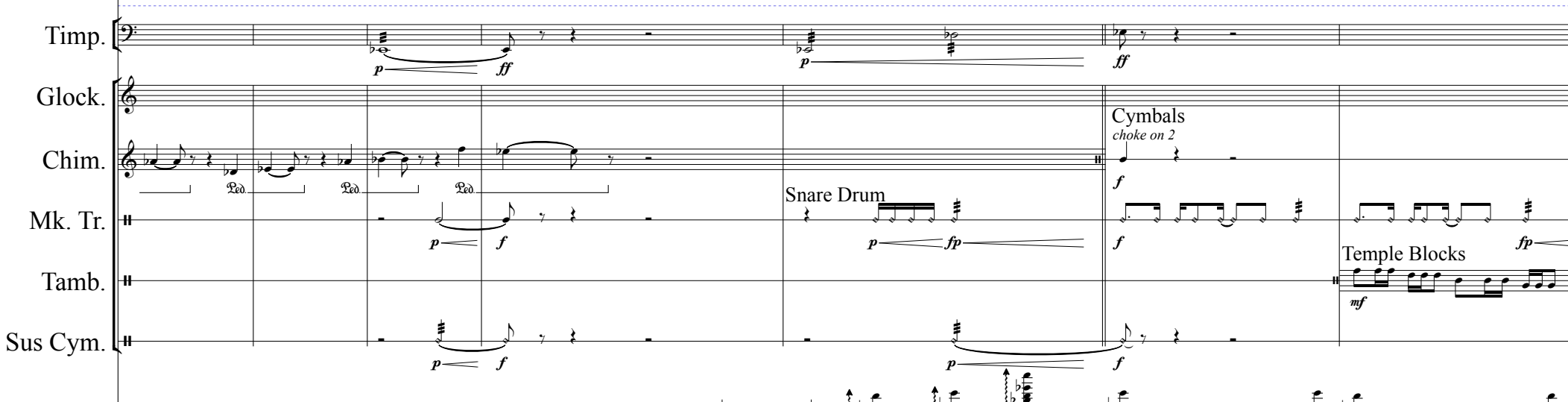

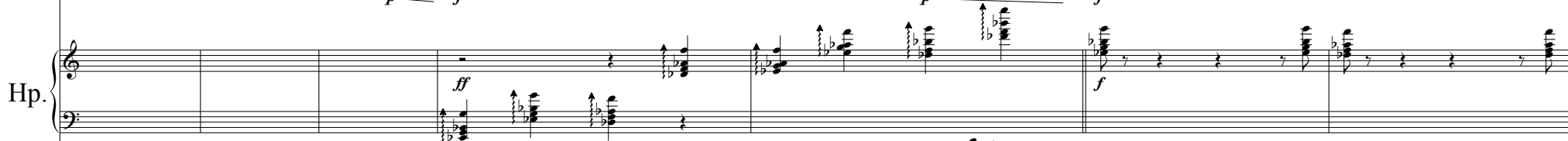

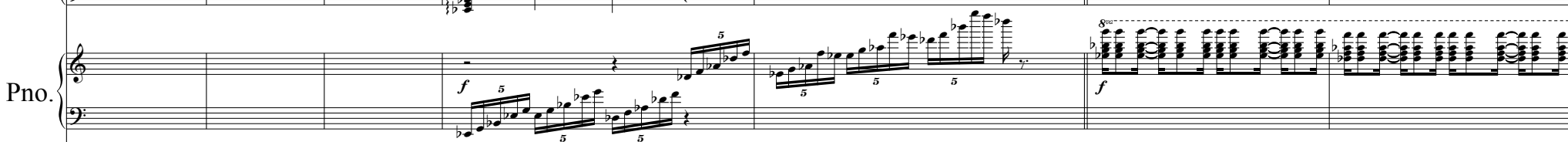

S. Bass 


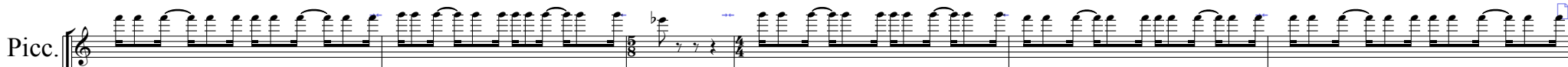

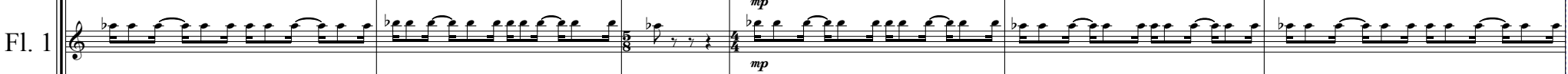
Fl. $2 \ldots \ldots \ldots \ldots$ Ob.1

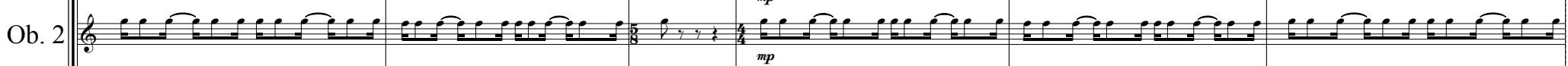

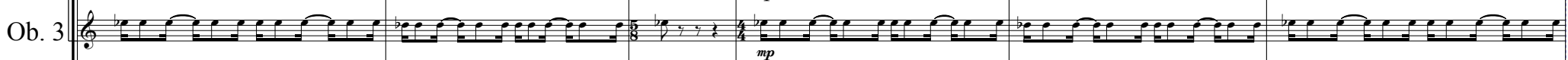
$\mathrm{EbCl}$ (b)

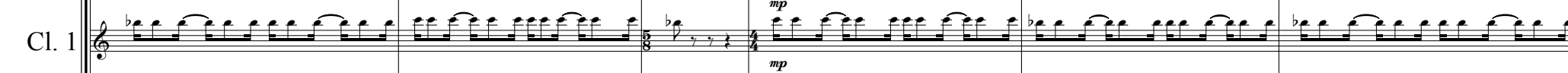

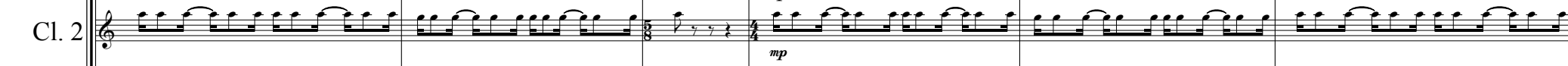
$\mathrm{Cl} .3 \mathrm{Cl} . \mathrm{COCO}$ Alto Sax. 2 Sari. Sax.

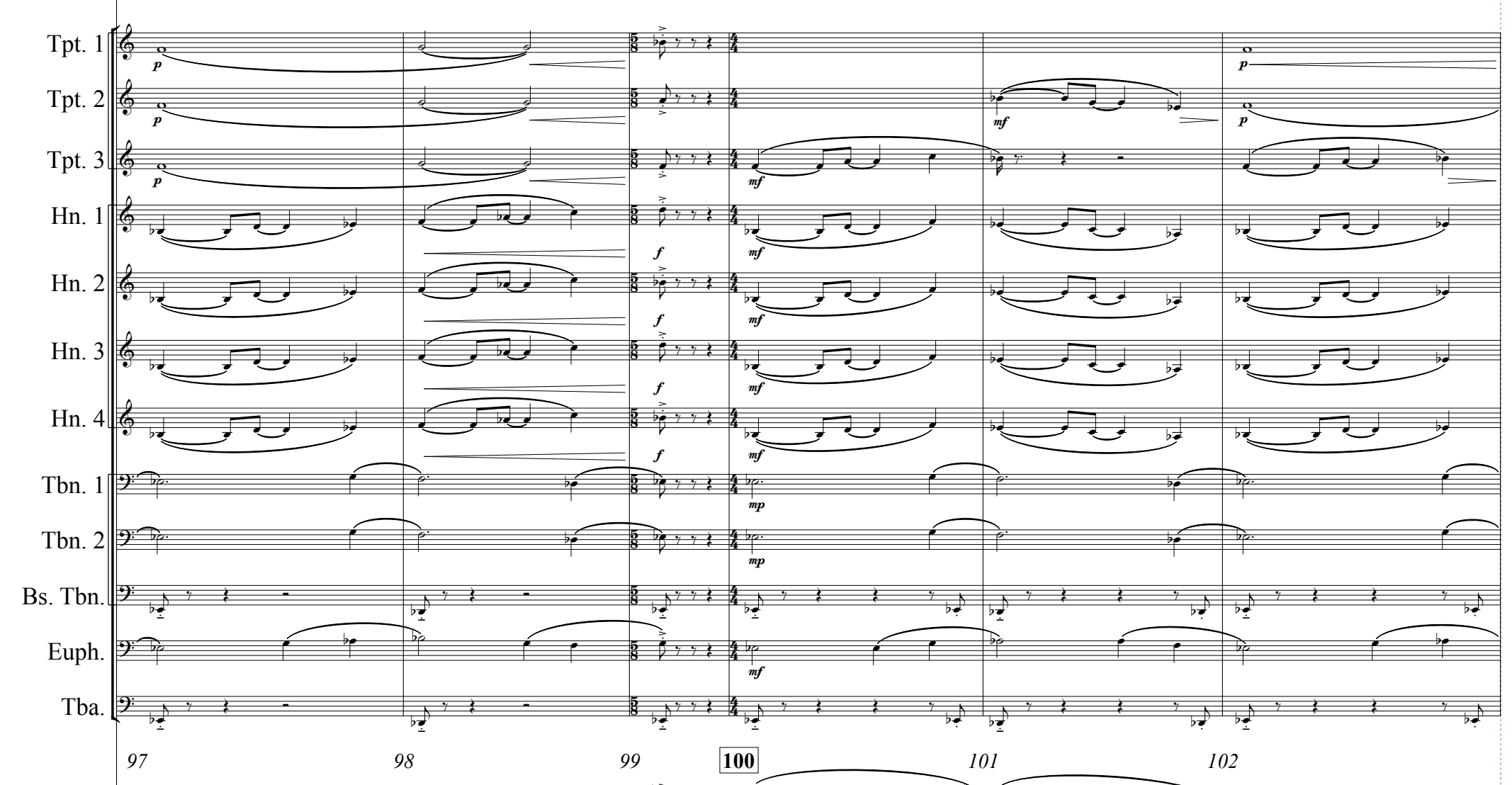
Xyl.

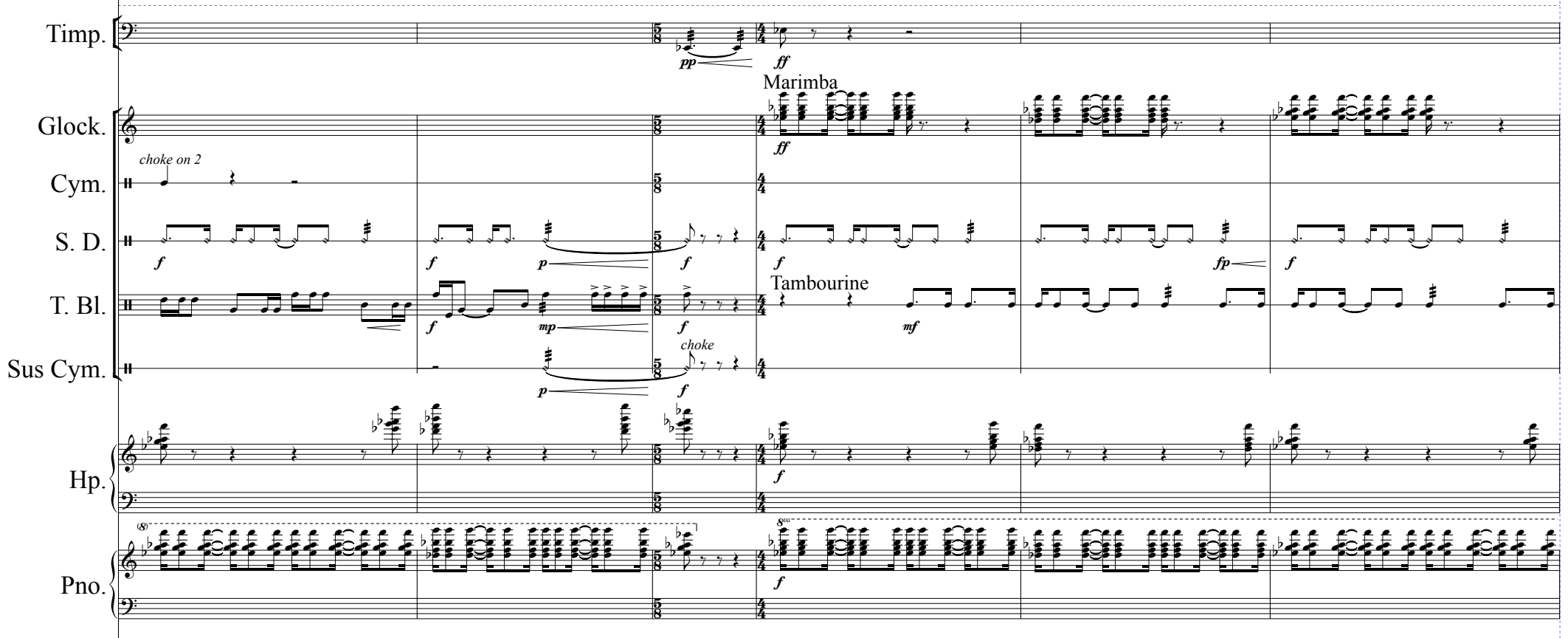
S. Bass 


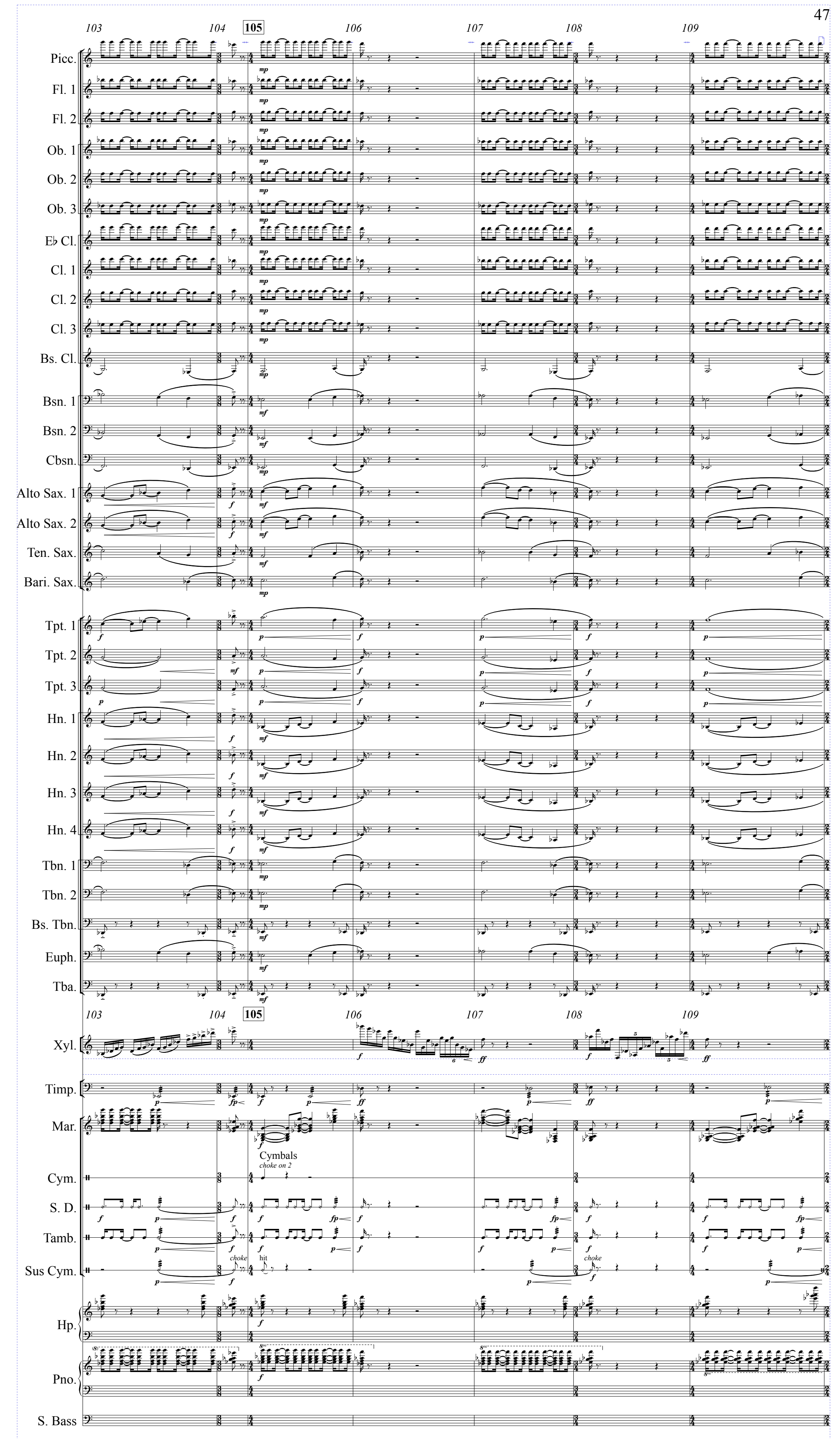




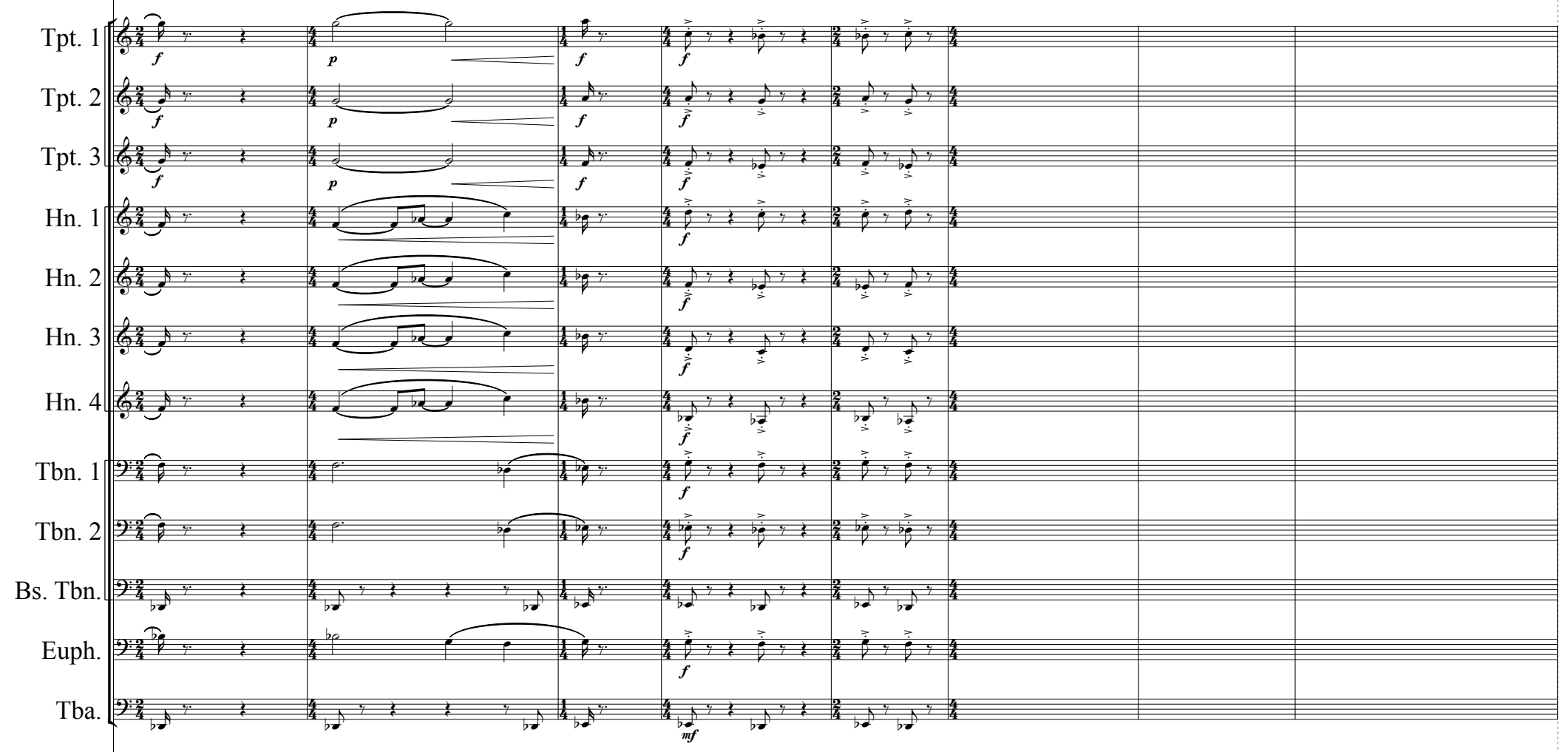
$\mathrm{Xyl}(110$

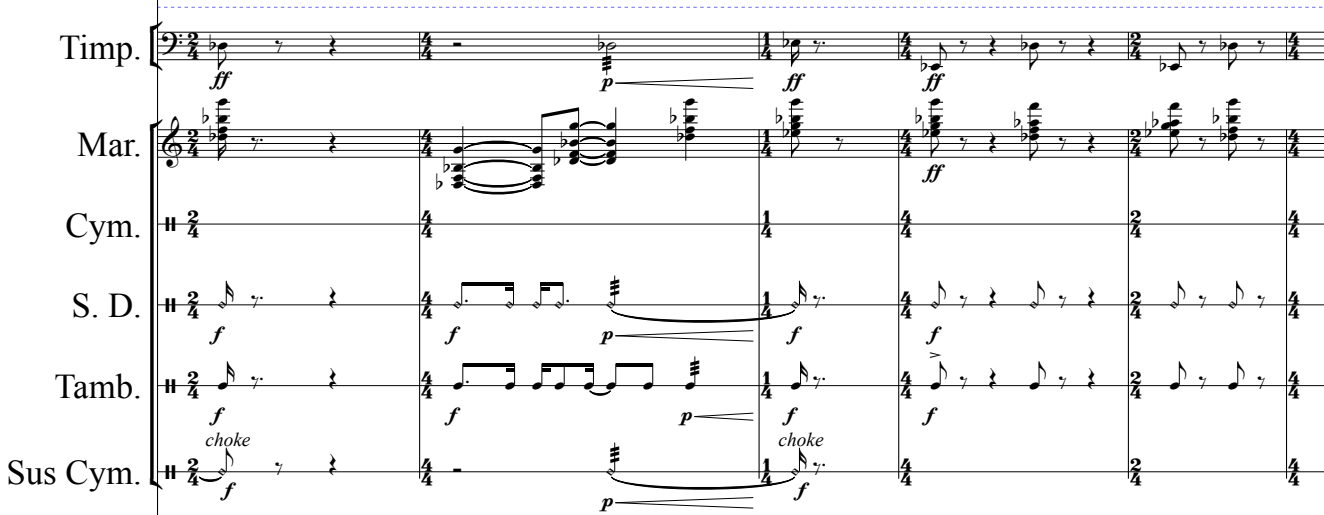

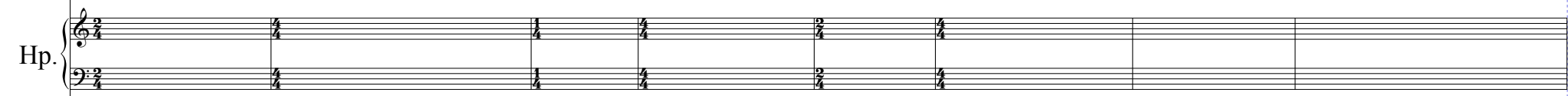

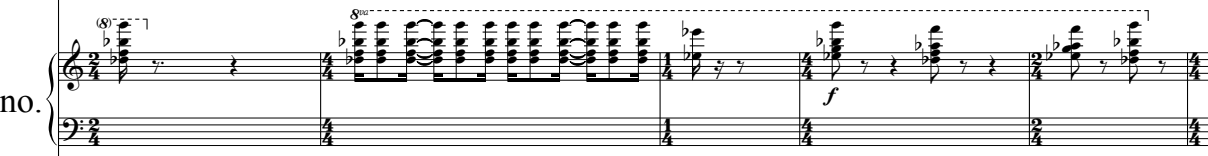

S. Bass 

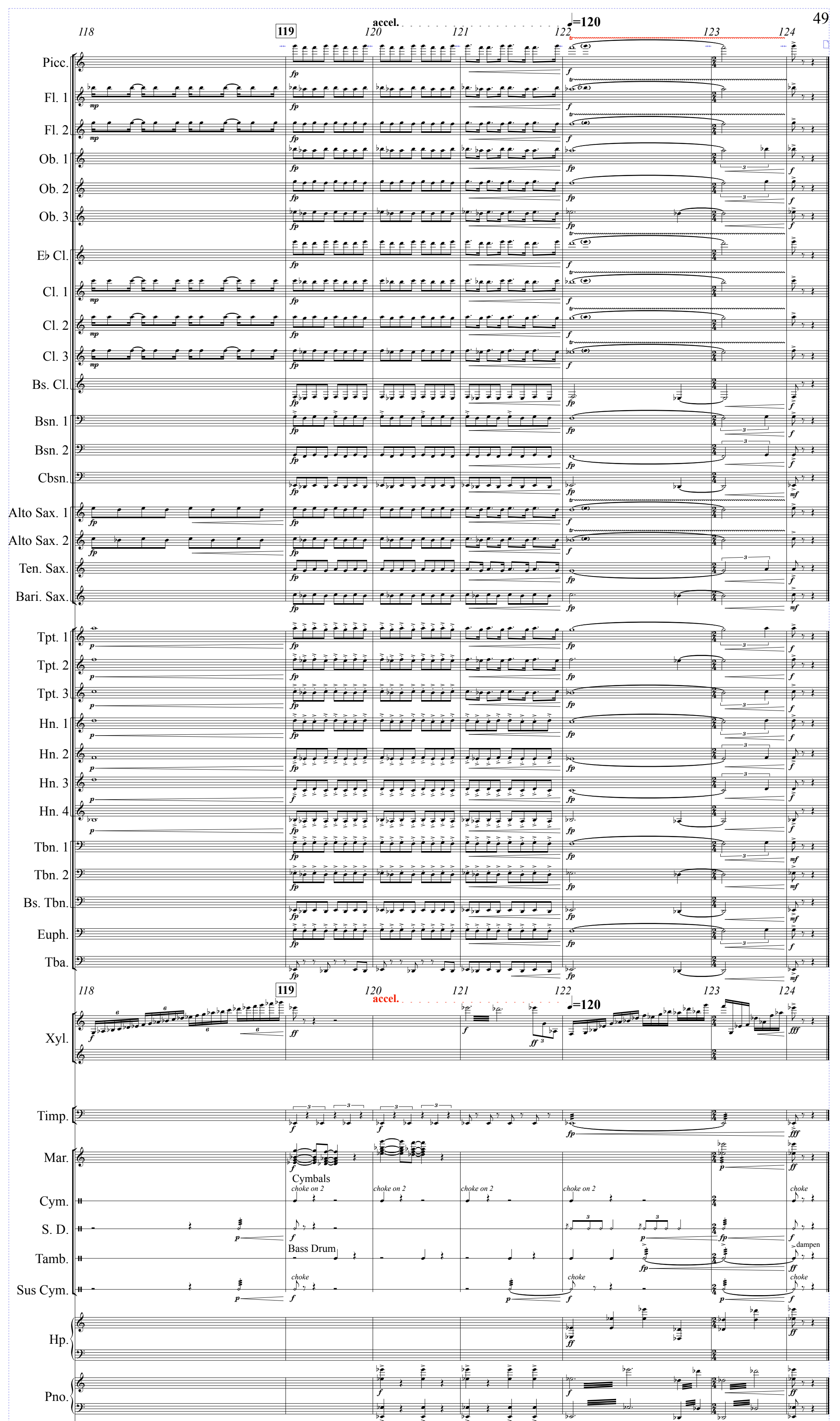

S. Bass $\frac{0000}{p}$ 


\section{CURRICULUM VITAE}

Ross Elliott

elliottr21@gmail.com

\section{Education}

Master of Music in Music Composition, 2015-2017

University of Louisville

Bachelor of Music in Music Composition, 2011-2015

Bowling Green State University

\section{Principal Teachers}

Composition

Steve Rouse (2015-2017); Mikel Kuehn (2014-2015); Christopher Dietz (2013-2014)

Piano

Krista Wallace-Boaz (2016-2017); Solungga Liu (2011-2015)

\section{Selected Guest Artist Lessons and Masterclasses}

Kaija Saariaho, Carlos Sanchez-Gutierrez, Andrew Norman

\section{Selected Honors}

Warren Babb Award and Nelson Keyes Award, 2015-2017

\section{Awards}

National Federation of Music Clubs - Young Composer's Award - 2014, A Process of a Mind (piano solo)

\section{Selected Compositions and Performances}

I am for TTBB Men's Chorus (2017) - ca. 6:00

Where the days go for soprano and piano (2016) - ca. 3:45

Premiere performance, March 7, 2017

Fourth's Quarrel for orchestra - ca. 1:30

Reading, April 12, 2016

Wings of the Phoenix for brass quintet (2015) - ca. 5:00

Premiere performance, Novemeber 18, 2015

A Process of a Mind for solo piano (2013-2014) - ca. 9:00

Performance, April 19, 2015 